\title{
Recent Advances in Zinc Oxide Nanostructures with Antimicrobial Activities
}

\author{
Yuchao Li ${ }^{1}\left(\mathbb{D}\right.$, Chengzhu Liao ${ }^{2, *}$ and Sie Chin Tjong ${ }^{3, *}$ \\ 1 Department of Materials Science and Engineering, Liaocheng University, Liaocheng 252000, China; \\ liyuchao@lcu.edu.cn \\ 2 Department of Materials Science and Engineering, Southern University of Science and Technology, \\ Shenzhen 518055, China \\ 3 Department of Physics, City University of Hong Kong, Tat Chee Avenue, Kowloon, Hong Kong, China \\ * Correspondence: liaocz@sustech.edu.cn (C.L.); aptjong@gmail.com (S.C.T.)
}

Received: 12 October 2020; Accepted: 19 November 2020; Published: 22 November 2020

\begin{abstract}
This article reviews the recent developments in the synthesis, antibacterial activity, and visible-light photocatalytic bacterial inactivation of nano-zinc oxide. Polycrystalline wurtzite $\mathrm{ZnO}$ nanostructures with a hexagonal lattice having different shapes can be synthesized by means of vapor-, liquid-, and solid-phase processing techniques. Among these, $\mathrm{ZnO}$ hierarchical nanostructures prepared from the liquid phase route are commonly used for antimicrobial activity. In particular, plant extract-mediated biosynthesis is a single step process for preparing nano- $\mathrm{ZnO}$ without using surfactants and toxic chemicals. The phytochemical molecules of natural plant extracts are attractive agents for reducing and stabilizing zinc ions of zinc salt precursors to form green $\mathrm{ZnO}$ nanostructures. The peel extracts of certain citrus fruits like grapefruits, lemons and oranges, acting as excellent chelating agents for zinc ions. Furthermore, phytochemicals of the plant extracts capped on $\mathrm{ZnO}$ nanomaterials are very effective for killing various bacterial strains, leading to low minimum inhibitory concentration (MIC) values. Bioactive phytocompounds from green $\mathrm{ZnO}$ also inhibit hemolysis of Staphylococcus aureus infected red blood cells and inflammatory activity of mammalian immune system. In general, three mechanisms have been adopted to explain bactericidal activity of $\mathrm{ZnO}$ nanomaterials, including direct contact killing, reactive oxygen species (ROS) production, and released zinc ion inactivation. These toxic effects lead to the destruction of bacterial membrane, denaturation of enzyme, inhibition of cellular respiration and deoxyribonucleic acid replication, causing leakage of the cytoplasmic content and eventual cell death. Meanwhile, antimicrobial activity of doped and modified $\mathrm{ZnO}$ nanomaterials under visible light can be attributed to photogeneration of ROS on their surfaces. Thus particular attention is paid to the design and synthesis of visible light-activated $\mathrm{ZnO}$ photocatalysts with antibacterial properties
\end{abstract}

Keywords: semiconducting oxide; synthesis; heterostructure; antimicrobial activity; photocatalytic activity; free radicals; zinc ion; contact killing; phytocompounds; hemolysis

\section{Introduction}

Poor hygiene and ineffective hospital infection control practice contribute to the transmission of nosocomial pathogens. Antibiotics are the drugs commonly used for combating microorganisms. However, the overuse of antibiotics in humans and animals has led to the emergence of multidrug resistant (MDR) bacteria [1-4]. Staphylococcus aureus and Staphylococcus epidermidis are opportunistic pathogens that can cause surgical wound infections, bloodstream infections and infections associated with indwelling medical devices. They are capable of developing resistance to multiple antibiotics. Infections caused by MDR bacteria such as methicillin resistant Staphylococcus aureus (MRSA) and 
methicillin-resistant Staphylococcus epidermidis (MRSE) are difficult to treat, leading to high morbidity and mortality in patients [5-7]. Thus the spread of MDR bacteria poses a serious threat to public health globally. This motivates the researchers to develop various novel nanomaterials as alternatives to antibiotics for the treatment of MDR bacterial infections [8,9].

Nanomaterials with enhanced chemical, physical and mechanical characteristics than their bulk micromaterials have received considerable attention in materials science community recently [10-17]. Metal and metal oxide nanoparticles including silver, zinc, copper, zinc oxide, titanium dioxide, copper oxide, and iron oxide are known to exhibit antimicrobial properties against various bacterial strains [13,16-31]. Several mechanisms have been proposed for bactericidal activities of those nanoparticles (NPs) (Figure 1). These include: (a) the disruption of bacterial cell membrane and electron transport chain; (b) the generation of reactive oxygen species (ROS) and induction of oxidative stress, resulting from the interaction of NPs with bacterial cell membrane, and cellular components such as deoxyribonucleic acid (DNA) and protein; (c) released metal ions from metal or metal oxide NPs in intracellular environment. Those ions can react with the functional groups of nucleic acid and protein such as $-\mathrm{SH},-\mathrm{NH}$ and $-\mathrm{COOH}[14,16,25]$. As an example, silver nanoparticles (AgNPs) can interact with bacteria by releasing zero-valent metal $\left(\mathrm{Ag}^{0}\right)$ or $\mathrm{Ag}^{+}$ions, so creating ROS and oxidative stress. In this perspective, AgNPs are widely used in various commercial and healthcare products such as textiles, cosmetics, coatings, food packaging and wound dressings [14,32,33]. However, AgNPs are toxic, and would reduce the viability of several types of human cells in size- and concentration-dependent manners [14,34].

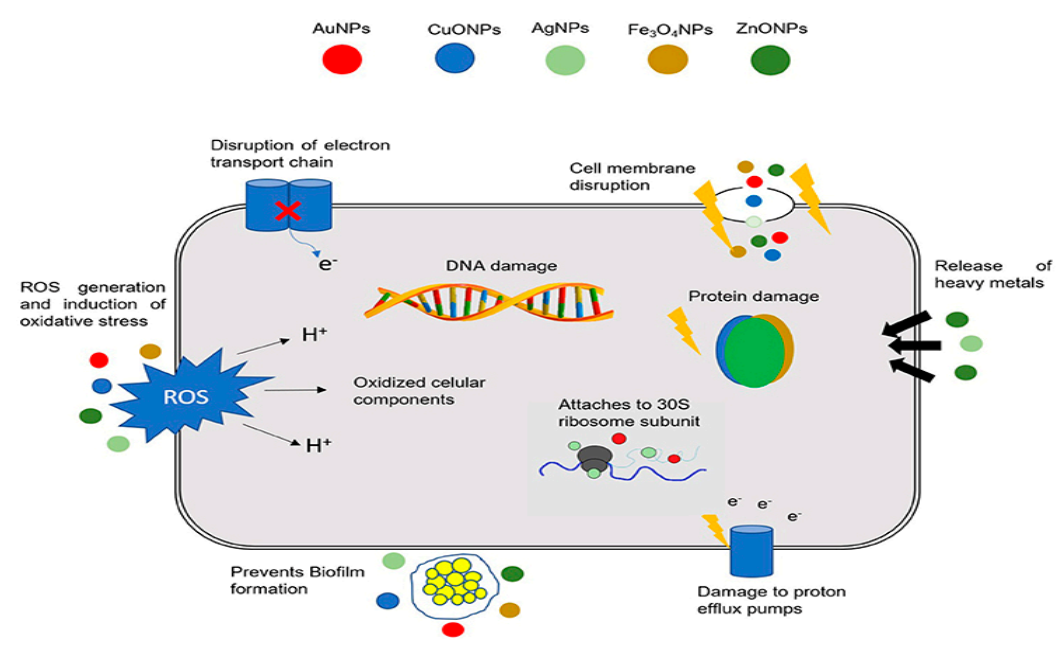

Figure 1. Antibacterial mechanisms of different nanoparticles (NPs) in fighting MDR bacteria. AuNPs: gold NPs, CuONPs: copper oxide NPs; AgNPs: silver NPs; $\mathrm{Fe}_{3} \mathrm{O}_{4} \mathrm{NPs}$ : iron oxide NPs, and ZnONPs: zinc oxide NPs. Reproduced from [16] under the terms of the Creative Commons Attribution License (CC BY).

Zinc oxide $(\mathrm{ZnO})$ with versatile properties is currently used for a wide range of chemical, electronic, textile, pharmaceutical and medical applications, including fillers of rubber composites, sunscreens, coatings, optoelectronic devices, sensors, photocatalysts and antimicrobial wound dressings. In rubber industry, $\mathrm{ZnO}$ is often employed as an additive for the sulfur vulcanization of rubbers, thereby enhancing the efficiency of the cross-linking system (Figure 2) [21,35]. ZnO is an n-type semiconductor due to the presence of zinc interstitials and oxygen vacancies in its crystalline lattice. It has a large exciton binding energy of $60 \mathrm{meV}$, and a wide bandgap energy of $3.37 \mathrm{eV}$ [36]. Moreover, $\mathrm{ZnO}$ exhibits a high dielectric permittivity $(\kappa=8.66)$, thus making it an attractive material for forming gate dielectric in semiconductor devices [37]. Generally, hafnium oxide $\left(\mathrm{HfO}_{2}\right)$ with a larger bandgap (5.3-5.7 eV) is commonly used as a high- $\mathrm{k}$ gate insulating material in semiconductors [38]. So $\mathrm{HfO}_{2}$ and $\mathrm{ZnO}$ dielectrics can effectively replace conventional thermally grown $\mathrm{SiO}_{2}$ gate oxide [37]. $\mathrm{ZnO}$ with a 
wide bandgap absorb ultraviolet (UV) light effectively, giving rise to antibacterial and UV-protection properties. In this respect, $\mathrm{ZnO}$ nanostructures show great potential for use in photodetectors, laser diodes, sensors, and solar cells [39-41]. Moreover, ZnO NPs can be incorporated into polymers, textile or cotton fibers, thereby producing UV-absorbing packaging films and fabrics for food and medical textile applications [42-46]. By utilizing polymers with several beneficial characteristics such as ease of processing, good moldability, and mechanical properties [47-54], materials scientists are capable of developing functional nanocomposites with UV-shielding properties. More importantly, nano-ZnO exhibits selective toxicity to bacteria, rendering its great potential for antibacterial applications in many fields such as water disinfection, food preservation and medical wound dressings [27,43-46,55].

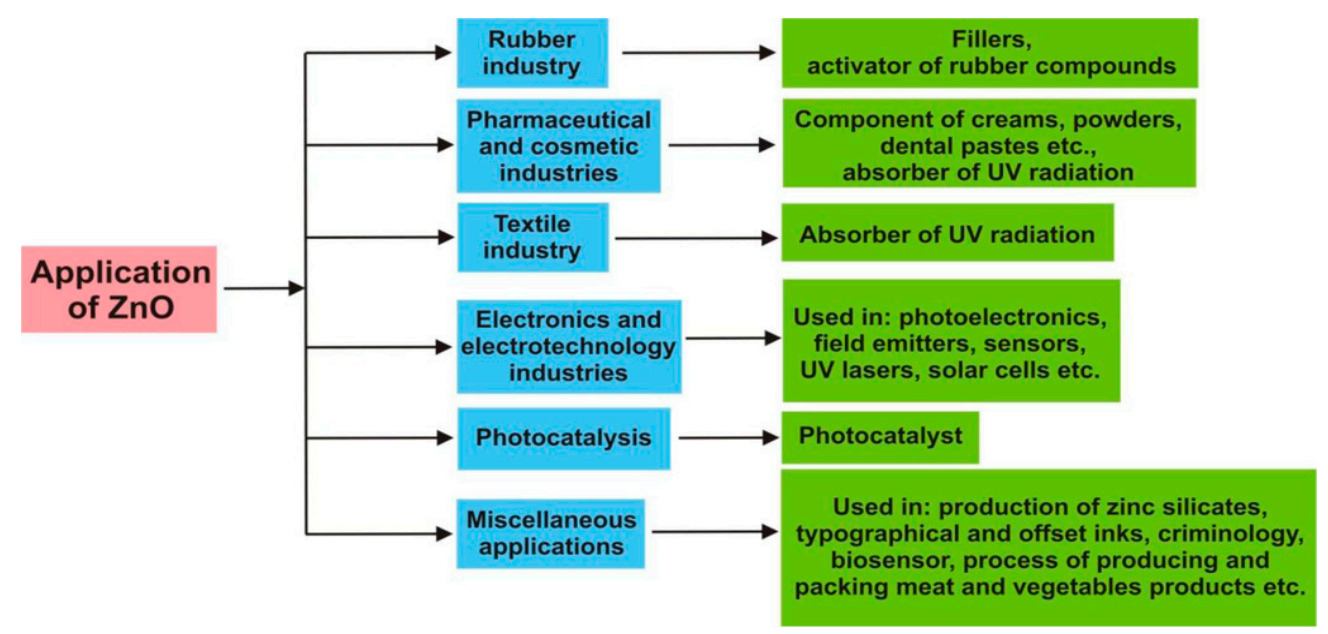

Figure 2. Schematic representation showing versatile applications of $\mathrm{ZnO}$ nanoparticles in chemical, electronic, textile, pharmaceutical and cosmetic industries. Reproduced from [35] the terms of the Creative Commons Attribution License (CC BY).

$\mathrm{ZnO}$ also exhibits additional attractive properties such as low cost, high photochemical stability and photocatalytic activity [56]. In general, irradiation of a photocatalytic semiconductor with photons of equal or higher energy than its bandgap, electron in the valence band (VB) jumps across the large bandgap into the conduction band (CB), creating a positively charged hole in the VB simultaneously. The photoinduced electron $\left(e^{-}\right)$-hole $\left(h^{+}\right)$pair then migrates to the semiconductor surface that provides reactive sites for these charge carriers. As such, $e^{-}$reacts with adsorbed oxygen molecules to form superoxide anion $\left(\bullet \mathrm{O}_{2}{ }^{-}\right)$, while $h^{+}$reacts with water/hydroxyl molecules to yield hydroxyl radical $(\bullet \mathrm{OH})$ and $\mathrm{H}^{+}$, as well as hydrogen peroxide $\left(\mathrm{H}_{2} \mathrm{O}_{2}\right)$. The $\bullet \mathrm{O}_{2}{ }^{-}, \bullet \mathrm{OH}$ and $\mathrm{H}_{2} \mathrm{O}_{2}$ are generally referred to as "reactive oxygen species". $\mathrm{ZnO}$ has a wide bandgap of $3.37 \mathrm{eV}$, resulting in a sharp UV emission in luminescence spectrum [36,57]. By interacting ZnO with bacterial cells under UV irradiation, $e^{-}-h^{+}$pairs can be created readily for the ROS production. Those radical species are very effective in disrupting bacterial respiratory chain, DNA and protein functions, leading to cell death [58]. However, UV radiation accounts for less than 5\% while visible light makes up $45 \%$ of the total solar spectrum [59]. Therefore it is necessary to extend the optical response of $\mathrm{ZnO}$ from UV into the visible light region for practical purposes. This can be achieved by doping nano- $\mathrm{ZnO}$ with metals and non-metals, modifying with carbon nanomaterials, and coupling with other oxide semiconductors to form heterostructures [60-66]. In a previous article, we summarized and discussed the toxic effects of nano-ZnO toward mammalian (eukaryotic) cells [67]. This article provides an updated comprehensive review on the synthesis and antibacterial activity of $\mathrm{ZnO}$ hierarchical nanostructures. Particular attention is paid to the the latest developments in the design and synthesis of $\mathrm{ZnO}$ heterostructures with visible-light photocatalytic bactericidal activity via metal and non-metal doping, carbon nanomaterial modification, and semiconductor heterojunction formation. 


\section{Photocatalytic Property of Nanostructured ZnO}

The creation, recombination and separation of photoinduced charge carriers affect photocatalytic performance of nano-ZnO greatly. Moreover, photocatalytic behavior depends greatly on the size, structure, shape, and defects of $\mathrm{ZnO}$ nanostructures. Nanosized $\mathrm{ZnO}$ with enhanced surface area exhibits improved photocatalytic activity for bacterial inactivation than micro-ZnO. ZnO exhibits three crystalline structures including wurtzite (B4), zinc blende (B3), and rocksalt (B1). Wurtzite is the most common and thermodynamically stable crystal structure. $\mathrm{ZnO}$ zinc-blende phase is metastable under ambient conditions. The wurtzite structure of $\mathrm{ZnO}$ transforms into cubic rocksalt structure under high pressures $\geq 6 \mathrm{GPa}$ [68-71]. Wurtzite $\mathrm{ZnO}$ is hexagonal with a space group of $\mathrm{P}_{3} \mathrm{mc}$ having lattice parameters $\mathrm{a}=0.32496 \mathrm{~nm}$ and $\mathrm{c}=0.52042 \mathrm{~nm}$; the $\mathrm{c} / \mathrm{a}$ ratio is 1.6018 , being close to that of an ideal hexagonal close-packed structure of 1.633 [72]. In the hexagonal unit cell, four oxygen ions are bounded with each tetrahedral $\mathrm{Zn}$ ion, and each tetrahedral oxygen ion is coordinated by four $\mathrm{Zn}$ ions. So the wurtzite-type $\mathrm{ZnO}$ consists of tetrahedrally coordinated $\mathrm{O}^{2-}$ and $\mathrm{Zn}^{2+}$ ions, which are piled alternatively along the c-axis [73]. The specific distribution of $\mathrm{Zn}$ cations and $\mathrm{O}^{2-}$ anions leads to the formation of polar Zn-(0001) and O-(0001) planes. The positively charged Zn-terminated (0001) surface is chemically active, while negatively charged O-terminated (0001) is relatively inert. Thus Zn-(0001) surface favors the growth of $\mathrm{ZnO}$ nanocrystals along the $<0001>$ direction [74,75], giving rise to the formation of nanoparticles, nanorods and nanoflowers [74,76-83].

The photocatalytic activity of $\mathrm{ZnO}$ is limited by several factors including fast recombination of electron-hole pairs under UV irradiation, poor visible-light absorbance, and susceptibility to photocorrosion in aqueous environments. The photogenerated charge carriers can readily recombine either in the bulk or at the surface of $\mathrm{ZnO}$ through the dissipation of energy in form of light or heat. Photocorrosion arises from the dissolution of $\mathrm{ZnO}$ into $\mathrm{Zn}^{2+}$ ions in aqueous solutions under UV irradiation [84-89]. As such, oxygen atoms in the $\mathrm{ZnO}$ lattice are oxidized by photogenerated holes to release $\mathrm{Zn}^{2+}$. In other words, photogenerated holes on the $\mathrm{ZnO}$ surface attack the $\mathrm{Zn}$-O bond, leading to the dissociation of $\mathrm{Zn}^{2+}$ from the surface $[85,86]$. So the holes would react with $\mathrm{ZnO}$ rather than with adsorbed surface water molecules to form hydroxyl radicals. Photocorrosion reactions of $\mathrm{ZnO}$ with photoinduced holes are expressed as follows [86-88],

$$
\mathrm{ZnO}+2 h^{+} \rightarrow \mathrm{Zn}^{2+}+0.5 \mathrm{O}_{2}
$$

or

$$
\mathrm{ZnO}+\mathrm{H}_{2} \mathrm{O}+2 h^{+} \rightarrow \mathrm{Zn}^{2+}+2 \mathrm{OH}
$$

In addition, $\mathrm{ZnO}$ undergoes dissolution in strong acidic and alkaline solutions, thereby degrading its photocatalytic performance [85]. As such, photocatalytic activity of $\mathrm{ZnO}$ is limited in mild $\mathrm{pH}$ solutions only. The chemical reactions of $\mathrm{ZnO}$ in acidic and alkaline solutions are given by $[87,88]$,

$$
\begin{gathered}
\text { Acidic medium } \mathrm{ZnO}+2 \mathrm{H}^{+} \rightarrow \mathrm{Zn}^{2+}+\mathrm{H}_{2} \mathrm{O} \\
\text { Alkaline medium } \mathrm{ZnO}+\mathrm{H}_{2} \mathrm{O}+2 \mathrm{OH}^{-} \rightarrow\left[\mathrm{Zn}(\mathrm{OH})_{4}\right]^{2-}
\end{gathered}
$$

Because of the above mentioned drawbacks, $\mathrm{ZnO}$ nanostructures have not been explored fully as $\mathrm{TiO}_{2} \mathrm{NPs}$ with good photostability for photocatalytic applications. It remains a big challenge to develop nano- $\mathrm{ZnO}$ with excellent photocatalytic efficacy. In this respect, much efforts have been spent by the researchers to improve the photocatalytic performance of nano-ZnO by suppressing electron-hole pair recombination, extending the optical absorption edge to the visible region, and enhancing photocorrosion resistance [87-92]. Recombination of electron-hole pairs can be impeded by trapping photogenerated electrons or holes, thereby extending the lifetime of separated charge carriers. The photocatalytic activity of nano-ZnO under visible light can be improved through the induction of oxygen vacancy defects, the doping of metal/non-metal elements, the modification with carbon 
nanomaterials, and the formation of heterojunctions by coupling with other semiconductor oxides. In general, oxygen vacancies enhance optical absorbance of $\mathrm{ZnO}$ in the visible region. Those vacancies produce midgap state near the top of $\mathrm{VB}$ of $\mathrm{ZnO}$, acting as a deep donor level [93-96].

\subsection{Metal Dopants}

Magnesium (alkaline earth metal), transition metals, and noble metals can be utilized to mofify photocatalytic activity of nano-ZnO. Magnesium ions with a smaller ionic radius can replace zinc ions in the ZnO lattice. Magnesium doping generally widens the bandgap of ZnO NPs [97-99]; the bandgap values increase with increasing $\mathrm{Mg}$ dopant concentrations [99]. As mentioned, $\mathrm{ZnO}$ with a wide bangap is ineffective to induce electron-hole pairs under visible light. However, magnesium doping induces many oxygen vacancy defects in $\mathrm{ZnO} N P s$ due to the size difference between $\mathrm{Mg}^{2+}$ $(0.057 \mathrm{~nm})$ and $\mathrm{Zn}^{2+}$ ions $(0.074 \mathrm{~nm})[97,100]$. Those oxygen vacancies facilitate the generation of a high level of ROS in MgZnO NPs under dark, daylight and visible light. As a result, MgZnO NPs exhibit good antibacterial activity against $E$. coli with or without visible light/daylight [97].

\subsubsection{Transition Metal Doped ZnO}

The photocatalytic performance of $\mathrm{ZnO}$ nanostructures under visible light can be enhanced by doping with transition metals and noble metal NPs. Typical transition metal dopants include copper $(\mathrm{Cu})$, iron $(\mathrm{Fe})$, cobalt $(\mathrm{Co})$, manganese $(\mathrm{Mn})$, nickel $(\mathrm{Ni})$ and chromium $(\mathrm{Cr})$ [100-112], while noble metal NPs used are gold (Au), and silver (Ag) [113-119]. The ionic radius of $\mathrm{Zn}^{2+}, \mathrm{Co}^{2+}, \mathrm{Cu}^{2+}$, and $\mathrm{Mn}^{2+}$ is $0.074,0.072,0.073$, and $0.080 \mathrm{~nm}$, respectively [100,106]. Apparently, $\mathrm{Co}^{2+}$ and $\mathrm{Cu}^{2+}$ are the best transition metal dopants because of their similar ionic size with $\mathrm{Zn}^{2+}$. These cations can readily substitute for $\mathrm{Zn}^{2+}$ without causing a large lattice distortion. Figure 3a shows the UV-visible spectra of pure $\mathrm{ZnO}, \mathrm{Mn}$-doped $\mathrm{ZnO}$ and $\mathrm{Co}$-doped $\mathrm{ZnO}$ nanowires. The bandgap energy of these nanowires determined from Tauc plots are shown in Figure 3b [108]. The bandgap of $\mathrm{ZnO}$ (3.26 eV) reduces to $3.20 \mathrm{eV}$ and $3.11 \mathrm{eV}$ by doping with $\mathrm{Mn}^{2+}$ and $\mathrm{Co}^{2+}$, respectively. The bandgap reduction can be attributed to the introduction of midgap states below the CB (Figure 3c). The midgap states serve as effective sites for trapping electrons to retard recombination of electron-hole pairs. A red shift of the optical absorption edge facilitates the formation of ROS on Co- and Mn-doped $\mathrm{ZnO}$ under visible light irradiation. Figure 4 shows an example of the formation of oxygen superoxide and hydroxyl radicals on Mn-doped ZnO NPs for degrading Orange II dye upon solar light irradiation [109].

As recognized, two or more types of metallic cations can substitute for $\mathrm{Zn}^{2+}$ in the $\mathrm{ZnO}$ lattice to further improve the phototocatalytic activity. This is commonly referred to as the 'co-doping' approach. Comparing with a single-element doping, enhanced photocatalytic performance of co-doped $\mathrm{ZnO}$ arises from the synergistic effect of each ionic dopants in increasing visible light absorption. As such, co-doping is a promising approach for tuning the dopant populations, electronic properties, and magnetic properties of metal oxide semiconductors [120]. Recently, Modwi et al. reported that doping $\mathrm{ZnO}$ with $5 \% \mathrm{Cu}$ alone reduces its bandgap from 3.15 to $2.95 \mathrm{eV}$. Moreover, co-doping $5 \% \mathrm{Cu} / \mathrm{ZnO} \mathrm{NPs}$ with $1 \% \mathrm{Fe}, 1 \% \% \mathrm{Ni}$, or $1 \% \mathrm{Ag}$ further decreases the bandgap to $2.90,2.83$ and $2.79 \mathrm{eV}$, respectively [101]. 
(a)

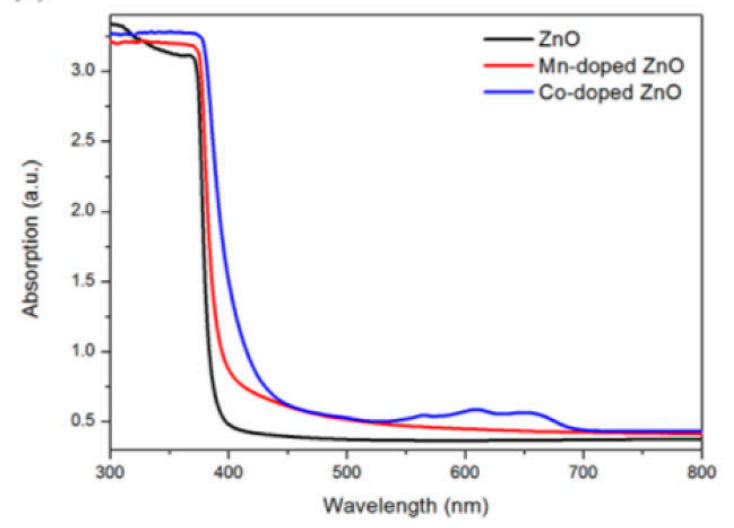

(b)

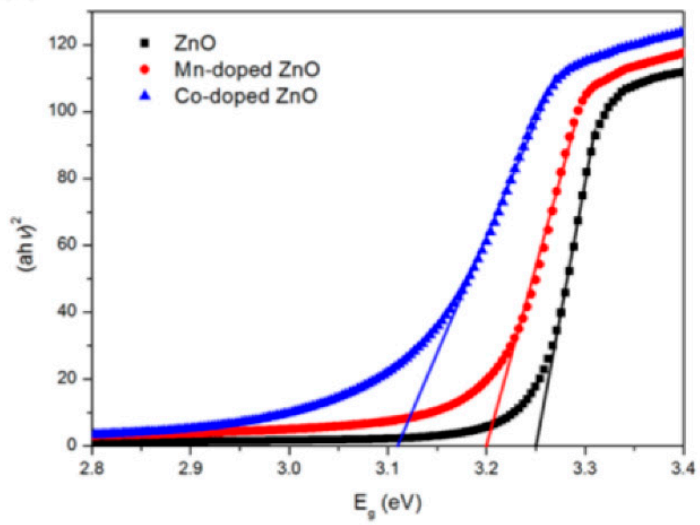

(c)

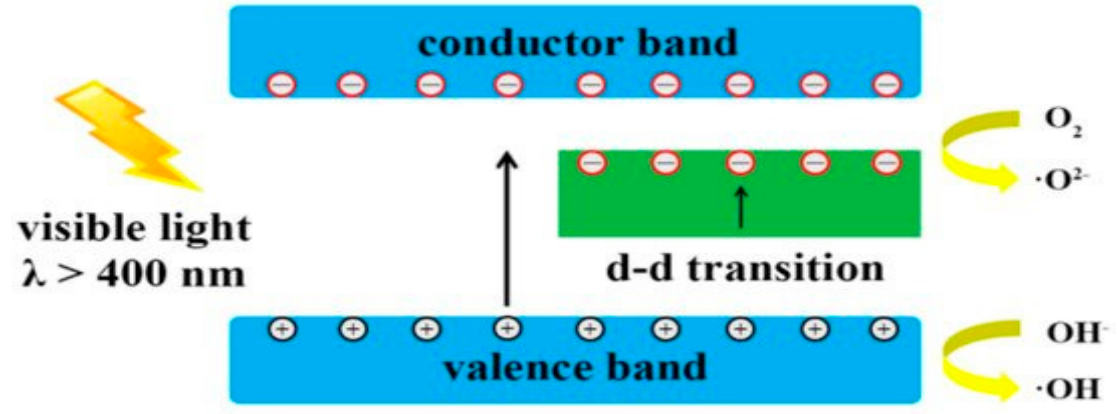

Mn-doped or Co-doped ZnO

Figure 3. (a) UV-visible spectra of pure $\mathrm{ZnO}, \mathrm{Mn}$-doped $\mathrm{ZnO}$ and Co-doped $\mathrm{ZnO}$ nanowires, and (b) Tauc plots of $(\alpha \mathrm{h} v)^{2}$ versus $h v$ for $\mathrm{ZnO}$-based nanowires showing the reduction of bandgap energy through transition metal doping. (c) The generation of superoxide anion and hydroxyl radicals on $\mathrm{ZnO}$ nanowires under visible light due to the creation of midgap states in the bandgap by doping with $\mathrm{Mn}$ or Co. Reproduced from [108] under the terms of the Creative Commons Attribution License (CC BY).
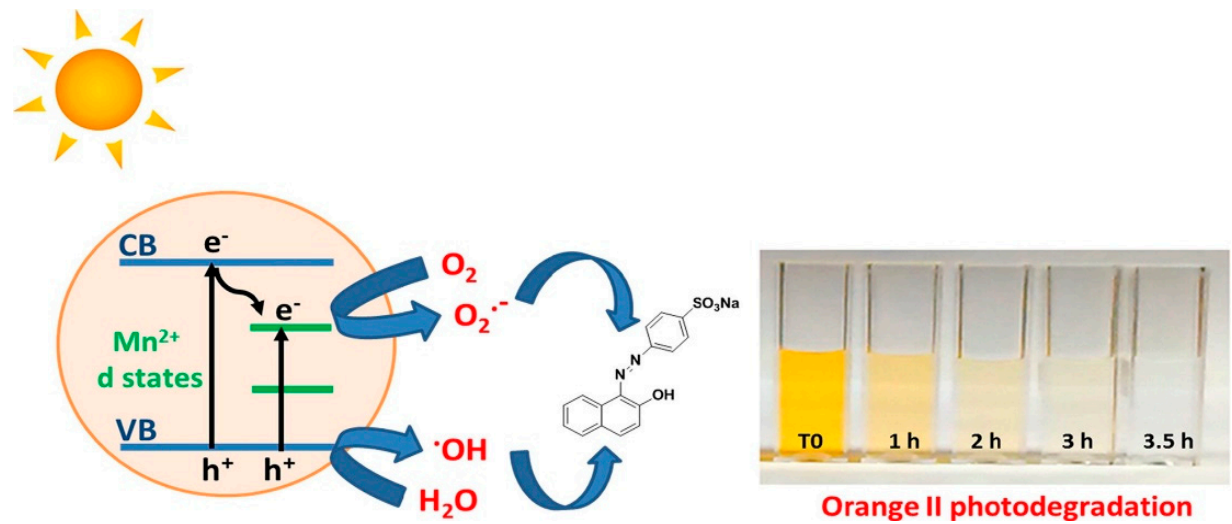

Figure 4. Formation of superoxide anion and hydroxyl radicals on Mn-doped $\mathrm{ZnO}$ nanoparticles for degrading Orange II dye under solar light irradiation at different intervals of time. Reproduced from [109] with permission of Elsevier.

\subsubsection{Noble Metal Doped ZnO}

The photocatalytic efficiency of $\mathrm{ZnO}$ under visible light can also be improved by doping with noble metals such as Au, and Ag [113-118]. By modifying with noble metals, a Schottky barrier is established at the interface junction that facilitates the electron-hole pair separation, thus retarding the recombination of photogenerated charge carriers [121]. Furthermore, noble metal NPs exhibit 
localized surface plasmon resonance (LSPR) resulting from a collective oscillation of free electrons in the electromagnetic field of the incident light. After excitation, the electron oscillations lose their collective nature in which LSPR decays into hot electrons and holes via Landau damping at a relatively short time scale [122-124]. The frequency range for inducing LSPR effect relies greatly on the chemical nature of noble metal nanoparticles. For instance, AgNPs and AuNPs absorb photons and induce LSPR upon visible light irradiation. In contrast, platinum (Pt) NPs display LSPR in the UV range, so exhibiting a strong absorption at $\sim 380 \mathrm{~nm}$ [125]. Therefore, PtNPs induce a blue shift in the optical spectrum of $\mathrm{Pt} / \mathrm{ZnO}$ nanocomposites [126]. In this respect, plasmonic AgNPs are commonly employed to enhance photocatalytic efficiency of $\mathrm{ZnO}$ under visible light $[127,128]$. As mentioned, a Schottky barrier is established at the metal/ZnO interface when noble metal comes in contact with $\mathrm{ZnO}$. The Fermi energy level (FM) of AgNPs or AuNPs is higher than ZnO Fermi level (FMO), leading to the transfer of electron from the FM of AgNPs or AuNPs to the FMO until the attainment of a new equilibrium Fermi level (FEq) [127]. Under visible light, LSPR absorption causes a rapid heating of noble metal NPs.Thus hot electrons from AgNPs/AuNPs are injected into the $\mathrm{CB}$ of $\mathrm{ZnO}$ for reacting with adsorbed oxygen molecules to create superoxide anion radical. The superoxide anion then reacts with $\mathrm{H}_{2} \mathrm{O}$ to generate hydroxyl radicals. On the contrary, photoexcited electrons in the $\mathrm{CB}$ of $\mathrm{ZnO}$ are transferred to AgNPs or AuNPs upon exposure to UV light. This is because $\mathrm{CB}$ of $\mathrm{ZnO}$ is higher than the newly generated Fermi energy level of AgNPs/ZnO or AuNPs/ZnO. As such, AgNPs or AuNPs act as electron trapping sites, thus enhancing the charge separation efficiency of $\mathrm{ZnO}$ (Figure 5A,B) [127].

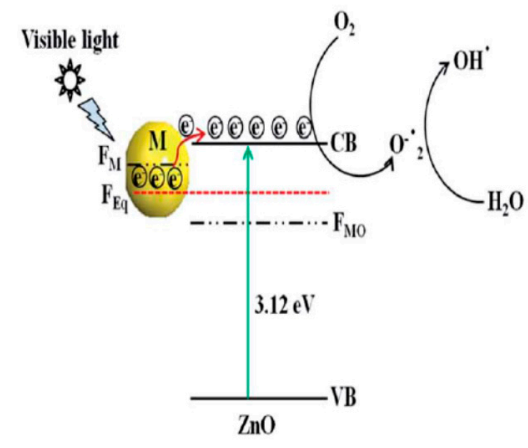

A

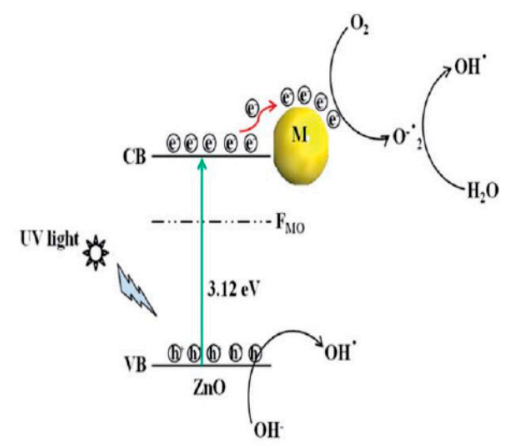

B

Figure 5. (A) Visible light induces localized surface plasmon resonance (LSPR) in AgNPs or AuNPs such that hot electrons are injected into the $\mathrm{CB}$ of $\mathrm{ZnO}$ for generating superoxide anion and hydroxyl radicals. (B) Under UV irradiation, photoexcited electrons are transferred from the $\mathrm{CB}$ of $\mathrm{ZnO}$ to AgNPs or AuNPs. VB = valence band, CB: conduction band, FMO: Fermi level of metal oxide, FM: Fermi level of metal, FEq: Fermi level of equilibrium, and M: Au and Ag. Reproduced from [127] with permission of the Royal Society of Chemistry.

\subsection{Non-Metal Dopants}

Metal dopants have a certain limitation for achieving high photocatalytic activity under visible-light, especially at high concentrations. This is due to photogenerated charge carriers recombine at trapping defect sites, leading to a reduction in the photocatalytic efficiency. In this respect, non-metal dopants such as carbon, nitrogen, and sulfur can be used to improve visible-light photocatalytic activity of $\mathrm{ZnO}$ [129-134]. Non-metal dopants introduce an intermediate energy level just above the $\mathrm{VB}$ of $\mathrm{ZnO}$. Accordingly, the dopants narrow the bandgap and facilitate the separation of photoexcited charge pairs in $\mathrm{ZnO}$. For example, sulfur dopant can elevate the valence band maximum by hybridizing S-3p orbital with the $\mathrm{VB}$ of $\mathrm{ZnO}$, leading to a bandgap reduction of $\mathrm{ZnO}$ from $3.22 \mathrm{eV}$ to $2.85 \mathrm{eV}$ [129]. Zhang et al. demonstrated that carbon doping is effective for narrowing bandgap of $\mathrm{ZnO}$ nanorods from $\sim 3.19$ to $\sim 2.72 \mathrm{eV}$. Carbon doping induces the formation of oxygen vacancy defects in $\mathrm{ZnO}$, thereby serving as the trapping sites for photogenerated electrons. In this respect, carbon doping 
and oxygen vacancies increase the separation efficiency of photogenerated electron-hole pairs, thus enhancing the photocatalytic activity of $\mathrm{ZnO}$ [130]. Similarly, carbon-doped $\mathrm{ZnO}$ nanorods and $\mathrm{C}$-doped $\mathrm{ZnO}$ nanoparticles have been reported to have a reduced bandgap energy of 2.69 and $3.08 \mathrm{eV}$, respectively [131].

\section{Metal/Non-Metal Co-Dopants}

In a recent study of Gupta et al., $\mathrm{N}$ and $\mathrm{Cu}$ co-dopants narrow the bandgap of $\mathrm{ZnO}$ NPs effectively [135]. Figure 6a shows the Tauc plots of the Kubelka-Munk function vs photon energy for $\mathrm{ZnO}$ NPs, and $\mathrm{Cu}$-doped $\mathrm{ZnO}$ NPs with $0.5 \%, 1.5 \%, 2.5 \%$ and $5.0 \% \mathrm{Cu}$, denoting as $\mathrm{Cu} 0.5 \mathrm{Z}, \mathrm{Cu} 1.5 \mathrm{Z}$,

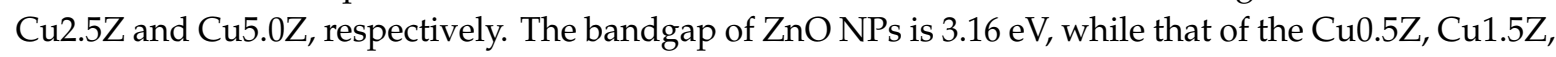
$\mathrm{Cu} 2.5 \mathrm{Z}$ and $\mathrm{Cu} 5.0 \mathrm{Z}$ is $3.09,3.00,2.91$ and $2.84 \mathrm{eV}$, respectively. By doping with nitrogen, the bandgap of $\mathrm{N}$-doped $\mathrm{ZnO}$ slightly decreases to $3.11 \mathrm{eV}$ (Figure $6 \mathrm{~b}$ ). Co-doping of $\mathrm{ZnO}$ with $\mathrm{N}$ and $0.5 \%, 1.5 \%$, $2.5 \%, 5.0 \% \mathrm{Cu}$ (i.e., $\mathrm{Cu} 0.5 \mathrm{NZ}, \mathrm{Cu} 1.5 \mathrm{NZ}, \mathrm{Cu} 2.5 \mathrm{NZ}$ and $\mathrm{Cu} 5.0 \mathrm{NZ}$ ) leads to a further bandgap reduction having the energy value of 3.07, 2.91, 3.03 and $2.98 \mathrm{eV}$, respectively. The reduction of band gap is due to the hybridization of $\mathrm{N}-2 \mathrm{p}$ state with $\mathrm{O}-2 \mathrm{p}$ level. This creates a defect energy state just above the VB of $\mathrm{ZnO}$, serving as the site for trapping the holes. Meanwhile, $\mathrm{Cu}^{2+}$-doping introduces a sub-energy level below the $\mathrm{CB}$, acting as the site for trapping electrons. These defect states promote photogenerated charge separation, and improve photocatalytic activity in the visible region. Figure $6 \mathrm{c}$ reveals that the $(\mathrm{N}, \mathrm{Cu})$ co-doped $\mathrm{Cu} 5.0 \mathrm{NZ}$ exhibits a higher absorbance than $\mathrm{Cu} 5.0 \mathrm{Z}$ in the visible light region. This is due to the synergistic action of both $\mathrm{Cu}^{2+}$ and $\mathrm{N}$ dopants in $\mathrm{Cu} 5.0 \mathrm{NZ}$ during the photoexcitation process [135]. Similarly, synergistic effects of both $\mathrm{Mn}^{2+}$ and $\mathrm{N}$ dopants also enhance the absorption of $\mathrm{ZnO}$ nanofibers in the visible-light region [136].
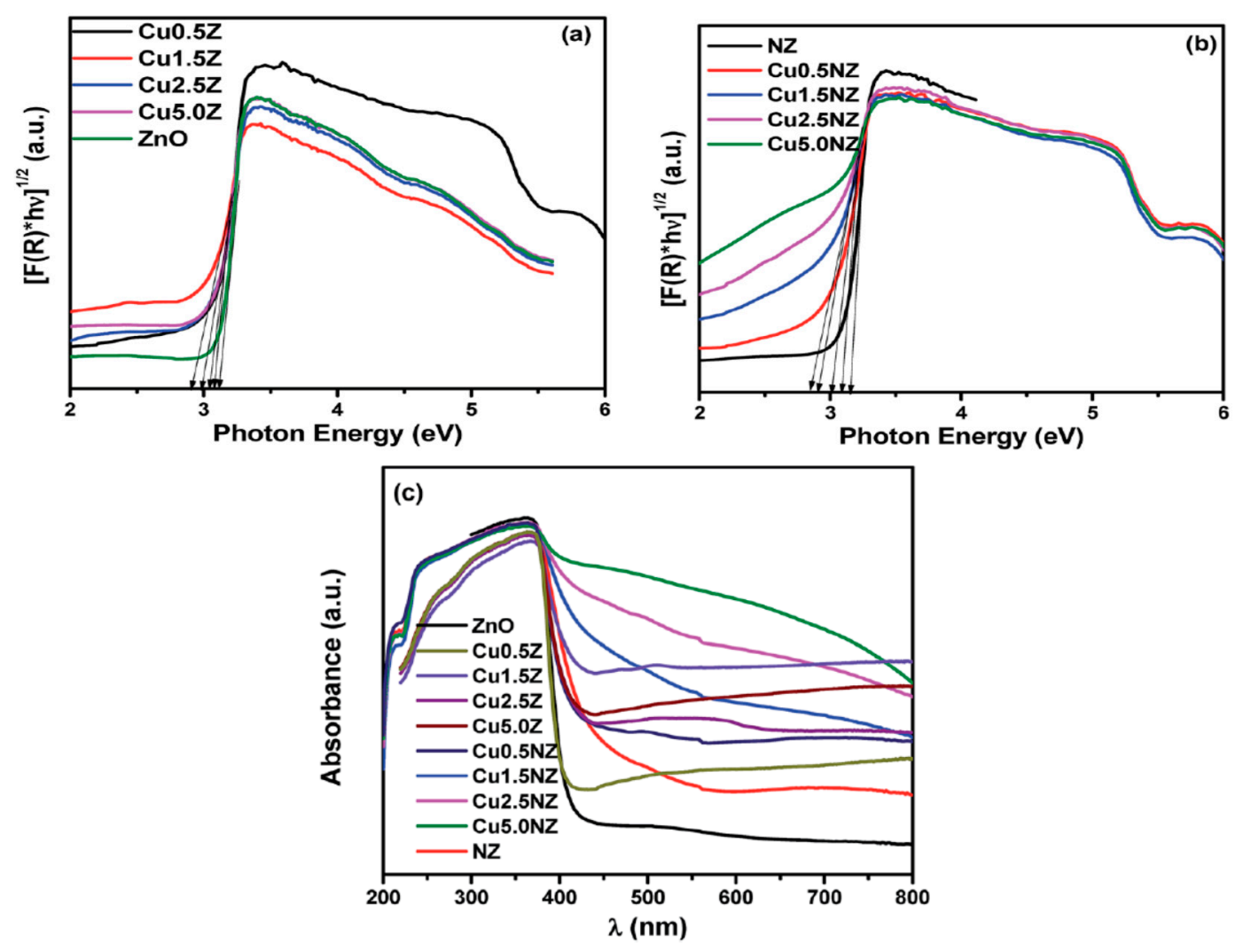

Figure 6. The plots of Kubelka-Munk function vs photon energy for evaluating bandgap energy of (a) ZnO and Cu0.5Z, Cu1.5Z, Cu2.5Z and Cu5.0Z, and (b) NZ, Cu0.5NZ, Cu1.5NZ, Cu2.5NZ and Cu5.0NZ. (c) Optical absorbance of ZnO, Cu0.5Z, Cu1.5Z, Cu2.5Z, Cu5.0Z, NZ, Cu0.5NZ, Cu1.5NZ, $\mathrm{Cu} 2.5 \mathrm{NZ}$ and $\mathrm{Cu} 5.0 \mathrm{NZ}$. Reproduced from [135] with permission of the Royal Society of Chemistry. 


\subsection{Carbon Nanomaterials Modified $\mathrm{ZnO}$}

\subsubsection{Graphene}

Graphene exhibits a two-dimensional honeycomb lattice consisting of a single layer of $\mathrm{sp}^{2}$ hybridized carbon atoms. It is a building block of carbonaceous materials including zero-dimensional (0D) fullerene, one-dimensionl (1D) carbon nanotube (CNT), and three-dimensional (3D)-graphite [137]. A single graphene layer rolls into a cylindrical shape to form a single-walled carbon nanotube (SWCNT), while multiple graphene layers roll into a multi-walled carbon nanotube (MWCNT). Graphene and CNTs exhibit excessively high elastic modulus ( 1 TPa), excellent electrical conductivity, high optical transparency, large surface area, and superior antimicrobial properties [13,137-143]. Therefore, graphene and its derivatives, as well as CNTs show attractive applications as transparent conducting films in optoelectronic devices, conducting fillers of functional polymer nanocomposites, active photocatalysts for water splitting, and drug delivery vehicles in the pharmaceutical field [50-54,144-159]. In the case of photocatalysis, graphene and CNTs improve the photocatalytic activity and reduce photocorrosion of $\mathrm{ZnO}$ markedly [89,160-162].

Large-area graphene layers for optoelectronic applications are generally prepared from chemical vapor deposition (CVD) $[160,161]$. However, the high cost of fabrication, tedious film transferring procedure, contamination and defect formation in the film during the transfer process, have limited the widespread use of graphene in optoelectronic industry [163-166]. In this respect, graphene oxide (GO) is considered as an alternative for graphene. It can be synthesized in large quantities by oxidation-exfoliation of graphite flakes in a mixture of concentrated sulfuric acid, sodium nitrate, and potassium permanganate, using a modified Hummers process [167]. The as-synthesized GO contains hydroxyl and epoxide groups on the graphene basal plane, with carboxyl and carbonyl groups at the edges [168]. Those oxygen functional groups impair electrical conductivity of graphene, causing GO to become an insulator. Therefore, the oxygenated groups of GO must be removed in order to restore its electrical conductivity. Several reducing agents, such as hydrazine hydrate, sodium borohydride, and hydroquinone can reduce GO into reduced graphene oxide (RGO) $[169,170]$. However, those agents remove oxygenated groups of GO to a certain degree. Thus RGO still bears a small fraction of residual oxygen groups. Among those reductants, hydrazine hydrate is commonly used for forming RGO, but it is highly toxic and explosive. Alternatively, RGO can be obtained through hydrothermal reduction of GO in an aqueous sulfuric acid suspension [171].

Graphene oxide sheet with the lateral size up to several micrometers acts as a 2D template for nucleating $\mathrm{ZnO}$ crystals during the synthesis process. So oxygenated groups of $\mathrm{GO}$ favor the nucleation of $\mathrm{ZnO}$ nanocrystals by interacting with zinc salt precursor. As such, $\mathrm{Zn}^{2+}$ ions released from the $\mathrm{Zn}$ salt precursor tend to interact with the negatively charged oxygen functional groups on GO via electrostatic interactions. Consequently, oxygenated groups are removed from GO, leading to the formation of RGO-ZnO nanocomposites [161,172]. Figure 7a shows the typical optical absorbance of $\mathrm{RGO} / \mathrm{ZnO}$ nanocomposites. The enhanced absorbance of nanocomposites with increasing RGO content in the visible light range can be readily observed. Without $\mathrm{RGO}$, neat $\mathrm{ZnO}$ nanorod has a low absorbance in the visible light as expected. The bandgap of neat $\mathrm{ZnO}$ is $3.17 \mathrm{eV}$, and decreases to 3.07, $3.03,2.94$, and 2.88 by modifying with $1 \%, 3 \%, 5 \%$, and $10 \%$ RGO, respectively (Figure $7 \mathrm{~b}$ ). Similarly, $\mathrm{Wu}$ et al. also indicated that strong interactions between $\mathrm{ZnO}$ and $\mathrm{GO}$ during hydrothermal synthesis favor the formation of visible-light active RGO-ZnO nanocomposites [173]. 

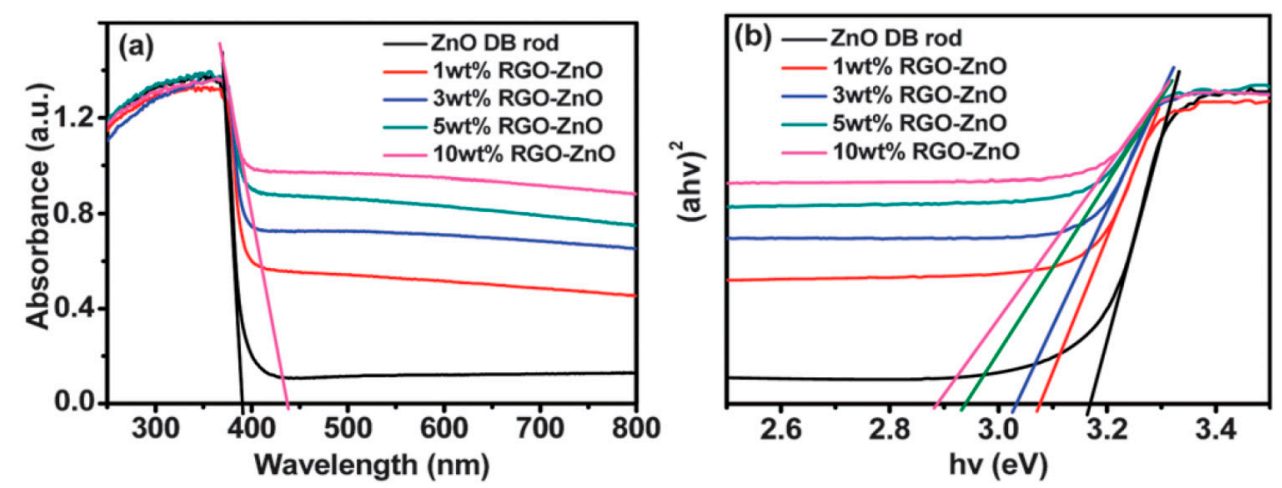

Figure 7. (a) UV-vis diffuse reflectance spectra, and (b) the plots of Kubelka-Munk function versus light energy for neat $\mathrm{ZnO}$ nanorod and $\mathrm{RGO} / \mathrm{ZnO}$ nanocomposites. Reproduced from [172] with permission of the Royal Society of Chemistry.

As mentioned, graphene modification is an effective way to prevent photocorrosion of $\mathrm{ZnO}$ [89,160-162]. Under visible light irradiation, photoexcited electrons from the graphene sheet are injected into the CB of ZnO NPs. Consequently, those electrons reduce surface oxygen molecules through a series of reactions to produce superoxide anion, hydrogen peroxide and hydroxyl radical for bacterial inactivation (Figure 8) [173]. In this context, photocorrosion resulting from the $\mathrm{ZnO}$ degradation due to the attack of positively charged holes as described by the reaction (1) and reaction (2) can be avoided. Therefore, graphene sheet plays the role of a photosensitizer by directly injecting photoexcited electrons into the $\mathrm{CB}$ of $\mathrm{ZnO}$ under visible light without inducing positively charged holes. On the other hand, graphene with excellent electrical conductivity also acts as an electron acceptor for $\mathrm{ZnO}$. By irradiating $\mathrm{ZnO}$ with $\mathrm{UV}$ light, photogenerated electrons are holes are created in the $\mathrm{CB}$ and $\mathrm{VB}$, respectively. The electrons are then transferred from the $\mathrm{CB}$ of $\mathrm{ZnO}$ to graphene sheet, thereby inhibiting the recombination of electron-hole pairs, enhancing photocatalytic activity and photostability of $\mathrm{ZnO}$ nanostructures. On the other hand, photogenerated holes in the $\mathrm{VB}$ of $\mathrm{ZnO}$ react with the adsorbed hydroxyl group to give reactive hydroxyl species. As a result, photogenerated holes would not destruct the structural integrity of $\mathrm{ZnO}$ by degrading the $\mathrm{Zn}$-O bond for releasing $\mathrm{Zn}^{2+}$ from the surface [87]. This implies that the photocorrosion of $\mathrm{ZnO}$ nanostructures can be prevented under UV irradiation effectively by modifying with graphene.

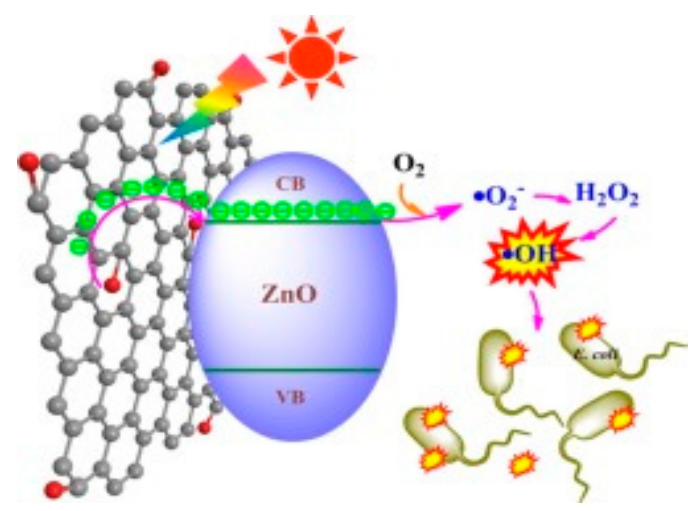

Figure 8. Electron transfer from graphene sheet to the conduction band of $\mathrm{ZnO}$ under visible light for generating ROS. Reproduced from [173] with permission of Elsevier.

\subsubsection{Carbon Nanotubes}

Carbon nanotubes with large aspect ratios are inert, exhibiting no oxygenated functional groups on their surfaces. However, hydroxyl and carboxyl functional groups can be formed on CNTs by oxidizing in a mixture of $\mathrm{H}_{2} \mathrm{SO}_{4} / \mathrm{HNO}_{3}(3: 1 ; v / v)$ [174]. Analogously, those oxygen functional groups 
can react with $\mathrm{Zn}^{2+}$ ions deriving from the dissolution of $\mathrm{ZnO}$ salt precursor in an aqueous solution for nucleating $\mathrm{ZnO}$ nanocrystals. This leads to homogeneous dispersion of ZnO NPs on the CNTs. Under the UV exposure, photogenerated electron from the $\mathrm{CB}$ of $\mathrm{ZnO}$ is transferred to the CNT. Therefore, $\mathrm{CNT}$ acts as an effective electron trapping site, hindering the recombination of electron-hole pair (Figure 9) [175]. On the contrary, photoexcited electron is injected from the CNT to the CB of ZnO under visible light irradiation for triggering the formation of ROS.

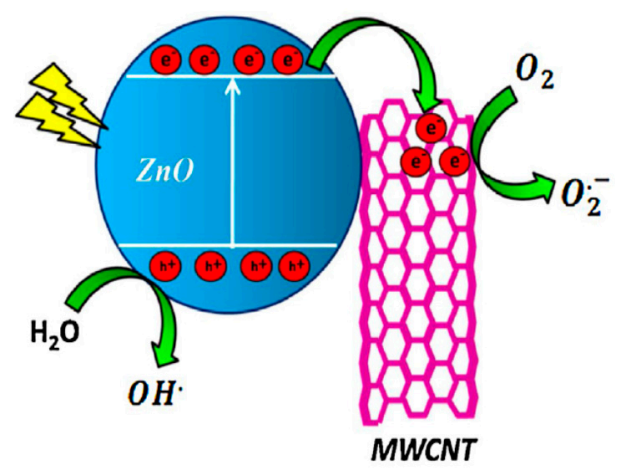

Figure 9. The transfer of photogenerated electron from the conduction band of $\mathrm{ZnO}$ to a single nanotube under UV irradiation. Reproduced from [175] with permission of Elsevier.

\subsection{Semiconductor Heterojunctions}

Coupling $\mathrm{ZnO}$ with semiconductors of different bandgap energies is considered to be an effective strategy to form visible-light-driven photocatalysts. $\mathrm{ZnO}$ can form heterojunctions with other semiconductors such as copper oxide $(\mathrm{CuO})$, titania $\left(\mathrm{TiO}_{2}\right)$, tin oxide $\left(\mathrm{SnO}_{2}\right)$, cadmium sulfide $(\mathrm{CdS})$, and zinc sulfide $(\mathrm{ZnS})$. Some semiconductors have a larger bandgap energy than $\mathrm{ZnO}$. So they are unfavored materials for coupling with $\mathrm{ZnO}$ to form visible-light-activated photocatalysts. As an example, the bandgap energy of $\mathrm{SnO}_{2}$ is $3.67 \mathrm{eV}$ [176], thus facilitating the formation of UV-responsive $\mathrm{ZnO} / \mathrm{SnO}_{2}$ heterojunctions [177]. Titania is an UV-active semiconductor with a bandgap energy of $3.2 \mathrm{eV}[178,179]$. ZnS with a wide bandgap of 3.6-3.8 eV absorbs UV light only [180]. CdS is a visible-light active semiconductor with a narrow bandgap of $2.40 \mathrm{eV}$ [180]. However, CdS is a highly toxic carcinogen, and thus unfavorable to form $\mathrm{CdS} / \mathrm{ZnO}$ heterojunction based on public health considerations. On the other hand, $\mathrm{CuO}$ and iron oxide $\left(\alpha-\mathrm{Fe}_{2} \mathrm{O}_{3}\right)$ have a relatively narrow bandgap of $2.00 \mathrm{eV}$ and $2.20 \mathrm{eV}$, respectively [180,181], so they are ideal metal-oxide semiconductors for coupling with $\mathrm{ZnO}$ to yield visible-light photocatalyts.

The visible-light photocatalytic performance of semiconductor heterojunctions depends greatly on the energy band alignment of the CB and VB of two dissimilar materials. Certain conditions must be met for achieving improved photocatalytic activity of semiconductor heterostructures under visible light. There exists three types of coupled heterojunctions, i.e., type-I, type-II and type-III in terms of the alignment of their energy levels (Figure 10a) [181-186]. In type-I heterostructure, the CB and VB levels of the smaller bandgap semiconductor lie between those of a wider bandgap semiconductor. Therefore, photoexcited electron and hole from the larger bandgap material migrate across the heterojunction and accumulate at the $\mathrm{CB}$ and VB of smaller bandgap semiconductor under visible light irradiation, producing ROS accordingly. In type-II heterostructure, both the $\mathrm{CB}$ and VB of narrow-gap semiconductor lie above those of large bandgap material. In this respect, photoexcited electron from the narrow-gap semiconductor moves to the large bandgap material, while the hole migrates from the large-gap material across the junction in the opposite direction. Thus type II heterojunction is very effective to promote the charge carrier separation, thereby reducing the recombination of electron-hole pairs. The $\mathrm{CuO} / \mathrm{ZnO}$ and $\mathrm{Cu}_{2} \mathrm{O} / \mathrm{ZnO}$ systems are typical examples of the type-II heterostructure $[90,185]$. For the $\mathrm{CuO} / \mathrm{ZnO}$ system, photogenerated electron from the $\mathrm{CB}$ of $\mathrm{CuO}$ is transferred to the $\mathrm{CB}$ of $\mathrm{ZnO}$ for generating superoxide anion, while the hole from the $\mathrm{VB}$ of $\mathrm{ZnO}$ is migrated to the $\mathrm{VB}$ of $\mathrm{CuO}$ for creating hydroxyl radical (Figure 10b). The formation of type-II 
$\mathrm{CuO} / \mathrm{ZnO}$ heterojunction improves the separation of photogenerated electron-hole pair, leading to enhanced photocatalytic activity under visible light [185]. In type-III heterostructure, the bandgaps of two dissimilar semiconductors do not overlap at all. So the transfer of electron and separation of electron-hole pair are unlikely to occur at the heterojunction.

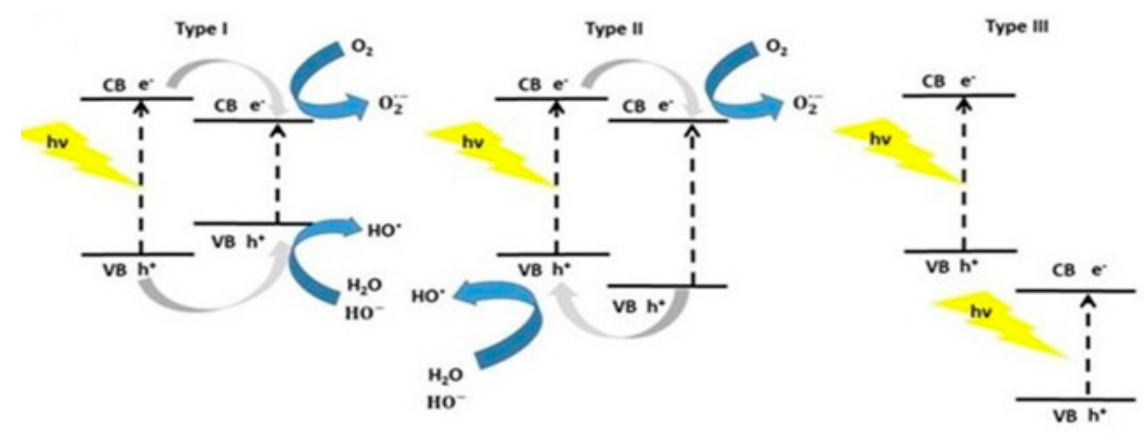

(a)

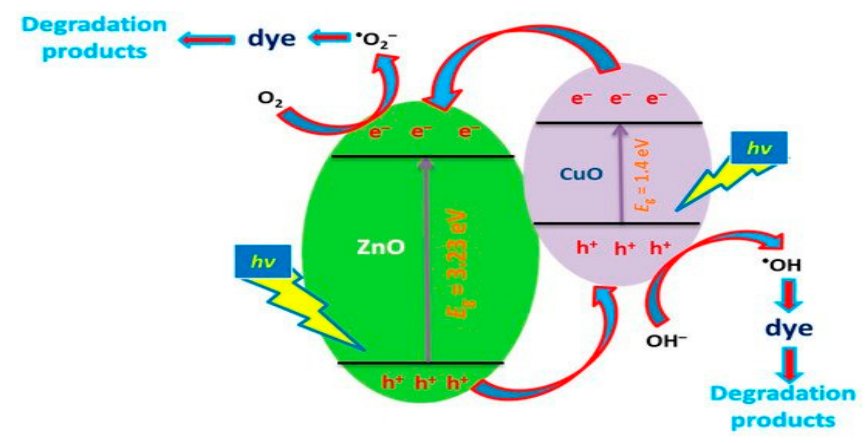

(b)

Figure 10. (a) Energy band alignments of type-I, type-II, and type-III heterojunctions. Reproduced from [186] with permission of Frontiers under the Creative Commons Attribution License. (b) The charge carrier transfer in $\mathrm{CuO} / \mathrm{ZnO}$ photocatalyst under sunlight irradiation. Reproduced from [185] the terms of the Creative Commons Attribution License.

\section{Synthesis of ZnO Nanostructures}

\subsection{Vapor Phase Route}

Zinc oxide of zero-, one-, two- and three-dimensional nanostructures can be synthesized by means of vapor-, liquid-, and solid-phase processing techniques. Conventional French process is a straightforward method to fabricate $\mathrm{ZnO}$ nanostructures by melting zinc at $1000-1400{ }^{\circ} \mathrm{C}$ in an air or oxygen atmosphere. As such, zinc vapor chemically reacts with oxygen to form $\mathrm{ZnO}$ with a purity of up to $99.9 \%$, and sizes ranging from about $0.1 \mu \mathrm{m}$ down to the nanoscale dimension. The $\mathrm{ZnO}$ nanostructures produced include nanorods, nanoplates, nanoboxes, polyhedral drums and irregularly-shaped particles. Those nanostructures generally grow either along the $<0001>$ or $<1010>$ plane directions [186]. The ratio between the $\mathrm{Zn}$ vapor pressure and oxygen pressure, or the $\mathrm{Zn} / \mathrm{O}$ flux ratio must be carefully monitored for attaining the desired $\mathrm{ZnO}$ nanostructures [187]. Very recently, Hanif et al. reported a facile synthesis of spherical ZnO NPs $(21.31 \mathrm{~nm})$ with high crystallinity through the thermolysis of zinc acetate dihydrate $\left[\mathrm{Zn}\left(\mathrm{CH}_{3} \mathrm{COO}\right)_{2} \cdot 2 \mathrm{H}_{2} \mathrm{O}\right]$ under high temperatures and pressures [188].

The vapor-phase methods include physical vapor deposition (PVD), chemical vapor deposition (CVD), and molecular beam epitaxy (MBE). PVD techniques include sputtering, thermal evaporation and pulsed laser deposition [189]. Sputtering is a typical plasma-assisted PVD technique in which collisions between gaseous ions and the target material resulting in the ejection of atoms from the 
target surface [190]. A typical inert gas such as argon is ionized under the application of direct-current (DC), or radio-frequency (RF) voltages. The inclusion of additional magnetic field further increases the ionization rate of inert gas, and guides the ion flux towards the substrate. So magnetron sputtering employs strong electric and magnetic fields to trap electrons close to the target surface to deposit $\mathrm{ZnO}$ film on the substrate. Magnetron sputtering offers the advantages of high deposition rate and low substrate temperature, but suffers from the high equipment cost and high defect concentration in the deposited films [191]. Pulsed laser deposition (PLD) is based on the ablation of target material placed inside the vacuum chamber using a laser source [192]. A high-power laser beam strikes $\mathrm{ZnO}$ or pure $\mathrm{Zn}$ target, resulting in its local heating and evaporation. This leads to the deposition of high purity $\mathrm{ZnO}$ film on the substrate [193-195]. PLD is simple and versatile, however, the use of high vacuum deposition chamber and high-power laser source, as well as the particulate emission during the target ablation are the major drawbacks of this process $[196,197]$.

As it is known, atomic layer deposition (ALD) and chemical vapor deposition (CVD) are widely used for a large-scale production of thin films for electronic and optoelectronic device applications. In particular, ALD has been employed for forming a large range of metal oxide films including $\mathrm{ZnO}$ [198-200]. In the process, chemical precursor reactants (e.g., diethylzinc and water vapor) are alternatively introduced into the growth chamber, and react sequentially on desired substrate surfaces to form nano- $\mathrm{ZnO}$ films of uniform and reproducible thickness, even at low deposition temperatures of $25-300{ }^{\circ} \mathrm{C}[199,200]$. Recently, 1D-ZnO nanostructures have received considerable attention because of their potential applications in advanced optoelectronic devices. The CVD method is an effective tool to fabricate $1 \mathrm{D}-\mathrm{ZnO}$ using $\mathrm{Zn}$ source material, i.e., a mixture of $\mathrm{ZnO} / \mathrm{C}$ powder in the presence of metal catalyst such as $\mathrm{Au}$ or tin. The process requires high-temperature heat unit deriving from thermal, microwave or radio frequency induced plasma [201]. Vaporization of $\mathrm{ZnO} / \mathrm{C}$ is achieved through carbothermal reduction of $\mathrm{ZnO} / \mathrm{C}$ powder at elevated temperatures. In the process, i.e., $\mathrm{Zn}$ or $\mathrm{ZnO} / \mathrm{C}$ powder is placed inside a furnace quartz tube, and heated at $800-1000^{\circ} \mathrm{C}$ to achieve zinc vapor saturation. The substrate (sapphire or silicon) is coated with Au catalyst. The growth of $1 \mathrm{D}-\mathrm{ZnO}$ nanostructures has been ascribed to the vapor-liquid-solid (VLS) mechanism [202,203]. The condensation of zinc vapor on $\mathrm{Au}$ results in the formation of liquid $\mathrm{Au}-\mathrm{Zn}$ alloy droplet. Subsequently, supersaturation of the liquid with $\mathrm{Zn}$ vapor leads to the nucleation of crystals at the liquid-solid interface, facilitating the growth of $1 \mathrm{D}-\mathrm{ZnO}$ [204]. As mentioned, Zn-terminated (0001) surface with a higher surface energy $\left(\gamma_{\mathrm{zn}}=2.49 \mathrm{~J} / \mathrm{m}^{2}\right)$ is more active than the O-(0001) plane having a lower surface energy $\left(\gamma_{\mathrm{O}}=\right.$ $\left.1.35 \mathrm{~J} / \mathrm{m}^{2}\right)$ [204]. Thus the $\mathrm{Zn}$-(0001) plane provides an effective site for nucleating crystals, leading to anisotropic growth of $\mathrm{ZnO}$ nanorods along the c-axis direction (Figure 11a,b) [74,205]. In other words, the growth rate is faster on the $\mathrm{Zn}-(0001)$ plane having higher surface energy, and so vertically aligned nanorods grow preferentially along the $<0001>$ direction.

One-dimensional $\mathrm{ZnO}$ nanostructures can also be synthesized without using metal catalysts. In this respect, zin vapor condenses directly onto the surface of a solid substrate, and the vapor-solid (VS) mechanism is responsible for the growth of catalyst-free $\mathrm{ZnO}$ nanostructures $[79,206,207]$. As the VS grown $\mathrm{ZnO}$ nanostructures are catalysts free, thus it is more difficult to control over their morphology than those formed from the VLS mechanism using the catalysts. Several processing parameters such as temperature, oxygen and argon flow rate, amount of precursor, growth time, and type of the substrates, affect the morphology of nano- $\mathrm{ZnO}$ greatly. In particular, the growth temperature plays a key role to regulate the morphology of nano-ZnO ranging from polycrystalline thin films to nanowhiskers [207]. Very recently, Karnati et al. employed high pressure assisted pulsed laser deposition to form vertically aligned $\mathrm{ZnO}$ nanorods on various substrates. Temperature and number of pulsed laser shots during the deposition play important roles in the alignment of $\mathrm{ZnO}$ nanorods [79]. Kong and Wang reported that $1 \mathrm{D}-\mathrm{ZnO}$ of various morphologies such as nanobelts, nanowires, nanorings, nanohelixes/nanosprings, nanocombs, nanobows, and nanocages can be synthesized under specific growth conditions using a solid-vapor phase thermal sublimation method [208,209]. Helical ZnO nanobelts with top and 
bottom flat surfaces consist of $\pm(0001)$ polar surfaces serve as the building blocks to form nanorings, nanohelixes and nanosprings (Figure 12) [208,209].

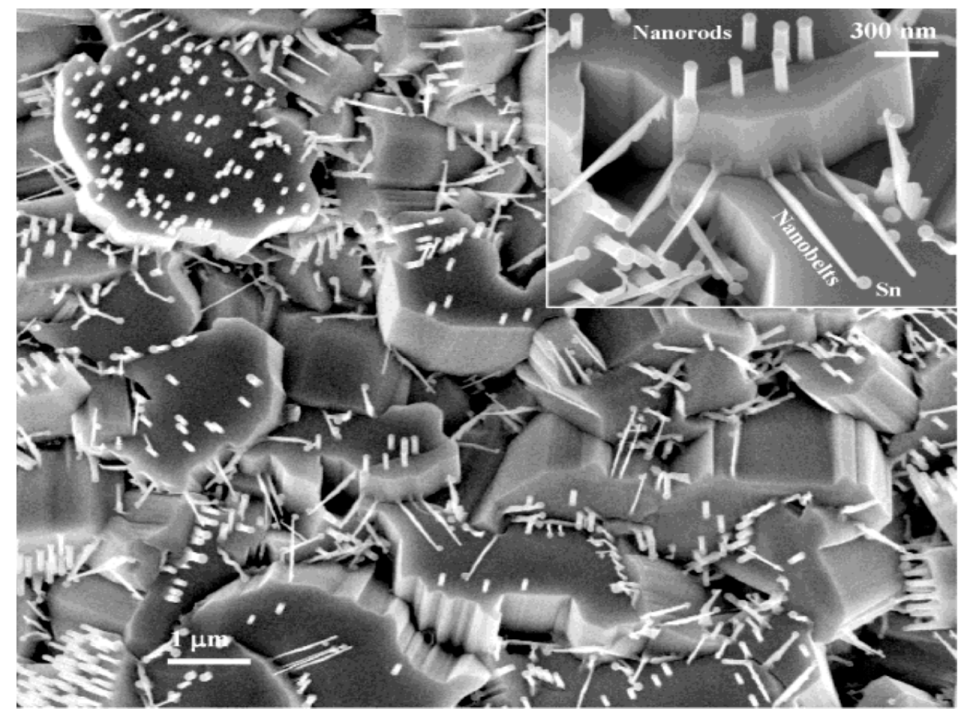

(a)

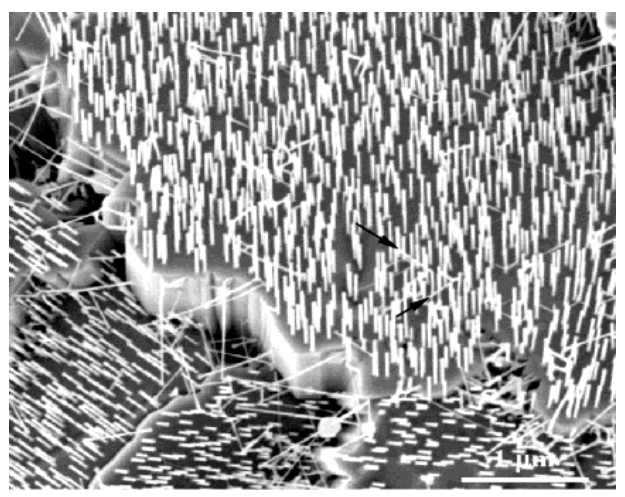

(b)

Figure 11. (a) Scanning electron microscope (SEM) image showing ZnO nanorods and nanobelts grown on the top (0001) and side surfaces of the $\mathrm{ZnO}$ microrods, respectively for $15 \mathrm{~min}$. Inset: Magnified SEM image. (b) SEM image of $\mathrm{ZnO}$ nanorods and nanobelts after growing for $30 \mathrm{~min}$ at $1100{ }^{\circ} \mathrm{C}$. Black arrows indicate nanobelts. Reproduced from [205] with permission of the American Chemical Society.

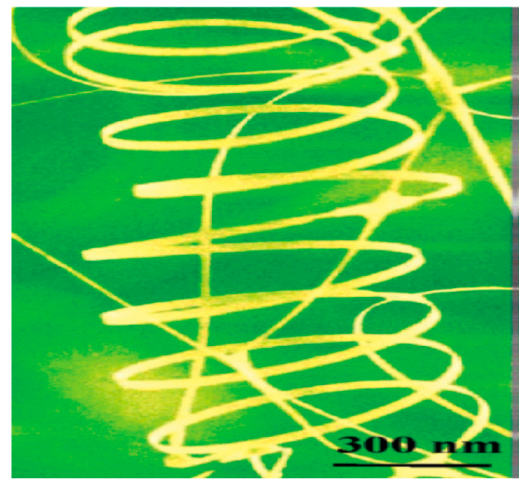

(a)

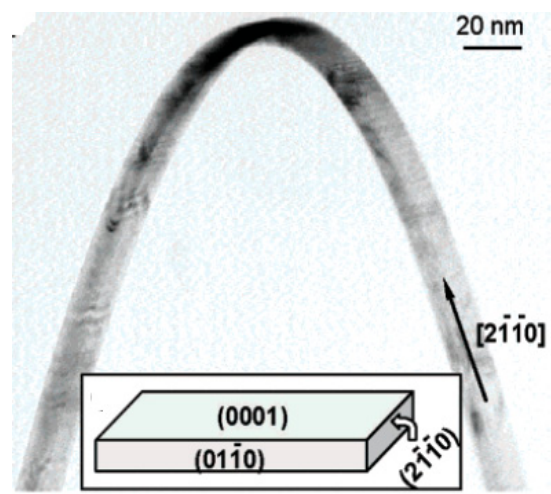

(b)

Figure 12. (a) SEM image of $\mathrm{ZnO}$ nanobelts. (b) Transmission electron micrograph of a helical nanobelt. Inset: structural model of $\mathrm{ZnO}$ nanobelt. Reproduced from [208] with permission of the American Chemical Society. 


\subsection{Liquid-Phase Route}

\subsubsection{Co-Precipitation Method}

The liquid phase synthesis can be used to fabricate $\mathrm{ZnO}$ nanomaterials in an aqueous or organic medium using a wide range of precursors under different processing conditions. Liquid phase synthesis has many advantages over vapor phase route for fabricating $\mathrm{ZnO}$ nanostructures in terms of simplicity, versatility, low cost, low temperature and scalability. The solution phase synthesis generally includes co-precipitation, sol-gel, hydrothermal/solvothermal treatment, and microemulsion. $\mathrm{ZnO}$ nanostructures with different dimensions such as spherical nanoparticles, nanoprisms, nanorods, nanowires, nanodisks and nanoflowers can be obtained by controlling the synthetic parameters such as the types of metal salt precursor and solvent, zinc salt concentration, solution $\mathrm{pH}$ and temperature, reaction time, surfactant type and concentration, $\mathrm{ZnO}$ seed layer utilization, etc.

Co-precipitation method involves the dissolution of a metal salt precursor in water/organic solvent for precipitating oxo-hydroxide in the presence of a strong alkali metal hydroxide $(\mathrm{MOH} ; \mathrm{M}=\mathrm{Li}, \mathrm{Na}$, K, Cs), or weak hexamethylenetetramine (HMTA) [210-214]. In the process, zinc metal salt precursor decomposes in the solution to yield $\mathrm{Zn}^{2+}$ for forming $\mathrm{Zn}(\mathrm{OH})_{2}$. By adding $\mathrm{MOH}$ dropwise, $\mathrm{Zn}(\mathrm{OH})_{2}$ dissolves in the solution due to an increase of the basicity, and reacts with $\mathrm{OH}^{-}$to give $\left[\mathrm{Zn}(\mathrm{OH})_{4}\right]^{2-}$. The $\left[\mathrm{Zn}(\mathrm{OH})_{4}\right]^{2-}$ complex is generally known as the growth unit, serving as the nucleation site for growing $\mathrm{ZnO}$ crystals by precipitating on positively charged Zn-terminated (0001) surface [76,77,210]. Nano-ZnO is formed via dehydration of $\left[\mathrm{Zn}(\mathrm{OH})_{4}\right]^{2-}$. When hexamethylenetetramine $\left[\left(\mathrm{CH}_{2}\right)_{6} \mathrm{~N}_{4}\right]$ is used instead of $\mathrm{MOH}$, thermal decomposition of HMTA generates ammonia and formaldehyde (HCHO). Ammonia serves as a weak base by accepting hydrogen ions from water to produce ammonium $\mathrm{NH}_{4}^{+}$ and $\mathrm{OH}^{-}$ions. Hydroxyl ions are needed for triggering the precipitation reaction. Zinc ions from zinc salt precursor react with hydroxide ions to form $\mathrm{Zn}(\mathrm{OH})_{2}$ and $\left[\mathrm{Zn}(\mathrm{OH})_{4}\right]^{2-}$. Furthermore, zinc ions also react with ammonia to yield tetraamminezinc(II) complex ( $\mathrm{Zn}$-tetraamine), i.e., $\left[\mathrm{Zn}\left(\mathrm{NH}_{3}\right)_{4}\right]^{2+}$. The $\left[\mathrm{Zn}\left(\mathrm{NH}_{3}\right)_{4}\right]^{2+}$ complex also acts as the growth unit for $\mathrm{ZnO}$ nuclei. Overall, the reactions are given as follows $[210,211]$,

$$
\begin{gathered}
\left(\mathrm{CH}_{2}\right)_{6} \mathrm{~N}_{4}+6 \mathrm{H}_{2} \mathrm{O} \rightarrow 6 \mathrm{HCHO}+4 \mathrm{NH}_{3} \\
\mathrm{NH}_{3}+\mathrm{H}_{2} \mathrm{O} \rightarrow \mathrm{NH}_{4}^{+}+\mathrm{OH}^{-} \\
\mathrm{Zn}(\mathrm{OH})_{2-}+2 \mathrm{OH}^{-} \rightarrow\left[\mathrm{Zn}(\mathrm{OH})_{4}\right]^{2-} \\
{\left[\mathrm{Zn}(\mathrm{OH})_{4}\right]^{2-} \rightarrow \mathrm{ZnO}+\mathrm{H}_{2} \mathrm{O}+2 \mathrm{OH}^{-}} \\
\mathrm{Zn}^{2+}+4 \mathrm{NH}_{3} \rightarrow\left[\mathrm{Zn}\left(\mathrm{NH}_{3}\right)_{4}\right]^{2+} \\
{\left[\mathrm{Zn}\left(\mathrm{NH}_{3}\right)_{4}\right]^{2+}+2 \mathrm{OH}^{-} \rightarrow \mathrm{ZnO}+4 \mathrm{NH}_{3}+\mathrm{H}_{2} \mathrm{O}}
\end{gathered}
$$

Pourrahimi et al. dissolved several zinc salt precursors like zinc nitrate, chloride, sulfate and acetate in aqueous solutions in the presence of $\mathrm{NaOH}$ to synthesize nano- $\mathrm{nnO}$ [215]. The acetate precursor produces nanoprismatic particles with a narrow size distribution having an average size of $25 \mathrm{~nm}$. The chloride and sulfate precursors give rise to ZnO NPs with sizes of 10-30 nm, and larger particles (petals) with sizes of 80-100 nm, respectively. The petals derive from the self-assembly of nanoprisms along the $\mathrm{c}$ axis of $\mathrm{ZnO}$. For zinc nitrate salt, the petals link each other into flower-shaped particles with an average size of $500 \mathrm{~nm}$. Furthermore, acetate ions from zinc acetate are effective to stabilize nanoprisms during the crystal growth, thereby preventing their assembly to large petals. However, nitrate counter-ions favor the growth of nanoprisms into large petals and flower-like crystals. Akhtar et al. fabricated $\mathrm{ZnO}$ NPs by reacting zinc acetate dihydrate $\left(\mathrm{Zn}\left(\mathrm{CH}_{3} \mathrm{COO}\right)_{2} \cdot 2 \mathrm{H}_{2} \mathrm{O}\right)$ with $\mathrm{NaOH}$ [212]. Prismatic ZnO NPs with hexagonal/polygonal shapes having an average size of $21.34 \mathrm{~nm}$ are precipitated in the solution accordingly (Figure 13A,B) [212]. 

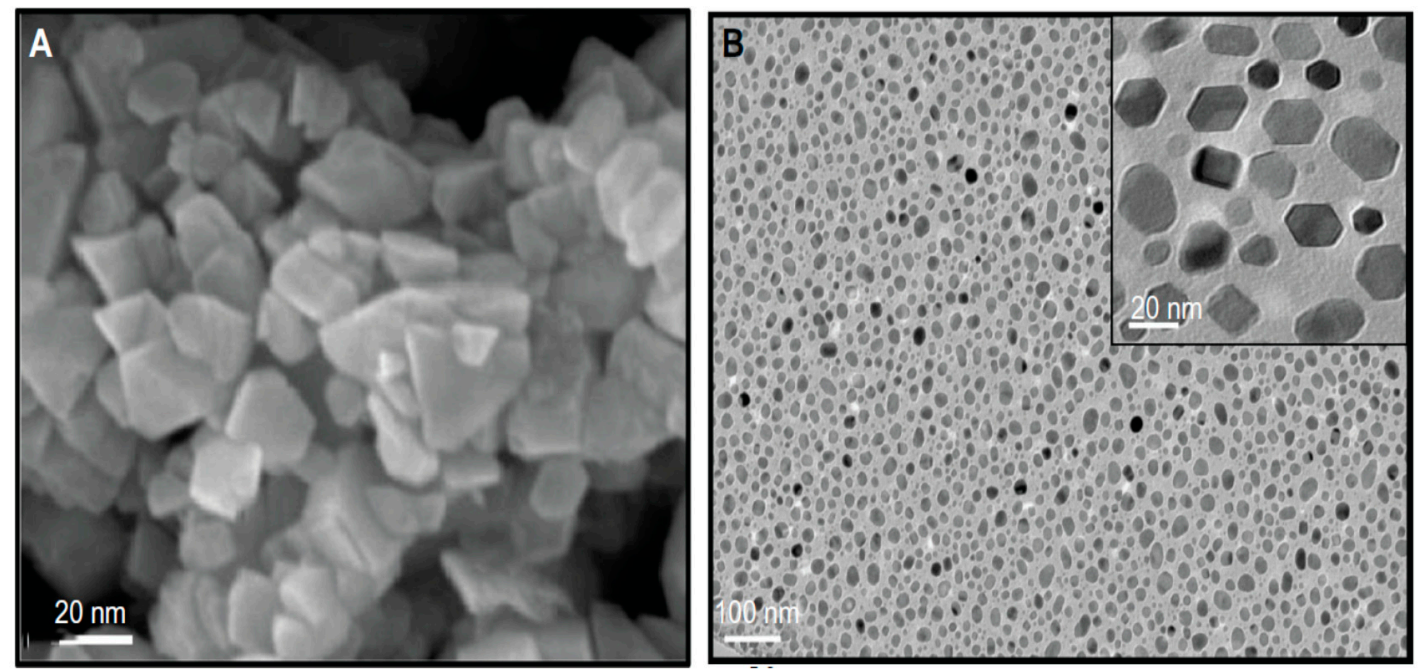

Figure 13. (A) SEM and (B) transmission electron microscope (TEM) images of ZnO nanoparticles (NPs) prepared by co-precipitation process using zinc acetate dihydrate and $\mathrm{NaOH}$. Inset in (B) shows a high-magnified TEM image of hexagonal shaped ZnO NPs. Reproduced from [212] under a Creative Commons License.

Biosynthesis

Comparing with chemical reagents, toxic free and eco-friendly plant extracts are cost competitive agents for preparing ZnO NPs [216-220]. The plant-based organic compounds are abundant and renewable bioresources. The phytochemical constituents such as alkaloids, flavonoids, phenols, amino acids, polysaccharides, and tannins extracted from various parts of plants like leaves, fruits, seeds and flowers can be used for driving reduction reactions during the $\mathrm{ZnO}$ synthesis. They also act as a capping agent/stabilizer for forming ZnO NPs. In some cases, hydroxyl and carboxylic groups of citrus fruit peel extracts (e.g., flavonol and carotenoid) serve as natural ligand agents for zinc ions from zinc salt precursor [217-219]. For instance, Fumar et al. proposed the reactions between functional groups of grapefruit peel extract and zinc ions from zinc sulfate precursor in forming a zinc-ligand complex as given in Figure 14a [217]. Figure 14b shows a facile and eco-friendly process for synthesizing ZnO nanoflowers using zinc nitrate and sea buckthorn fruit extract [220]. Apprarently, biosynthesis of $\mathrm{ZnO}$ nanoflowers is a single step process via the reactions between the functional groups of sea buckthorn fruit extract and zinc nitrate precursor. The resultant mixture is collected by centrifugation at $5000 \mathrm{rpm}$ for $15 \mathrm{~min}$ followed by calcination in a muffle furnace at $600^{\circ} \mathrm{C}$ for $2 \mathrm{~h}$ to form $\mathrm{ZnO}$ nanoflowers. Very recently, Thi et al. employed an aqueous extract of orange peel and zinc nitrate to synthesize ZnO NPs for antibacterial purposes [219]. The orange peel extract phytochemicals (e.g., flavonoid, limonoid, carotenoid) act as natural ligand agents. So hydroxyl aromatic ring groups from the extract tend to form a ligand complex with zinc ions from zinc nitrate. The reaction product is then dried at $150^{\circ} \mathrm{C}$ followed by calcination at $300-900^{\circ} \mathrm{C}$ to yield ZnO NPs. During drying and calcining stages, zinc ligand complex converts into ZnO NPs accordingly. The as-synthesized ZnO NPs exhibit low crystallinity, and their crystallinity improves with increasing calcination temperatures (Figure 14c) [219]. Fourier transform infrared spectra also reveal the peak intensity associated with the stretching vibration of $\mathrm{Zn}-\mathrm{O}$ at around $450 \mathrm{~cm}^{-1}$ increases while the band intensity due to organic functional groups $\mathrm{C}=\mathrm{C}$ and $\mathrm{C}=\mathrm{O}$ of orange peel extract at $1640 \mathrm{~cm}^{-1}$ decreases with increasing calcination temperatures. A broad band centered at $3448 \mathrm{~cm}^{-1}$ is ascribed to adsorbed water molecules on ZnO NPs (Figure 14d). Apparently, FTIR spectra confirms the presence of pell extract residuals on the nanoparticles upon calcination for different temperatures. Those phytochemicals are beneficial in assisting ZnO NPs for killing various bacterial strains. 


\section{ZnO Seed Layer}

Generally, $\mathrm{ZnO}$ nanorods prepared from co-precipitation without using a seeded substrate are oriented randomly. Thus, a two-step approach, including the synthesis of a thin seed layer on the substrate and co-precipitation in aqueous solutions, has been adopted widely to prepare vertical aligned $\mathrm{ZnO}$ nanorods/nanowires. The seed layer serves as the nucleation site for vertical growth of dense $\mathrm{ZnO}$ nanostructures [200,210,221-223]. ZnO seed layer can be deposited on desired substrates using PLD, ALD, spin coating and sol-gel techniques [200]. For instance, Liu et al. first deposited a thin $\mathrm{ZnO}$ seed layer on the glass and indium tin oxide (ITO) respectively, followed by growing ZnO nanorods on those substrates upon immersion in a solution of $\mathrm{Zn}\left(\mathrm{NO}_{3}\right)_{2}$ and HMTA [221]. Without $\mathrm{ZnO}$ seeding, the sizes of $\mathrm{ZnO}$ nanorods grown on bare substrates are larger than those on $\mathrm{ZnO}$-seeded substrates. This is due to few nucleation sites are available for forming crystals on bare substrates. In contrast, the coverage density of $\mathrm{ZnO}$ nanorod arrays is much higher on the seeded substrates as expected. More recently, Karim et al. synthesized $\mathrm{ZnO}$ nanorod arrays on $\mathrm{ZnO}$-seeded $\mathrm{SiO}_{2} / \mathrm{Si}$ substrate by dipping in an aqueous solution of zinc acetylacetonate hydrate and HMTA at $85^{\circ} \mathrm{C}$ for 0.5-4 h [223]. High-density of vertically aligned nanorods are grown on the $\mathrm{ZnO}$-seeded substrate for $0.5 \mathrm{~h}$. The length of $\mathrm{ZnO}$ nanorod array is $\sim 0.9 \mu \mathrm{m}$ (Figure 15a). By increasing immersion time to $2 \mathrm{~h}$, the length of $\mathrm{ZnO}$ nanorods is increased to $\sim 1.6 \mu \mathrm{m}$ (Figure 15b). As aforementioned, aligned $\mathrm{ZnO}$ nanorods can be prepared using vapor-phase CVD process. However, CVD requires a relatively high synthetic temperature, long deposition time, and large energy consumption for forming $\mathrm{ZnO}$ nanorods. Apparently, the liquid-phase solution synthesis offers a good opportunity for forming aligned $\mathrm{ZnO}$ nanorods at relatively low temperatures and low cost.

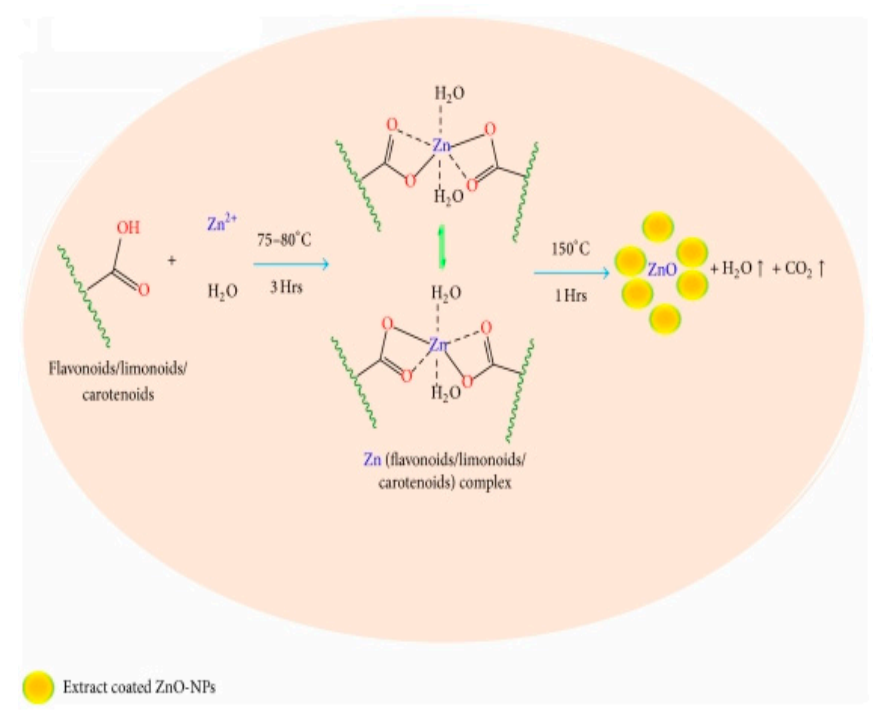

(a)

Figure 14. Cont. 


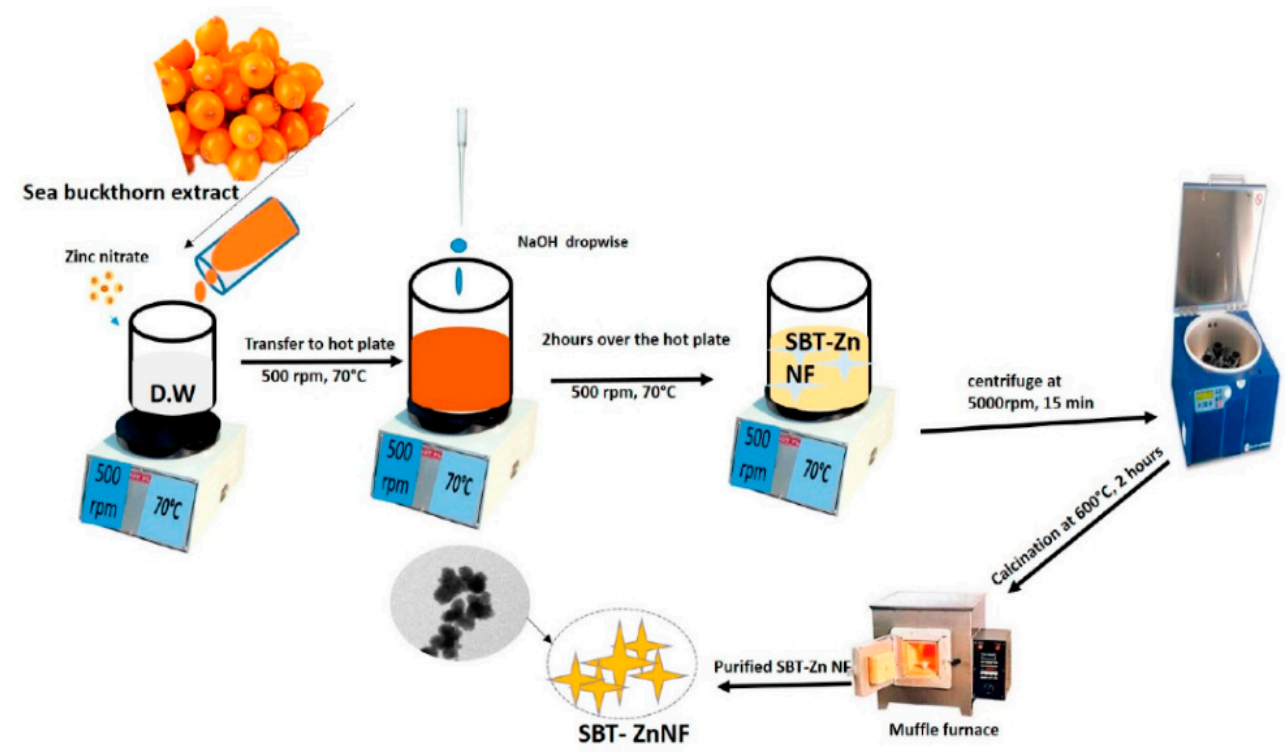

(b)

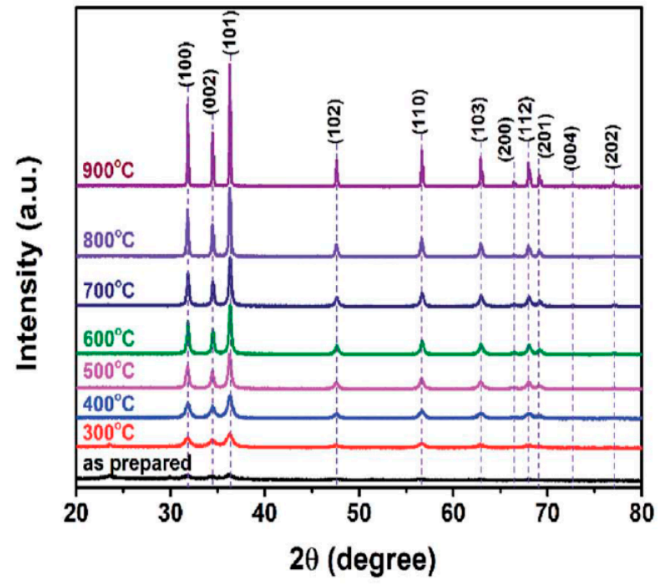

(c)

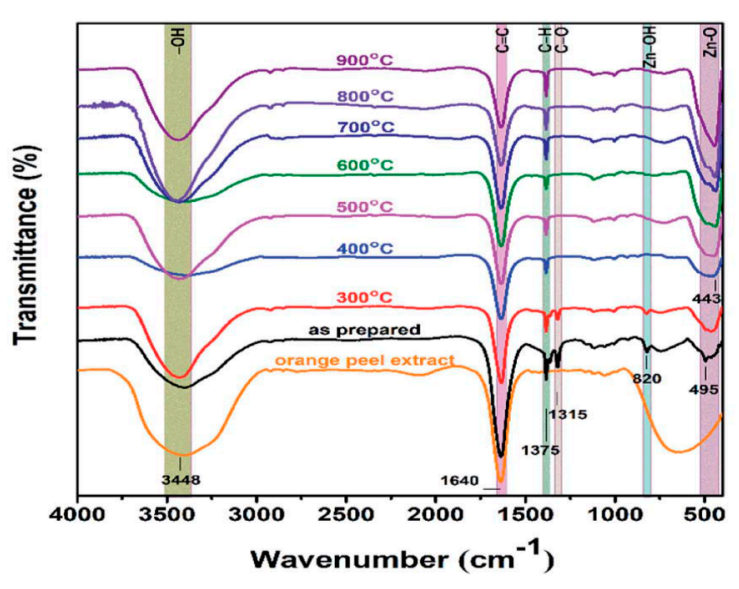

(d)

Figure 14. (a) Proposed reaction mechanism between functional groups of grapefruit peel extract and zinc ions from zinc sulfate in forming zinc-ligand complex and ZnO NPs after drying in an oven at $150{ }^{\circ} \mathrm{C}$. Reproduced from [217] under the Creative Commons Attribution License. (b) A schematic showing biosynthesis of $\mathrm{ZnO}$ nanoflowers (NFs) using $\mathrm{Zn}\left(\mathrm{NO}_{3}\right)_{2} \cdot 6 \mathrm{H}_{2} \mathrm{O}$ and sea buckthorn (SBT) fruit extract. Reproduced from [220] under the terms of the Creative Commons Attribution License. (c) X-ray diffraction patterns showing the wurtzite structure of as-synthesized $\mathrm{ZnO}$ nanoparticles calcined at different temperatures. $\mathrm{ZnO} N P s$ are biosynthesized from $\mathrm{Zn}\left(\mathrm{NO}_{3}\right)_{2} \cdot 6 \mathrm{H}_{2} \mathrm{O}$ and orange peel extract. (d) Fourier transform infrared spectra of orange peel extract and the as-synthesized ZnO NPs heat treated at different temperatures. Reproduced from [219] under the terms of the Creative Commons Attribution-NonCommercial 3.0 Unported License. 


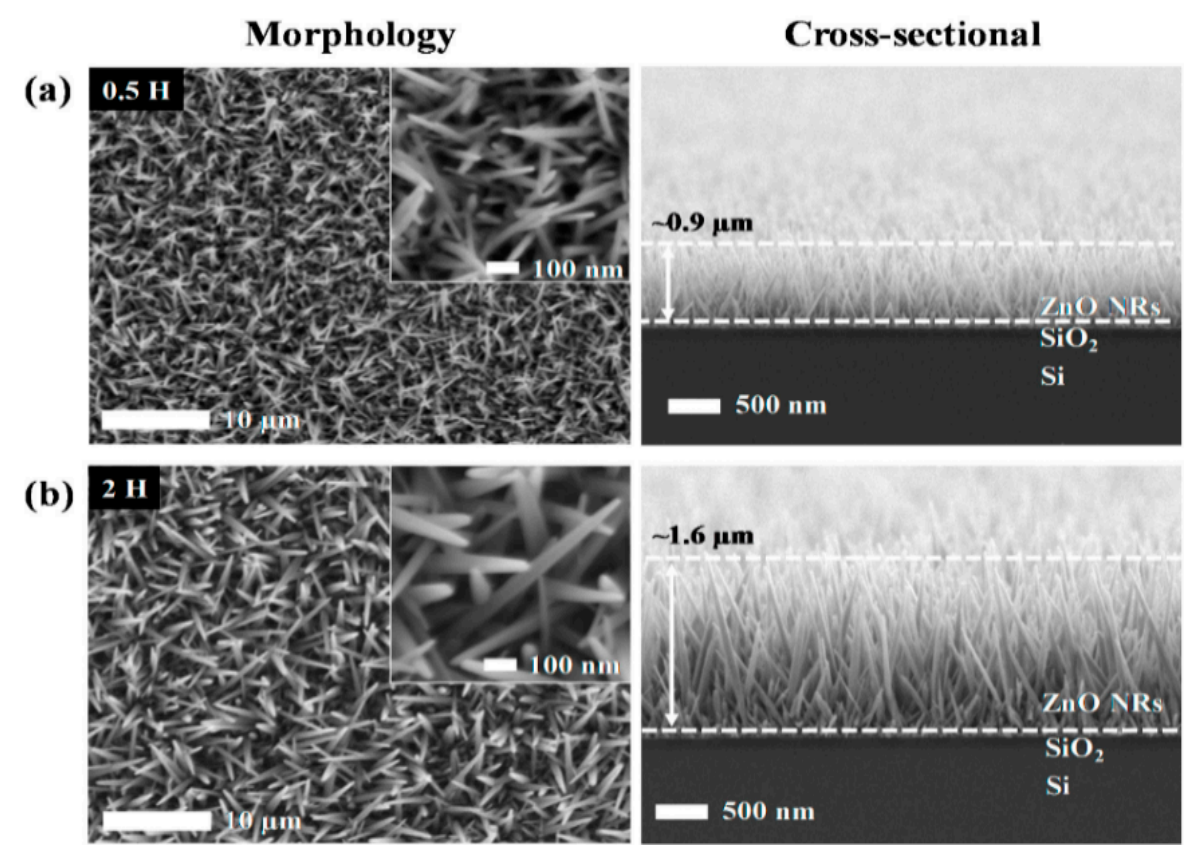

Figure 15. SEM images of top and cross-sectional views of $\mathrm{ZnO}$ nanorods formed on $\mathrm{ZnO}$-seeded $\mathrm{SiO}_{2} / \mathrm{Si}$ substrate by immersing in zinc acetylacetonate hydrate and HMTA solution for (a) $0.5 \mathrm{~h}$ and (b) 2 h. Insets in left panels of (a,b): High-magnification plan-view SEM images. Right panels: cross-sectional SEM micrographs. Reproduced from [223] under the terms of the Creative Commons Attribution License (CC BY).

Co-precipitation process generally yields a large particle size distribution, and poor control on the particle shape formation. Moreover, $\mathrm{ZnO}$ NPs tend to agglomerate into clusters during the synthesis. In this respect, capping agents or surfactants are added into zinc salt precursor solutions to control the morphology and size of $\mathrm{ZnO}$ nanostructures, and to prevent the aggregation of $\mathrm{ZnO}$ nanocrystals. Typical capping agents include cetyl trimethyl ammonium bromide (CTAB), sodium dodecyl sulfate (SDS), Triton X-100, oleic acid, elaidic acid, etc. [224-226]. Cationic CTAB and anionic SDS surfactants are typically used for stabilizing colloidal NPs. Ramimoghadam et al. demonstrated that the mixture of cationic-anionic CTAB and SDS surfactants can significantly modify the shape and size of ZnO NPs [225]. However, CTAB is highly toxic, and SDS is a hazardous agent [227]. Thus their use for stabilizing colloidal nanoparticles must be restricted. In this respect, recent attention has paid to the use of green chemical agents extracted from the plants such as ascorbic acid and citric acid for stabilizing colloidal ZnO NPs [228,229].

\subsubsection{Hydrothermal/Solvothermal Synthesis}

The hydrothermal/solvothermal strategy utilizes water or organic solvent as the reaction medium for synthesizing $\mathrm{ZnO}$ nanostructures in a sealed autoclave system at moderate to high reaction temperatures. The recent studies on hydrothermal/solvothermal synthesis of $\mathrm{ZnO}$ nanostructures/nanocomposites of different geometries have been reported elsewhere [230-237]. In some cases, surfactants are added to control the size and shape of nano-ZnO synthesized under hydrothermal or solvothermal treatment $[225,226,234]$. ZnO nanostructures can be synthesized hydrothermally with or without $\mathrm{ZnO}$-seeded substrates. For instance, Dong et al. prepared $\mathrm{ZnO}$ nanorod arrays using $\mathrm{ZnO}$ seeded ITO substrate, $\mathrm{Zn}\left(\mathrm{NO}_{3}\right)_{2} \cdot 6 \mathrm{H}_{2} \mathrm{O}$ precursor and HMTA weak base [230]. Figure $16 \mathrm{a}, \mathrm{b}$ are the SEM images showing the top view and $45^{\circ}$ tilt view of $\mathrm{ZnO}$ nanorod arrays grown on ITO in $0.05 \mathrm{M} \mathrm{Zn}\left(\mathrm{NO}_{3}\right)_{2} \cdot 6 \mathrm{H}_{2} \mathrm{O}$ and HMTA solution at $80{ }^{\circ} \mathrm{C}$ for $3 \mathrm{~h}$. The nanorod arrays with a hexagonal feature are oriented normal to the substrate. 


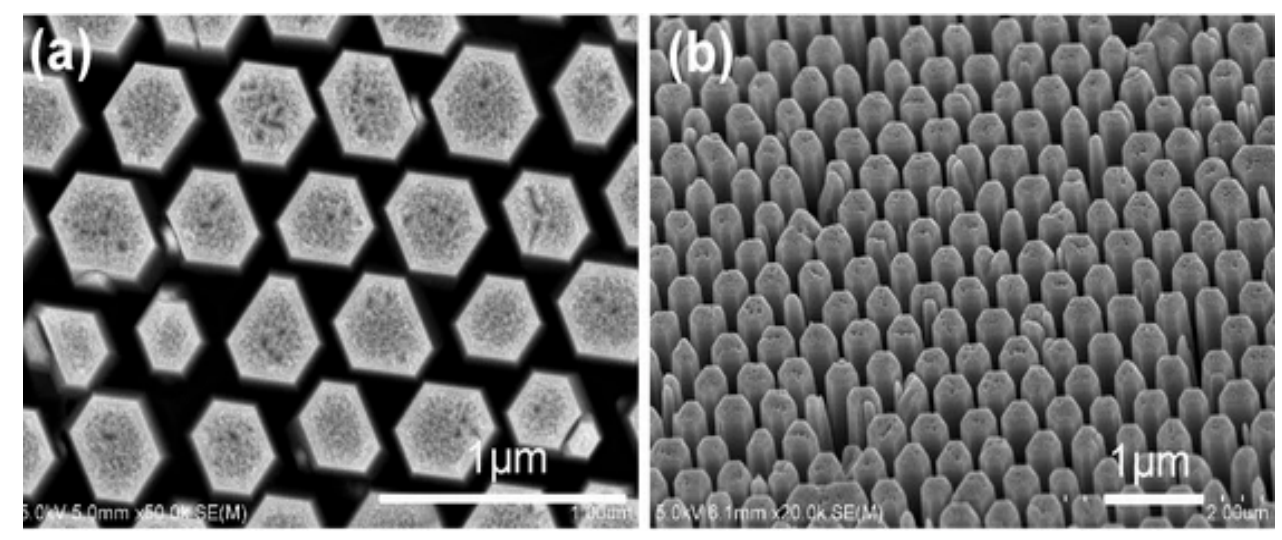

Figure 16. SEM images showing (a) top view and (b) $45^{\circ}$ tilt view of $\mathrm{ZnO}$ nanorod arrays. Reproduced from [230] under the terms of the Creative Commons Attribution 4.0 International License.

Qiu et al. prepared $\mathrm{ZnO}$ nanoflowes using a surfactant-free hydrothermal process. Thin- $\mathrm{ZnO}$ film coated glass slides, $\mathrm{Zn}\left(\mathrm{NO}_{3}\right)_{2} \cdot 6 \mathrm{H}_{2} \mathrm{O}$, and HMTA were used, and the mixed reagent solutions were preheated at $95^{\circ} \mathrm{C}$ for $12 \mathrm{~h} \mathrm{[231].} \mathrm{In} \mathrm{the} \mathrm{process,} \mathrm{ZnO-coated} \mathrm{glass} \mathrm{substrates} \mathrm{are} \mathrm{immersed} \mathrm{in} \mathrm{preheated}$ aqueous solutions for different time periods. As such, $\mathrm{ZnO}$ nanorods are grown on the seeded glass slide along $<0001>$ direction after dipping for $2 \mathrm{~h}$ (Figure 17a). By increasing the growth time to $4 \mathrm{~h}$, secondary nucleation takes place on nanorods, and the rods contact each other to form the petals [238]. Those petals then link together to form corolla (Figure $17 \mathrm{~b}$ and inset). More flower-like $\mathrm{ZnO}$ can be readily observed as the growth time increases to $6 \mathrm{~h}$ (Figure $17 \mathrm{c}$ and inset). Thus the formation of $\mathrm{ZnO}$ nanoflower derives from self-assembly of zincates into nonorods, and secondary nucleation on nanorods to form the petals. Further increasing the reaction time to $24 \mathrm{~h}$ leads to a complete formation of numerous nanoflowers on seeded glass substrate (Figure 17d).

As aforementioned, polar $\mathrm{Zn}$-terminated $\mathrm{ZnO}(0001)$ with a higher surface energy and reactivity than polar O-(0001), non-polar (2110) and (0110). Thus Zn-terminated (0001) plane attracts negatively charged $\left[\mathrm{Zn}(\mathrm{OH})_{4}\right]^{2-}$ to its surface during the synthesis process. The amount of $\left[\mathrm{Zn}(\mathrm{OH})_{4}\right]^{2}$ deposited on $\mathrm{Zn}$-(0001) surface increases with the growth time and temperature as expected. The growth units then self-assemble rapidly into nanoparticles on Zn-(0001) surface, and grow along the $<0001>$ direction to form 1D nanorods as shown in Figure 17a. Secondary nucleation occurs on the nanorod surfaces as the crystallization time increases during hydrothermal synthesis [238]. These rods contact and link each other under a prolonged reaction time to form $3 \mathrm{D}-\mathrm{ZnO}$ nanoflowers. Figure 18 is a schematic illustration showing the deposition of $\left[\mathrm{Zn}(\mathrm{OH})_{4}\right]^{2-}$ on $\mathrm{Zn}-(0001)$ surface, the self-assembly and growth of crystals along the $<0001>$ direction to form $1 \mathrm{D}$ nanorods, secondary nucleation on top of primary nanarods to yield flower flakes, and the final formation of $\mathrm{ZnO}$ nanoflowers [239]. 

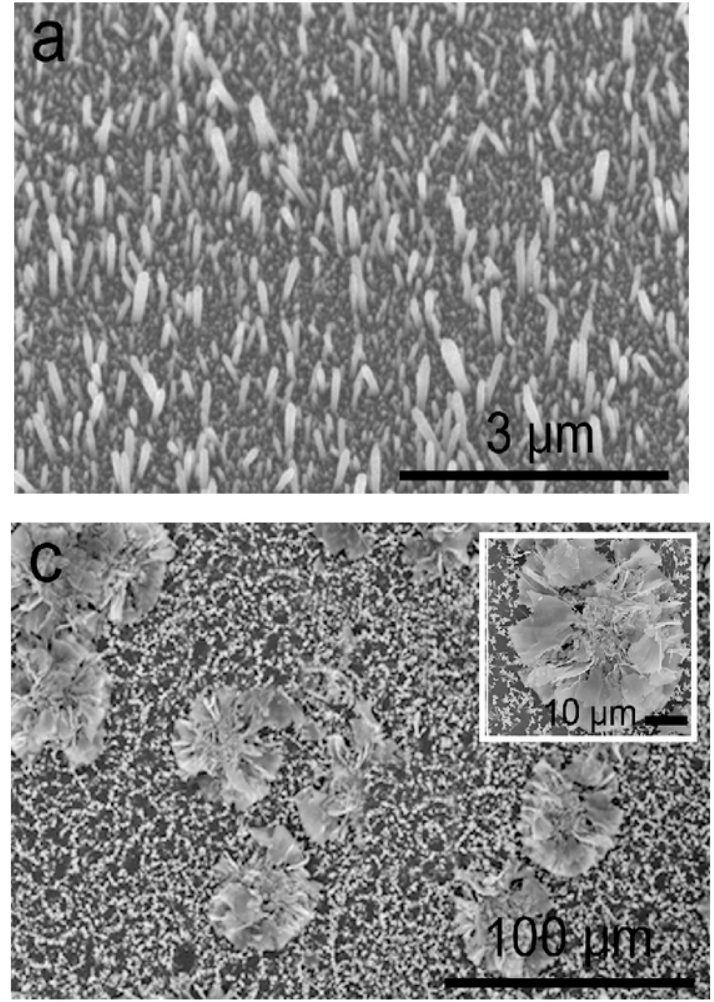
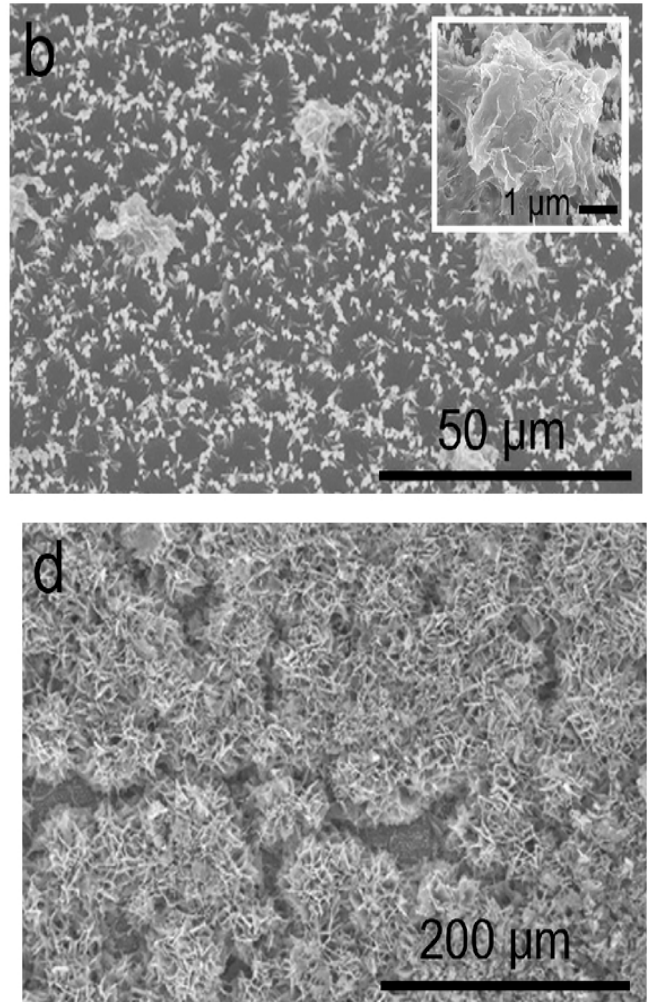

Figure 17. The effect of growth time on morphological evolution of flower-like $\mathrm{ZnO}$ nanostructures in preheated aqueous $\mathrm{Zn}\left(\mathrm{NO}_{3}\right)_{2} \cdot 6 \mathrm{H}_{2} \mathrm{O}$ and HMTA solutions: (a) $2 \mathrm{~h}$, (b) $4 \mathrm{~h}$, (c) $6 \mathrm{~h}$, and (d) $24 \mathrm{~h}$. Reproduced from [231] under the Creative Commons Attribution License.

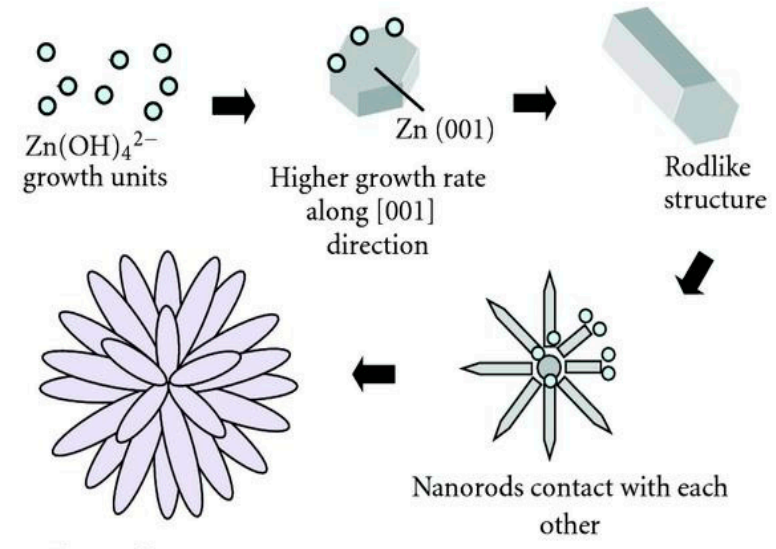

Flower-like structure

Figure 18. Schematic displaying the evolution of $\mathrm{ZnO}$ nanorods and $\mathrm{ZnO}$ nanoflowers from $\left[\mathrm{Zn}(\mathrm{OH})_{4}\right]^{2-}$ growth units. Reproduced from [239] under the Creative Commons Attribution License.

Agnihotri et al. employed $\mathrm{ZnO}$ seeded microscope glass substrates to grow $\mathrm{ZnO}$ nanorods, followed by decorating $\mathrm{ZnO}$ nanorods with AgNPs [235]. In the process, $\mathrm{ZnO}$ seeded glass substrates were first immersed in an aqueous solution of zinc nitrate and HMTA at $90^{\circ} \mathrm{C}$ for $1 \mathrm{~h}$ to produce $\mathrm{ZnO}$ nanorods. The as-grown $\mathrm{ZnO}$ nanorods were further hydrothermally treated in a mixed silver nitrate-arginine solution containing ascorbic acid to form AgNPs/ZnO nanocomposite. Ascorbic acid was used to reduce $\mathrm{Ag}^{+}$ions to AgNPs, while arginine amino acid was added to immobilize AgNPs on $\mathrm{ZnO}$ nanorods (Figure 19). The morphology of AgNPs/ZnO nanorods and the dispersion of AgNPs on a single $\mathrm{ZnO}$ nanorod are shown in Figure 20a,b, respectively. High-resolution TEM (HRTEM) images of the AgNP-ZnO interface, lattice fringes of $\mathrm{ZnO}$ and $\mathrm{AgNP}$ are shown in Figure 20c,e, respectively. 

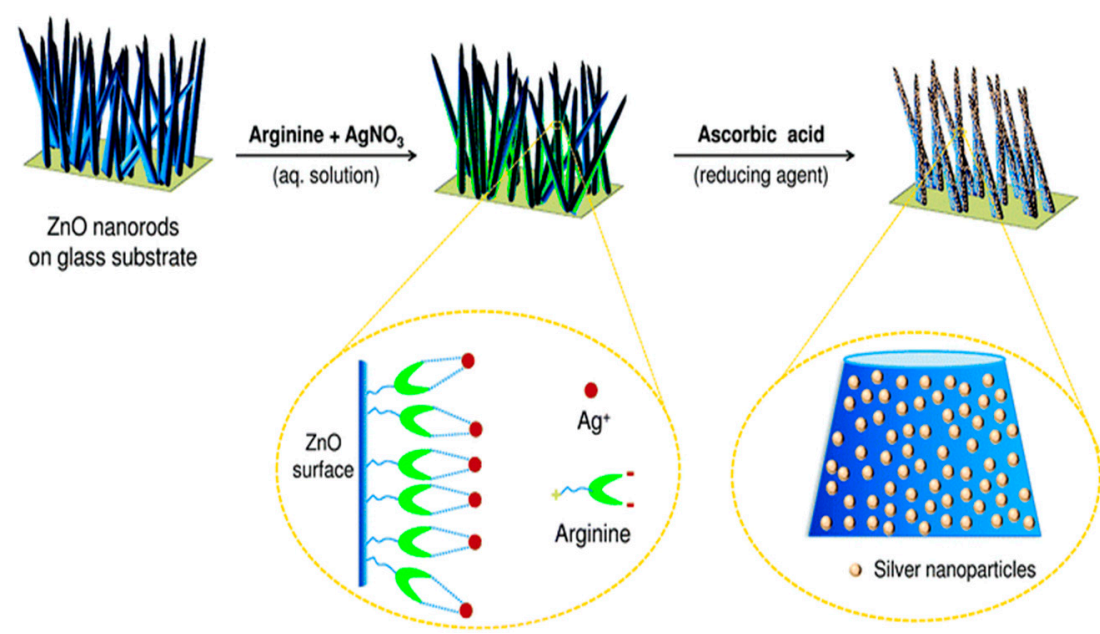

Figure 19. Schematic representation of the synthesis of $\mathrm{AgNPs} / \mathrm{ZnO}$ nanocomposite using arginine as a linker to immobilize AgNPs on $\mathrm{ZnO}$ nanorods. Reproduced from [235] under a Creative Commons Attribution 3.0 Unported License.
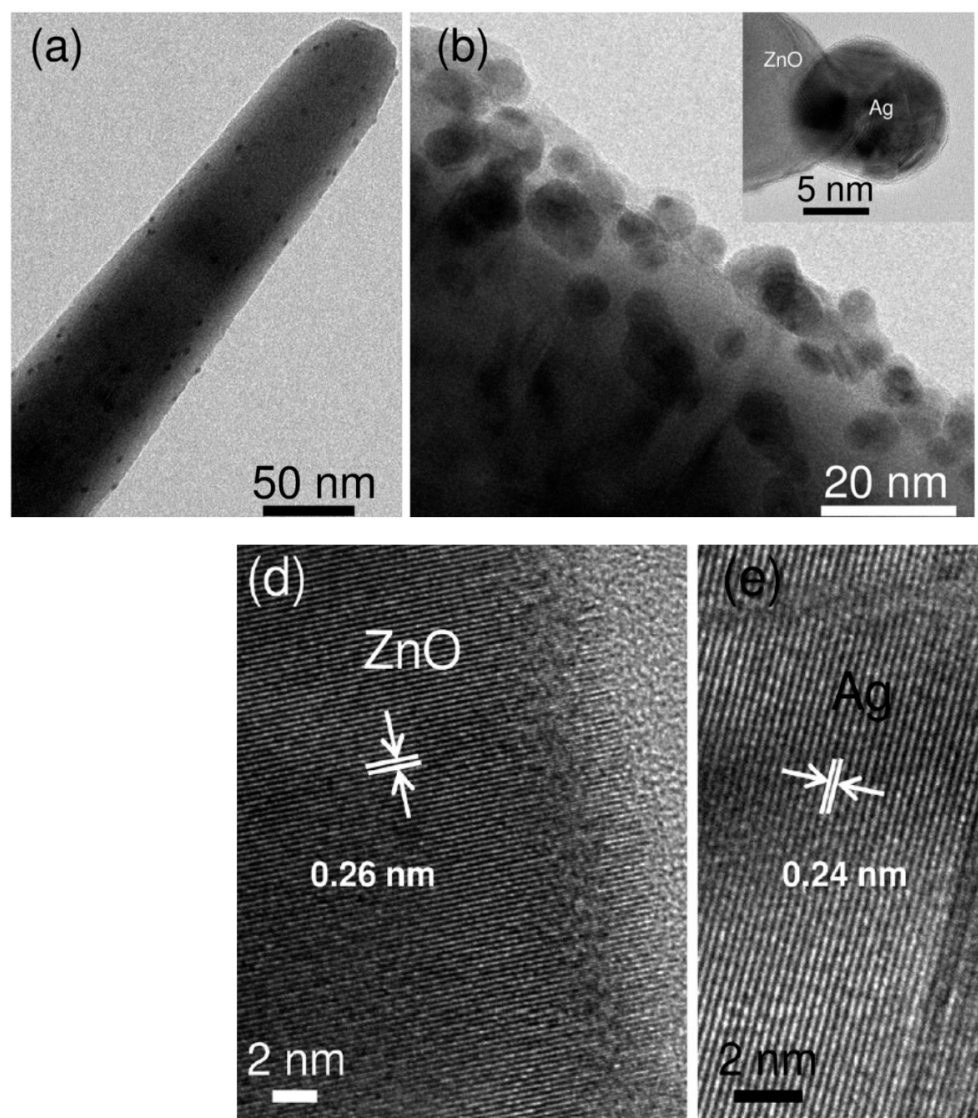

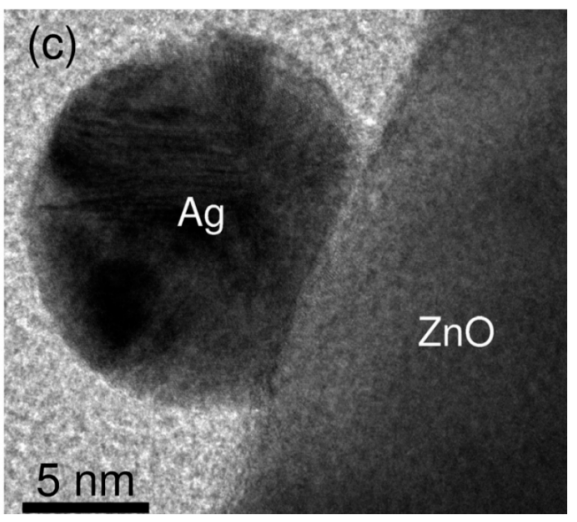

Zn
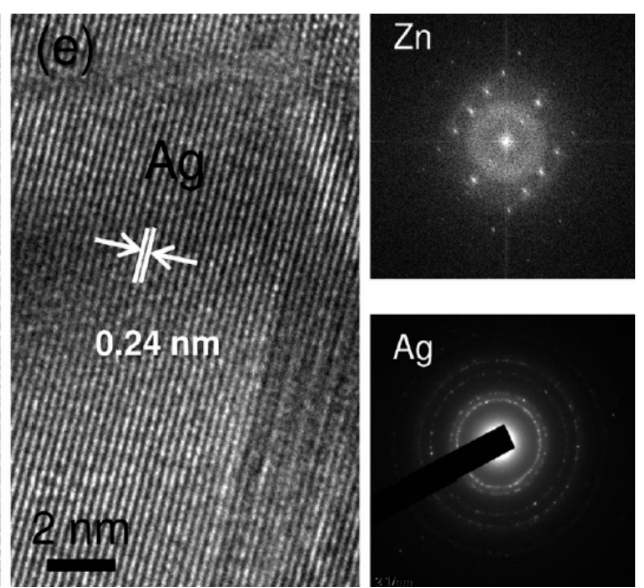

Figure 20. TEM images of (a) a single $\mathrm{ZnO}$ nanorod with uniformly dispersed AgNPs. (b) Side view of AgNPs/ZnO nanorod and immobilized AgNP at the tip of ZnO (inset). High-resolution TEM (HRTEM) images showing (c) a clear interface between $\mathrm{AgNP}$ and $\mathrm{ZnO}$, (d) lattice fringes with characteristic $\mathrm{d}$-spacing of $\mathrm{ZnO}$, and (e) lattice fringes of AgNP. The corresponding electron diffraction patterns of $\mathrm{ZnO}$ (above panel) and AgNP (below panel) are also presented. Reproduced from [235] under a Creative Commons Attribution 3.0 Unported License.

The formation of GO/ZnO nanocomposites is now considered. GO prepared by a modified Hummers process is thoroughly mixed with the solution of zinc salt and alkali hydroxide using 
either water or organic solvent [240]. The resulting solution is then treated hydrothermally [173,241], or solvothermally [242-245]. The oxygenated groups of GO are largely removed from graphene sheet during heating, leading to the formation of RGO [172,240,241,244]. In a certain case, ZnO NPs synthesized from co-precipitation is added directly to the GO solution [246]. Wang et al. synthesized $\mathrm{GO} / \mathrm{ZnO}$ nanocomposites solvothermally by dissolving zinc acetate in alcohol followed by adding $\mathrm{LiOH}$ and GO (Figure 21). The obtained precipitate was centrifuged, washed and dried at $60^{\circ} \mathrm{C}$ for 12 $h$ in a vacuum oven. The GO/ZnO nanocomposites with a respective mass ratio of 1:3 and 1:2 were synthesized accordingly [242]. The interaction between the $\mathrm{Zn}^{2+}$ and negatively charged oxygenated groups of GO leads to the formation of finely dispersed ZnO NPs on the graphene sheet having a lateral dimension of micrometer scale (Figure 21a). High-resolution transmission electron micrograph (HRTEM) displays the lattice fringes of $\mathrm{ZnO}$ particle with a diameter of $\sim 4 \mathrm{~nm}$ having a fringe distance of $0.28 \mathrm{~nm}$ (Figure 21b). This corresponds to the (100) spacing of $\mathrm{ZnO}$.

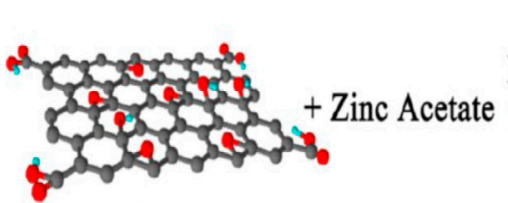

Graphene oxide

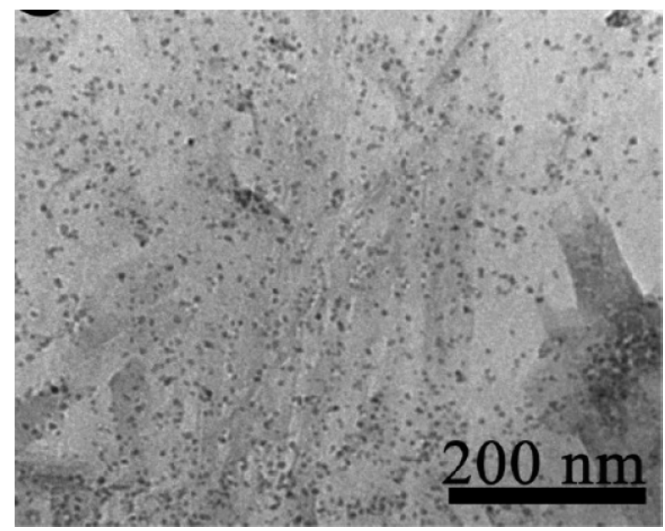

(a)
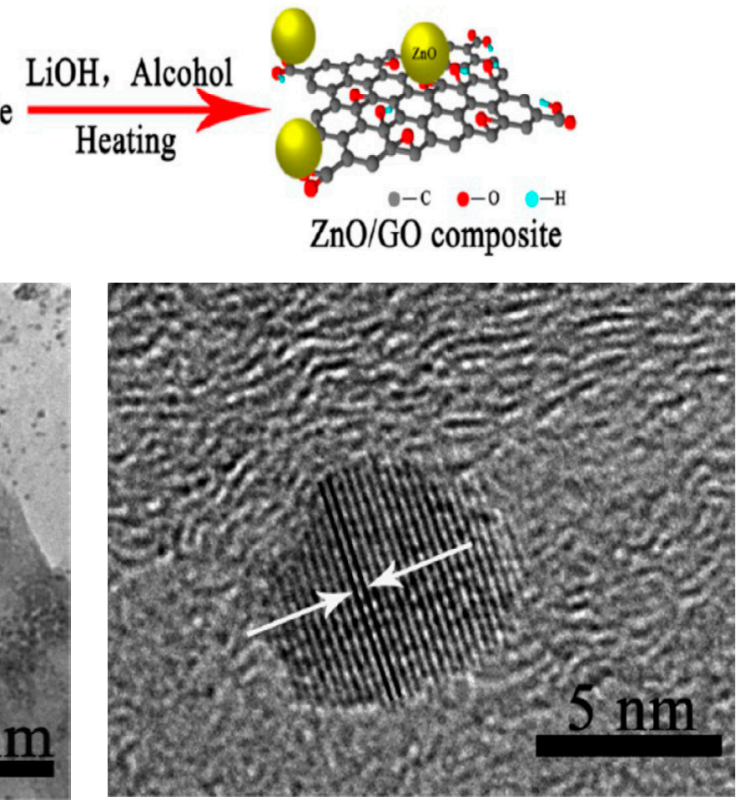

(b)

Figure 21. Formation of GO-ZnO nanocomposites using solvothermal process. (a) Transmission electron micrograph showing dispersion of $\mathrm{ZnO}$ nanoparticles on graphene sheet. (b) HRTEM image showing the lattice fringes of $\mathrm{ZnO}$ nanoparticle. Reproduced from [242] with permission of the American Chemical Society.

\subsubsection{Hydrolysis and Condensation Process}

The sol-gel process offers the advantage of simplicity for fabricating $\mathrm{ZnO}$ nanostructures of various morphologies [26,247-252]. Sol is the colloidal solution in which solid particles suspend in a liquid phase. The sol formation involves hydrolysis of metal alkoxide $\left((\mathrm{MOR})_{\mathrm{x}}\right)$ in an aqueous medium. The subsequent condensation reaction results in the formation of an M-O-M network. Conventionally, metal alkoxides are used as the precursors for sol-gel process. However, the high cost of zinc alkoxides limits their use for preparing $\mathrm{ZnO}$. So zinc salts such as zinc acetate dihydrate and zinc nitrate are used alternatively because of their ease of hydrolysis.

The sol-gel process is versatile, so nano- $\mathrm{ZnO}$ can also be prepared using a modified strategy, terming as 'Pechini process'. This strategy relies on the formation of metallic complexes deriving from the reaction of metal precursor with hydrocarboxylic acid, followed by a condensation reaction with polyalcohol, e.g., ethylene glycol (EG). Hydroxycarboxylic acid such as citric, glycolic or lactic acts as the chelating agent [248]. Polyol plays the role of the solvent and stabilizer by bridging molecules 
for metal salt precursor in forming a gel $[19,253]$. The advantages of this approach include the steric entrapment of metal cation complexes and the prevention of segregation of nano- $\mathrm{ZnO}$.

\subsubsection{Microemulsion Process}

Microemulsions are thermodynamically stable colloidal system consisting of transparent and isotropic mixtures of water, oil and surfactant. Microemulsions are typically classified into water in oil $(\mathrm{W} / \mathrm{O})$ and oil in water $(\mathrm{O} / \mathrm{W})$, which are stabilized by surfactant molecules. So small droplets (micelles) of one phase are dispersed throughout the continuous phase. The droplets are considered as nanoreactors to carry out chemical reactions for forming crystal nuclei. The steric stabilization due to surfactant molecules on the micelles prevents the nanoparticles from the agglomeration. Water-in-oil microemulsions are also known as reverse micelles. The synthesis of ZnO NPs using reverse micelles involves the mixing of two types of microemulsions, i.e., one with zinc salt precursor and another one with the precipitating agent. So the micelles undergo extensive collision and coalescence events, causing the exchange of reactants and subsequent reaction to form nuclei in micelles.

Hingorani et al. first reported the synthesis of $\mathrm{ZnO} N P s(5-40 \mathrm{~nm})$ from W/O microemulsions using zinc nitrate, ammonium carbonate (precipitating agent), CTAB (surfactant), 1-butanol (co-surfactant), and n-octane (oil phase). The first micelle solution comprised of zinc nitrate, n-octane and $\mathrm{CTAB} / 1$-butanol. The second micelle solution comprised of ammonium carbonate, n-octane and $\mathrm{CTAB} / 1$-butanol. After mixing the two micelle solutions, continuous collision and coalescence led to the precipitation of zinc carbonate and its subsequent transformation to ZnO NPs upon heating [254]. Since then, the synthesis of ZnO NPs using W/O emulsions had been carried out by the researchers using different organic compounds, surfactants and zinc salt precursors $[255,256]$. The drawbacks of microemulsion-based synthesis include the employment of a large amount of organic compound (oil phase) and the use of surfactant/cosurfactant for stabilizing the droplets.

\subsection{Solid State Route}

\section{Mechanochemical Process}

Mechanochemical process involves the milling of precursor powders in a ball mill for reducing their sizes to the nanoscale. The raw materials break-down into smaller particles and react chemically during milling or subsequent heat treatment to form a mixture phase of nanoparticles. A diluent is usually added to the starting materials during the milling process to separate the nanoparticles and prevent their subsequent growth. This is a solid state approach for fabricating $\mathrm{ZnO}$ NPs. Various types of grinding balls, often termed as the milling media, are used for milling raw powders. These include zirconia, stainless steel, and glass balls [257]. Generally, the size and shape of ground ZnO NPs depend greatly on the milling time of starting materials, calcination temperature and time [258-260]. So a longer milling time favors the formation of fined $\mathrm{ZnO}$ NPs. The drawbacks of this approach are time consuming, and the possible contamination of ground powders by milling medium.

Manzoor et al. employed mechanochemical method to fabricate $\mathrm{ZnO}$ NPs using anhydrous $\mathrm{ZnCl}_{2}$, anhydrous $\mathrm{Na}_{2} \mathrm{CO}_{3}$ and stainless steel balls in the presence of $\mathrm{NaCl}$ acting as a diluent [258]. The milled powders were then calcined at $250-400{ }^{\circ} \mathrm{C}$ for $30 \mathrm{~min}$. Spherical $\mathrm{ZnO}$ NPs $(19.4 \mathrm{~nm})$ with a narrow size distribution were achieved by heating the milled powders at $250^{\circ} \mathrm{C}$. However, calcination at higher temperatures of $350^{\circ} \mathrm{C}$ and $400^{\circ} \mathrm{C}$ led to the formation of larger $\mathrm{ZnO}$ NPs with mean sizes of $28.9 \mathrm{~nm}$ and $30.7 \mathrm{~nm}$, respectively. The reactions during ball milling and calcination were given as follows,

$$
\begin{gathered}
\text { Milling } \mathrm{ZnCl}_{2}+\mathrm{Na}_{2} \mathrm{CO}_{3}+6 \mathrm{NaCl} \rightarrow \mathrm{ZnCO}_{3}+8 \mathrm{NaCl} \\
\text { Calcination } \mathrm{ZnCO}_{3} \rightarrow \mathrm{ZnO}+\mathrm{CO}_{2}
\end{gathered}
$$

Very recently, Arsalani et al. ball-milled $\mathrm{ZnCl}_{2}, \mathrm{KOH}$ and MWCNTs to intiate the formation of $\mathrm{ZnO}$ nuclei on the tubes followed by hydrothermal treatment at $150^{\circ} \mathrm{C}$ for $15 \mathrm{~h}$ [260]. During the 
milling process, high-energy collision resulted in the dissociation of $\mathrm{KOH}$ and $\mathrm{ZnCl}_{2}$. As such, $\mathrm{Zn}^{2+}$ ions reacted with hydroxyl ions from $\mathrm{KOH}$ through electrostatic interactions, and then deposited on MWCNTs to yield $\mathrm{ZnO}$ nuclei. Further hydrothermal treatment facilitated the growth of $\mathrm{ZnO}$ nuclei into $\mathrm{ZnO}$ NPs with an average diameter of about $50 \mathrm{~nm}$ on the nanotubes.

\section{Antibacterial Performance}

\subsection{ZnO-Bacterial Interactions}

$\mathrm{ZnO}$ NPs are well known to exhibit antibacterial activity against pathogens in the absence of photocatalytic activity. The exact bactericidal mechanism of ZnO NPs are not clearly known and still under debate. Several mechanisms have been proposed for bactericidal activities of ZnO NPs, including the direct contact with cell membrane, release of metallic ions, generation of ROS, and internalization of ZnO NPs (Figure 22a) $[14,22,27,28,261,262]$. For direct contact killing mechanism, $\mathrm{ZnO} N P s$ tend to disrupt the cell membrane function, and interfere electron transport chain upon attachment on the cell wall, leading to the the ROS production [263,264]. As recognized, $\mathrm{pH}$ at the point of zero charge (pzc) of ZnO NPs is 9.4, so producing a net positive surface charge on those nanoparticles in acidic, neutral and slightly alkaline solutions [265]. Accordingly, positively charged $\mathrm{ZnO}$ NPs can attach readily on the cell membranes of Gram-positive and Gram-negative bacteria due to the electrostatic interaction. This interaction disrupts the membrane structure and damages the cell integrity, leading to the leakage of intracellular contents [264]. In particular, ZnO NPs with very small sizes (ca $\leq 10 \mathrm{~nm}$ ) can easily penetrate into cytoplasm, inducing the DNA damage and apoptosis. Generally, Gram-positive and Gram-negative bacteria have different sensitivity towards $\mathrm{ZnO} N P s$ due to the difference in their cell wall structures. Gram-positive bacteria have thick layers of peptidoglycan (20-80 nm), which are anchored to underlying cytoplasmic membrane via lipoteichoic acid (LTA). Likewise, wall bound teichoic acid is covalently attached to peptidoglycan via murein linkage units (Figure 22b) [266]. Peptidoglycan consists of repeated disaccharide units cross-linked by short peptides. In addition, peptidoglycan is relatively porous, and does not form a permeability barrier for small substrates. Together with teichoic acid and LTA containing phosphate groups, the cell wall of Gram-positive bacteria is a highly charged anionic polymer, thus favoring electrostatic attraction of positively charged nanoparticles [267]. In this respect, there is a greater affinity of $\mathrm{ZnO}$ to Gram-positive bacteria than Gram-negatives. On the contrary, peptidoglycan of Gram-negatives is thinner $(<10 \mathrm{~nm})$, and surrounded by an outer membrane containing lipopolysaccharides (LPS) (Figure 22c). LPS is a complex macromolecule, being impermeable to hydrophobic antibiotics. So outer membrane blocks the entry of numerous toxic compounds and prevents hydrophobic antibiotics from entering the organisms [268,269]. Therefore, Gram-negative bacteria with a thinner peptidoglycan layer and an outer membrane are more resistant to ZnO NPs than Gram-positives.

Joe et al. demonstrated that the antibacterial activity of $\mathrm{ZnO} N P$ s derives from an initial attachment of $\mathrm{ZnO} N P s$ on the bacterial cell walls, followed by release of $\mathrm{Zn}^{2+}$ ions and their subsequent penetration into the cytoplasm [22]. Once inside cytoplasm, $\mathrm{Zn}^{2+}$ ions interact with cellular organelles, thereby inhibiting the function of enzymes, deactivating proteins and DNA, and inducing oxidative stress [55]. Enzyme inhibition by zinc ions leads to an eventual cell death since enzymes are needed for performing essential metabolic pathways. Furthermore, $\mathrm{Zn}^{2+}$ ions also interact strongly with the protein-binding sites such as the sulfhydryl group of cysteine, thus inactivating the protein by forming $\mathrm{Zn}^{2+}$-cysteine complex [270]. $\mathrm{Zn}$ ion complex can also be formed by $\mathrm{Zn}^{2+}$ substitution into hydrogen bonds of deoxyribonucleic acid (DNA) base pairs, leading to the DNA damage and cell apoptosis [271]. Meanwhile, very fine $\mathrm{ZnO} N P s$ ( $c a \leq 10 \mathrm{~nm}$ ) can reach cytoplasm through the membrane disruption, resulting in enzyme inhibition as revealed by a marked suppression of the activity of $\beta$-galactosidase, a fundamental enzyme in bacterial metabolism [272]. 


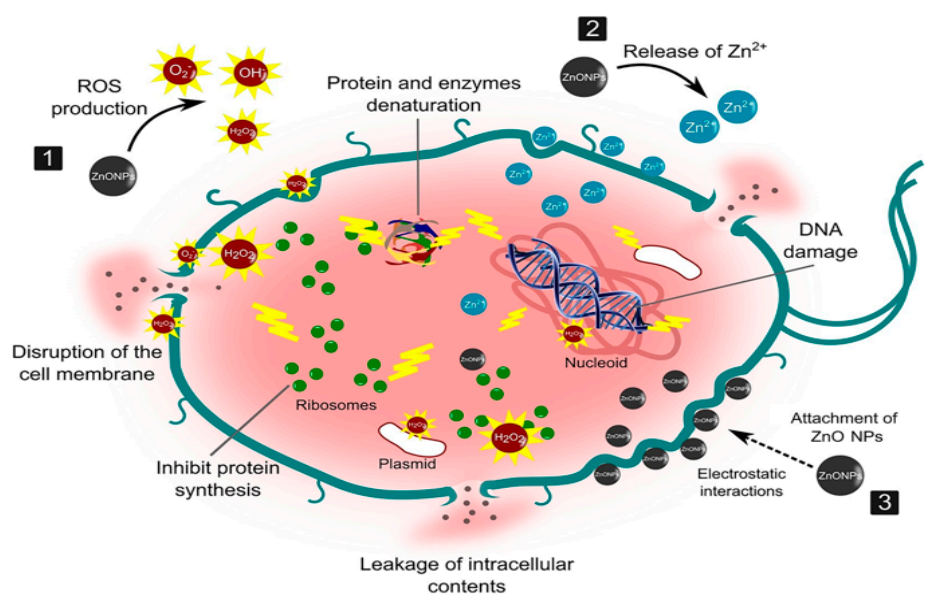

(a)

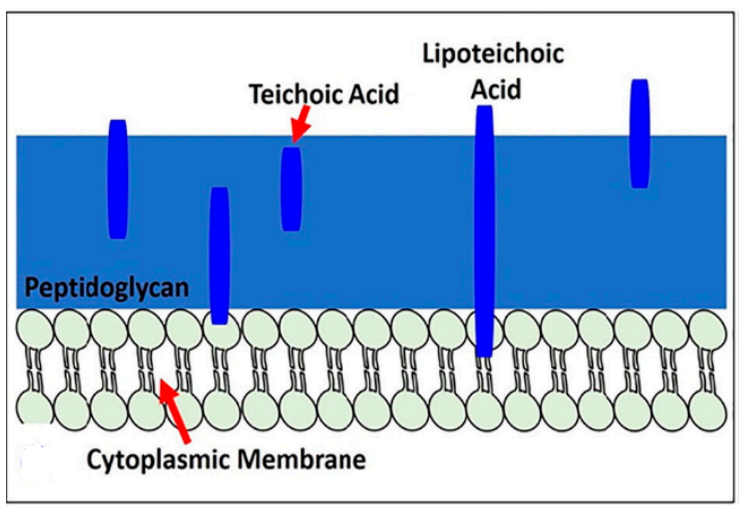

(b)

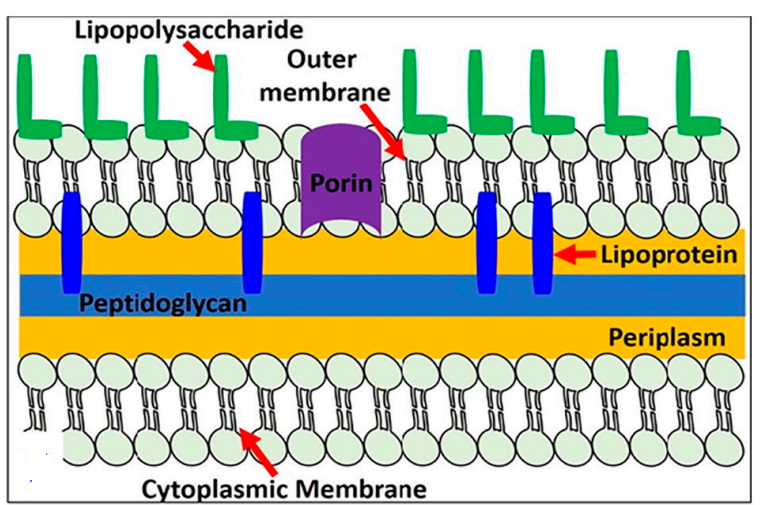

(c)

Figure 22. (a) Three possible mechanisms responsible for bactericidal activity of ZnO NPs: (1) The generation of reactive oxygen species (ROS), (2) release of $\mathrm{Zn}^{2+}$ ions, and (3) direct attachment on bacterial cell membrane. Reproduced from [261] under the terms of the Creative Commons Attribution 4.0 International License. Schematics showing the cell wall structures of (b) Gram-positive and (c) Gram-negative bacteria. Reproduced from [266] under the terms of the Creative Commons Attribution License.

The third possible mechanism for bactericidal activity of ZnO NPs is the ROS generation. Those reactive radicals interact with unsaturated fatty acids of phospholipid bilayer, leading to lipid peroxidation (LPO) that causes the loss of cellular functions [273]. As such, ROS induce oxidative stress and inactivate cellular surface proteins, resulting in a loss of membrane integrity and final cell death [274-276]. Thus ZnO NPs can induce ROS for killing bacteria even in the dark condition [262,277].

Very recently, Singh et al. employed commercially available ZnO NPs for killing Deinococcus radiodurans with extraordinary radiation resistance [276]. TEM was employed to observe the internalization of $\mathrm{ZnO}$ NPs as shown in Figure 23. The antibacterial activity of ZnO NPs in vitro was determined from different bioassays, including conventional colony count method, 3-(4,5-dimethylthiazol-2-yl)-2,5-diphenyltetrazolium bromide (MTT) assay, and propidium iodide (PI) uptake assay. Colony forming units (CFU) were quantified in terms of the percentage of viable cells. PI staining protocol was employed for detection of bacterial cell death through the assessment of plasma membrane integrity using PI dye. Viable cells with intact membranes excluded PI, while the cells with a loss of membrane integrity facilitated uptake of PI. Colony count method indicated that ZnO NPs greatly reduced the viability of bacterial cells under a dose-dependent manner. At a dose of $80 \mu \mathrm{g} / \mathrm{mL}$ $\mathrm{ZnO} N P s$, the viability reduced to $\sim 25 \%$ (Figure $24 \mathrm{a}$ ). A similar reduction trend in bacterial cell viability with increasing ZnO NPs concentrations was observed in the MTT assay (Figure 24b). Meanwhile, PI 
uptake assay showed an increase of PI uptake with increasing $\mathrm{ZnO}$ concentrations (Figure 24c). Thus $\mathrm{ZnO}$ NPs induced membrane damage by penetrating into cytoplasm, thereby facilitating the entry of PI dye inside the cells. The interaction of ZnO NPs with bacterial cell facilitates the ROS production in a concentration dependent manner (Figure 24d).
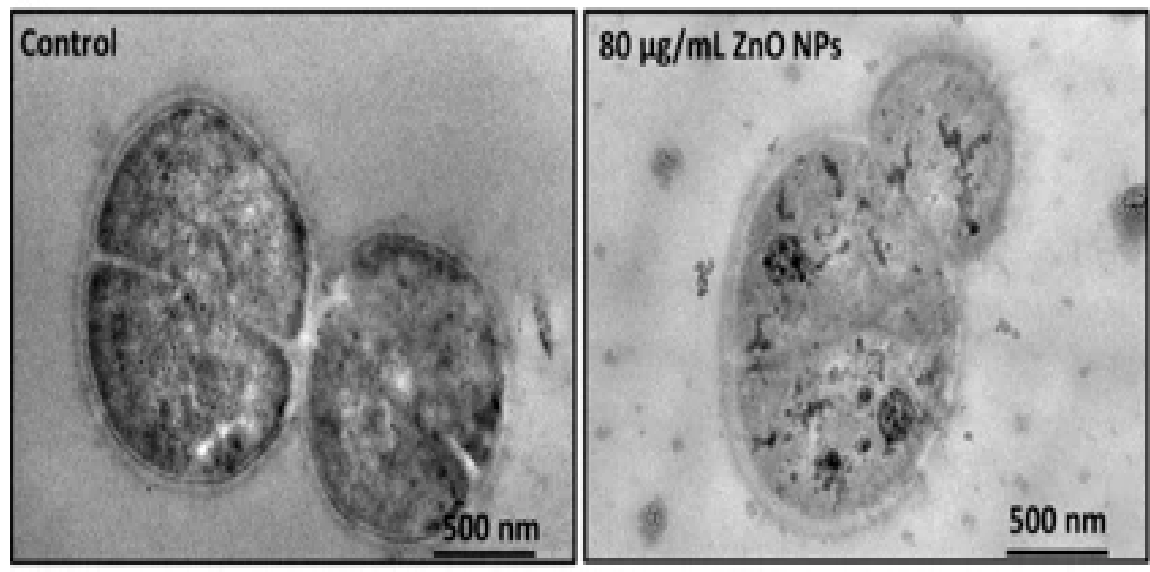

Figure 23. TEM images showing bare D. radiodurans cells (left panel), and internalization of $\mathrm{ZnO}$ NPs into bacterial cells (right panel). Reproduced from [276] under a Creative Commons Attribution 4.0 License.
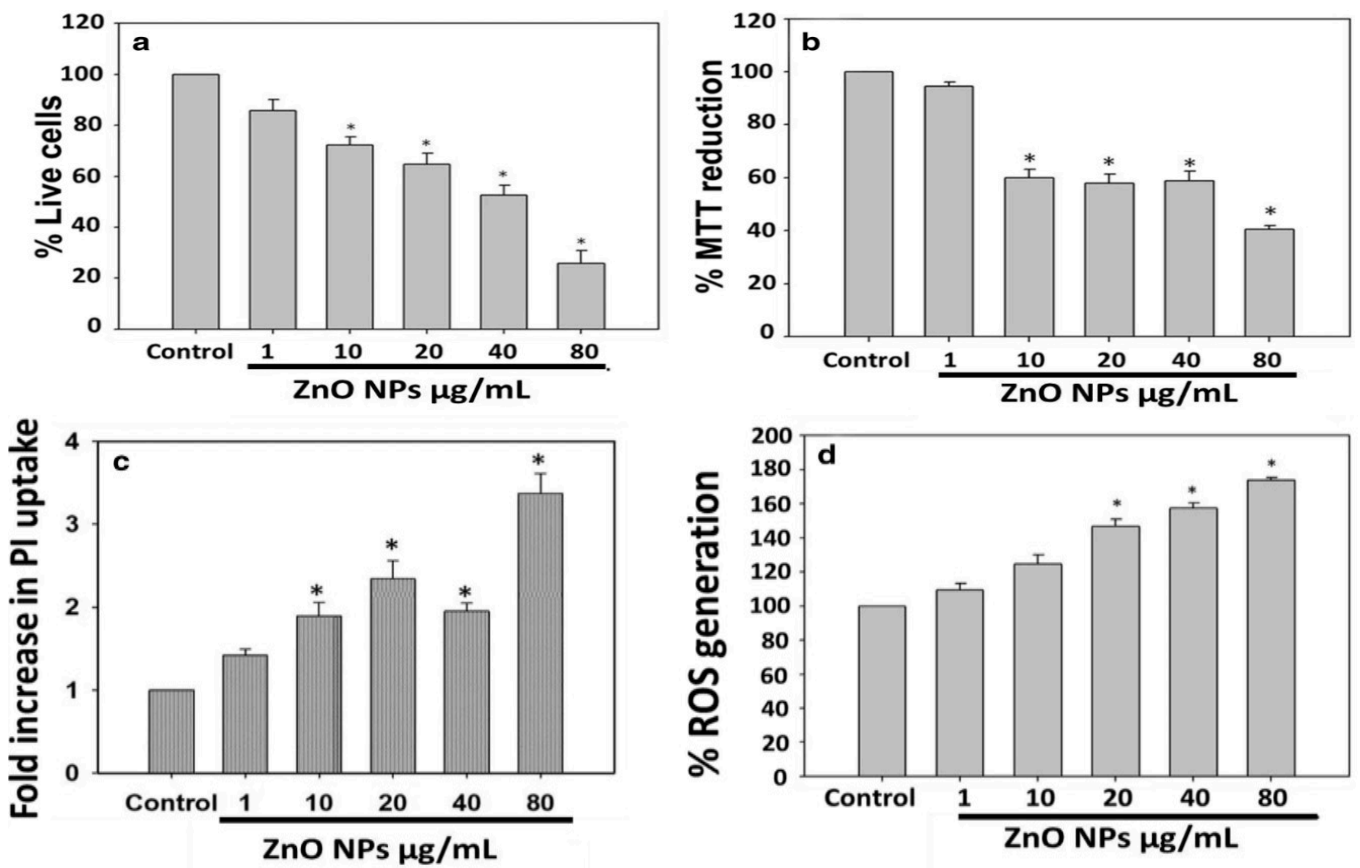

Figure 24. Reduction in viability of $D$. radiodurans upon exposure to $\mathrm{ZnO} N \mathrm{Ns}$ for $3 \mathrm{~h}$ as determined by: (a) Colony count method, (b) 3-(4,5-dimethylthiazol-2-yl)-2,5-diphenyltetrazolium bromide (MTT) assay, (c) propidium iodide (PI) uptake assay, and (d) ROS assay. The error bars are the standard deviation $(n=3) ;{ }^{*}$ denotes $p<0.05$. Reproduced from [276] under a Creative Commons Attribution 4.0 International License.

\subsubsection{Particle Size- and Dose-Dependence}

The antimicrobial activity of ZnO NPs depends greatly on their sizes and concentrations. The smaller the nanoparticle size, the higher the activity is. Gram-positive S. aureus and Gram-negative Escherichia coli (E. coli) are typically selected as model bacteria strains for assessing antibacterial activity of ZnO NPs [261,271,275-279]. As previously mentioned, very fine ZnO NPs interact strongly with 
bacterial membrane, thus disrupting the cell wall function and producing high ROS level. In particular, small ZnO NPs with a large surface area attach on the cell walls, so releasing more $\mathrm{Zn}^{2+}$ ions and inducing higher ROS levels than large nanoparticles. Moreover, very fine nanoparticles can easily penetrate cell membranes into cytoplasm than larger particles. Raghupathi et al. reported that the antimicrobial activity of ZnO NPs (12-212 nm) against $S$. aureus is inversely proportional to their size. $\mathrm{ZnO}$ NPs with a size of $12 \mathrm{~nm}$ exhibited the highest bactericidal activity than those with sizes of $142 \mathrm{~nm}$ and $212 \mathrm{~nm}$. The improved bactericidal effect resulted from the accumulation of very fine $\mathrm{ZnO}$ NPs on the outer cell membrane or in the cytoplasm, and the corresponding ROS generation [280]. Similarly, Mahamuni et al. also demonstrated that antibacterial and antibiofilm activities are inversely proportional to the size of ZnO NPs ( 15-23 nm). ZnO NPs with the smallest size of $\sim 15 \mathrm{~nm}$ exhibited excellent antibacterial and antibiofilm activities against Gram-positive S. aureus and Gram-negative Proteus vulgaris [255].

Leung et al. examined antimicrobial activity of commercial ZnO NPs with a mean size of $20 \mathrm{~nm}$ against E. coli using SEM imaging method [278]. Figure 25a shows that ZnO NPs interact with E. coli in a dose-dependent manner. At a low particle dose of $0.01 \mathrm{mg} / \mathrm{mL}$, few ZnO NPs attach on the surface of E. coli as expected. By increasing nanoparticle dose to $1 \mathrm{mg} / \mathrm{mL}$, many ZnO NPs adhere on E. coli due to electrostatic interactions, leading to the cell membrane damage in the form of holes as indicated by red arrows. The particle concentrations employed for SEM imaging are relatively high to facilitate the observation of ZnO-bacteria interactions. Recently, Arakha et al. demonstrated that direct contact of $\mathrm{ZnO} N P s$ with $E$. coli can result in the membrane blebbings, membrane damage, and membrane clumping leading to final cell death (Figure 25b) [275]. Dwivedi et al. investigated the effect of $\mathrm{ZnO}$ NPs $(10 \mathrm{~nm}$ ) concentrations on the ROS generation in P. aeruginosa (Figure 25c) [29]. Apparently, the ROS level increases with increasing ZnO NPs doses as expected. The dose-dependent effect of $\mathrm{ZnO}$ NPs on the ROS generation in D. radiodurans has been shown previously in Figure 24d.

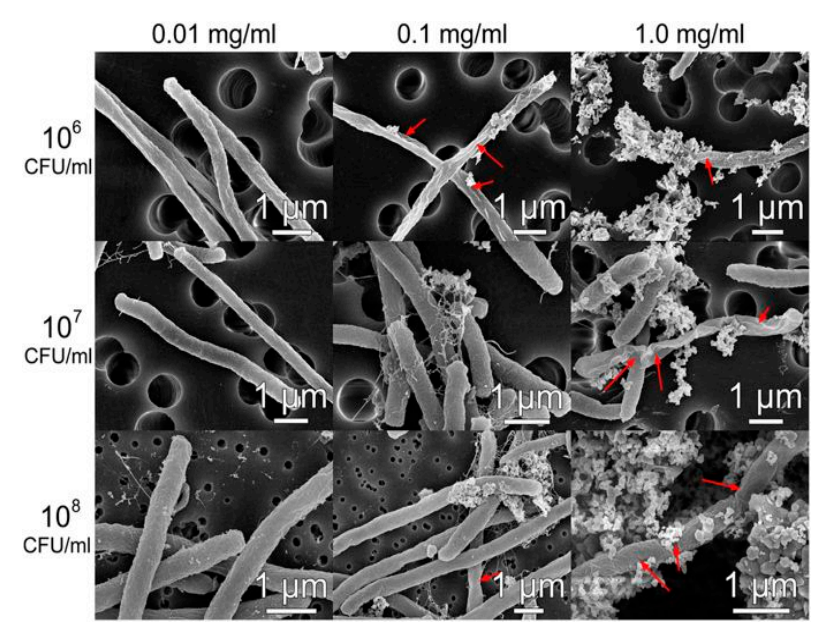

(a)
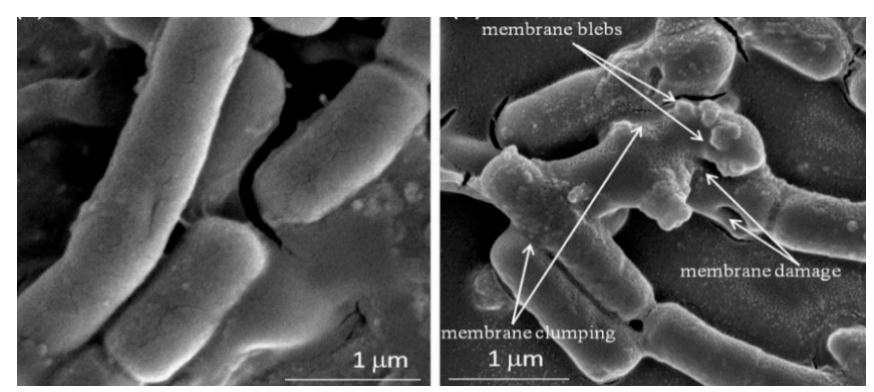

(b)

Figure 25. Cont. 


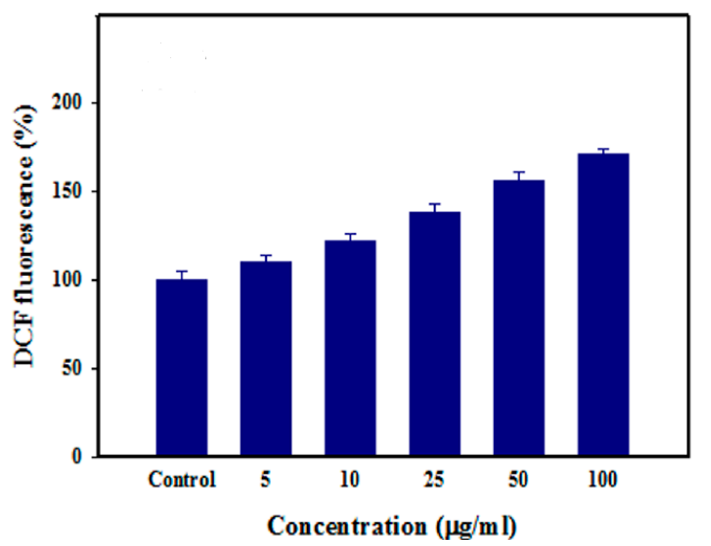

(c)

Figure 25. (a) SEM images of E. coli with concentrations of $10^{6}, 10^{7}$ and $10^{8} \mathrm{CFU} / \mathrm{mL}$ upon exposure to $\mathrm{ZnO}$ nanoparticles of different doses $(0.01,0.1$ and $1.0 \mathrm{mg} / \mathrm{mL})$. Reproduced from [278] under a Creative Commons Attribution 4.0 International License. (b) SEM images of untreated E. coli cells (left panel) and ZnO NPs treated E. coli cells (right panel). Direct contact of ZnO NPs on bacterial membranes due to electrostatic interactions leads to membrane blebling, membrane damage, and membrane clumping as indicated by white arrows. Reproduced from [275] under a Creative Commons Attribution 4.0 International License. (c) Fluorescent 2,7-dichlorofluorescein (DCF) data showing the ROS level in Pseudomonas aeruginosa treated with ZnO NPs $(5,10,25,50$ and $100 \mathrm{mg} / \mathrm{mL})$ for $24 \mathrm{~h}$. Reproduced from [29] under a Creative Commons Attribution License.

\subsubsection{Minimal Inhibitory Concentration}

The antimicrobial activities of $\mathrm{ZnO}$ nanostructures against various bacterial strains can be assessed by means of broth dilution and Kirby-Bauer disk diffusion techniques. The results are expressed in terms of minimum inhibitory concentration (MIC) and inhibition zone, respectively. More recently, da Silva et al. employed the sol-gel process using ethanolic zinc acetate solution and $\mathrm{LiOH}$ to synthesize $\mathrm{ZnO}$ NPs $(5.3 \mathrm{~nm}) ; \mathrm{ZnO} N P s$ were further heat treated at $600{ }^{\circ} \mathrm{C}$ to yield nanoparticles with sizes of $33.9 \mathrm{~nm}$ [26]. MIC values of the as-synthesized $\mathrm{ZnO}$ NPs and heat treated $\mathrm{ZnO}$ NPs against S. aureus were 78.2 and $208.2 \mu \mathrm{g} / \mathrm{mL}$, while MIC values of the same samples against $E$. coli were 312.5 and $1250 \mu \mathrm{g} / \mathrm{mL}$, respectively. Apparently, the as-synthesized ZnO NPs with a smaller size exhibited better bactericidal activity against both bacterial strains.

Generally, flavonoids and polyphenols extracted from natural plants are involved in the antibacterial activity of green $\mathrm{ZnO}$ nanostructures against various bacterial strains. Chen and coworkers synthesized $\mathrm{ZnO} N$ ss with a mean size of $\sim 18 \mathrm{~nm}$ by reducing $\mathrm{Zn}\left(\mathrm{NO}_{3}\right)_{2} \cdot 6 \mathrm{H}_{2} \mathrm{O}$ with Geranium wallichianum leaf extract. The bactericidal activity of spherical ZnO NPs against Gram positive S. aureus, Bacillus subtilis, Gram negative E. coli, Pseudomonas aeruginosa, and Klebsiella pneumoniae was investigated [31]. ZnO NPs were found to exhibit significant antimicrobial effect against those bacterial strains, especially Gram-positive bacteria. B. subtilis was the most vulnerable strain with an MIC value of $7.8 \mu \mathrm{g} / \mathrm{mL}$, while K. pneumoniae was the least susceptible bacteria having MIC value of $125 \mu \mathrm{g} / \mathrm{mL}$. The increased antibacterial efficacy of ZnO NPs was ascribed to the bioactive functional groups attached on the surface of nanoparticles.

Elumalai and Velmurugan biosynthesized ZnO NPs (mean size: $\sim 16.66 \mathrm{~nm}$ ) from A. Indica leaf extract, and investigated their antimicrobial activity against Gram-positive S. aureus, B. subtilis, Gram-negative E. coli, P. aeruginosa, and Proteus mirabilis [30]. Spherical ZnO NPs showed excellent antibacterial activity against those bacterial strains. Gram-positive bacteria, especially S. aureus is more sensitive to $\mathrm{ZnO}$ NPs. This can be ascribed to its cell wall structure containing porous and multilayered peptidoglycan as mentioned previously. The average values of zone of inhibition against S. aureus exposed to $\mathrm{ZnO}$ NPs with doses of $50 \mu \mathrm{g} / \mathrm{mL}$ and $200 \mu \mathrm{g} / \mathrm{mL}$, are $14.4 \pm 0.76 \mathrm{~mm}$ and $23 \pm 0.50 \mathrm{~mm}$, respectively. In contrast, the mean zones of inhibition against $E$. coli treated with $\mathrm{ZnO}$ 
NPs concentrations of $50 \mu \mathrm{g} / \mathrm{mL}$ and $200 \mu \mathrm{g} / \mathrm{mL}$, are $12.6 \pm 0.76 \mathrm{~mm}$ and $19.0 \pm 0.50 \mathrm{~mm}$, respectively. Moreover, MIC value of ZnO NPs against S. aureus and B. subtilis is $6.25 \mu \mathrm{g} / \mathrm{mL}$, while a higher MIC value of $25 \mu \mathrm{g} / \mathrm{mL}$ is needed for killing Gram-negative E. coli and P. aeruginosa. So the inactivation of Gram-negative bacteria requires a higher concentration of $\mathrm{ZnO} N P s$.

Abbasi et al. synthesized $\mathrm{ZnO}$ nanostructures from the callus extract of Silybum marianum (L.) Gaern. The as-synthesized $\mathrm{ZnO}$ exhibited a flower-like feature with a size of $44 \mathrm{~nm}$, having MIC values of 33.33 and $\geq 100 \mu \mathrm{g} / \mathrm{mL}$ against S. aureus and P. aeruginosa, respectively [281]. Paduraru et al. prepared spherical $\mathrm{ZnO}$ NPs and flower-like $\mathrm{ZnO}$ using polyol process and microwave-assisted hydrothermal method. In polyol synthesis, zinc acetate was dissolved in ethylene glycol by refluxing at $160^{\circ} \mathrm{C}$ to form a $1 \mathrm{M}$ solution. The mixture was refluxed for further $12 \mathrm{~h}$ at $160^{\circ} \mathrm{C}$, followed by centrifuging and drying in an oven to obtain spherical ZnO NPs with sizes of $14.63 \pm 0.47 \mathrm{~nm}$. The latter method involved microwave-assisted hydrothermal treatment of an aqueous solution of $\mathrm{ZnSO}_{4}$ and ammonia water at $120^{\circ} \mathrm{C}$ for $10 \mathrm{~min}$ [27]. ZnO-nanoflowers were formed by sefl-assembly of $\mathrm{ZnO}$ nanorods (length: $10^{3} \mathrm{~nm}$ ). The MIC values of ZnO-nanoflower against E.coli and candida albicans (fungus that causes human gut and skin diseases) were determined to be 1250 and $1250 \mu \mathrm{g} / \mathrm{mL}$, respectively. However, MIC values against E.coli and candida albicans were largely reduced to 625 and $312 \mu \mathrm{g} / \mathrm{mL}$ respectively by treating with fined ZnO NPs $(14.63 \mathrm{~nm})$ prepared by polyol process. Their results were tabulated in Table 1.

Very recently, Liu et al. employed microwave-assisted solvothermal method to synthesize ZnO tapered rods with an average length of $1 \mu \mathrm{m}$ using zinc acetate and ethylene glycol in the presence of CTAB. In addition, they also synthesized $7.7 \mathrm{~mol} \% \mathrm{AgNPs} / \mathrm{ZnO}$ nanocomposite by dispersing $\mathrm{ZnO}$ tapered rods in an aqueous solution of $\mathrm{AgNO}_{3}$ and few drops of $\mathrm{NaOH}$ at $80^{\circ} \mathrm{C}$. The bactericidal efficacy of $\mathrm{ZnO}$ rods and $\mathrm{AgNPs} / \mathrm{ZnO}$ nanocomposite against several bacterial strains was assessed accordingly [115]. In fact, AgNPs/ZnO nanocomposite exhibited a higher bactericidal activity than $\mathrm{ZnO}$ rods due to the presence of released silver ions from AgNPs and ROS generated from $\mathrm{ZnO}$. As a result, AgNPs/ZnO nanocomposite had lower MIC values than $\mathrm{ZnO}$ rods as listed in Table 1.

Abinaya et al. prepared $5 \% \mathrm{Cu} / \mathrm{ZnO}$ prismatic nanoparticles (nanoplates) using zinc acetate, copper acetate monohydrate and $\mathrm{NaOH}$ at $160{ }^{\circ} \mathrm{C}$ for $5 \mathrm{~h}$ by means of hydrothermal synthesis. They also hydrothermally synthesized $5 \% \mathrm{AgNPs} / \mathrm{ZnO}$ using zinc acetate, silver nitrate and $\mathrm{NaOH}$ at $160{ }^{\circ} \mathrm{C}$ for $5 \mathrm{~h}$ [28]. In their study, $5 \% \mathrm{AgNPs} / \mathrm{ZnO}$ and $5 \% \mathrm{Cu} / \mathrm{ZnO}$ hybrids exhibited much lower MIC values than pure $\mathrm{ZnO}$ against $S$. aureus and $E$. coli (Table 1). The $5 \% \mathrm{AgNPs} / \mathrm{ZnO}$ and $5 \% \mathrm{Cu} / \mathrm{ZnO}$ hybrids would release silver and copper ions respectively for bactericidal activity. In particular, $\mathrm{Ag}^{+}$ions from $5 \% \mathrm{AgNPs} / \mathrm{ZnO}$ hybrid were very effective for killing $E$. coli and S. aureus as evidenced by low MIC values of 38 and $40 \mu \mathrm{g} / \mathrm{mL}$, respectively. 
Table 1. Minimal inhibitory concentration (MIC) of $\mathrm{ZnO}$ nanostructures prepared by different processes.

\begin{tabular}{|c|c|c|c|c|c|c|}
\hline Material & Size (nm) & Shape & Synthesis Process & Bacterial Strains & $\mathrm{MIC}, \mu \mathrm{g} / \mathrm{mL}$ & Reference \\
\hline $\mathrm{ZnO}$ & $\sim 16.66$ & Spherical & Green & $\begin{array}{l}\text { Escherichia coli } \\
\text { Pseudomonas aeruginosa } \\
\text { Staphylococcus aureus } \\
\text { Bacillus subtilis }\end{array}$ & $\begin{array}{l}25 \\
25 \\
6.25 \\
6.25\end{array}$ & {$[30]$} \\
\hline $\mathrm{ZnO}$ & $\sim 18$ & Spherical & Green & $\begin{array}{l}\text { Escherichia coli } \\
\text { Pseudomonas aeruginosa } \\
\text { Klebsiella pneumonia } \\
\text { Staphylococcus aureus } \\
\text { Bacillus subtilis }\end{array}$ & $\begin{array}{l}15.625 \\
31.25 \\
125 \\
15.625 \\
7.8 \\
\end{array}$ & {$[31]$} \\
\hline $\mathrm{ZnO}$ & 44 & Nanoflower & Green & $\begin{array}{l}\text { Pseudomonas aeruginosa } \\
\text { Staphylococcus aureus }\end{array}$ & $\begin{array}{l}\geq 100 \\
33.33\end{array}$ & [281] \\
\hline $\mathrm{ZnO}$ & 14.63 & Spherical & Polyol & Escherichia coli & 625 & [27] \\
\hline $\mathrm{ZnO}$ & $\begin{array}{l}\sim 10^{3} \text { (length of } \\
\text { nanorods) }\end{array}$ & $\begin{array}{l}\text { Nanoflower formed by } \\
\text { self-assembly of rods }\end{array}$ & $\begin{array}{l}\text { Microwave-assited } \\
\text { hydrothermal }\end{array}$ & Escherichia coli & 1250 & [27] \\
\hline $\mathrm{ZnO}$ & 170 & Spherical & Co-precipitation & $\begin{array}{l}\text { Escherichia coli } \\
\text { Salmonella typhimurium } \\
\text { Bacillus subtilis } \\
\text { Enterococcus faecalis }\end{array}$ & $\begin{array}{l}50 \\
50 \\
100 \\
200\end{array}$ & [240] \\
\hline $\mathrm{ZnO}$ & 19 & Spherical & Sol-gel & $\begin{array}{l}\text { Escherichia coli } \\
\text { Klebsiella pneumoniae }\end{array}$ & $\begin{array}{l}500 \\
500\end{array}$ & [19] \\
\hline $\mathrm{ZnO}$ & $\begin{array}{l}\mathrm{ZnO}: 5.3 \\
\text { Heat-treated } \mathrm{ZnO}: \\
33.9\end{array}$ & $\begin{array}{l}\text { Spherical } \\
\text { Spherical }\end{array}$ & Sol-gel & $\begin{array}{l}\text { Escherichia coli } \\
\text { Staphylococcus aureus } \\
\text { Escherichia coli } \\
\text { Staphylococcus aureus }\end{array}$ & $\begin{array}{l}312.5 \\
78.2 \\
1250 \\
208.2\end{array}$ & [26] \\
\hline $\mathrm{ZnO}$ & $\begin{array}{l}\text { 100-250 (diameter); } \\
\text { 50-80 (thickness) }\end{array}$ & Prismatic nanoplates & Hydrothermal & $\begin{array}{l}\text { Escherichia coli } \\
\text { Staphylococcus aureus }\end{array}$ & $\begin{array}{l}82 \\
78\end{array}$ & [28] \\
\hline
\end{tabular}


Table 1. Cont

\begin{tabular}{|c|c|c|c|c|c|c|}
\hline Material & Size $(\mathrm{nm})$ & Shape & Synthesis Process & Bacterial Strains & $\mathrm{MIC}, \mu \mathrm{g} / \mathrm{mL}$ & Reference \\
\hline $\mathrm{ZnO}$ & $10^{3}$ (length) & Tapered rod (Spindle) & $\begin{array}{l}\text { Microwave-assited } \\
\text { solvothermal }\end{array}$ & $\begin{array}{l}\text { Escherichia coli } \\
\text { Salmonella typhimurium } \\
\text { Pseudomonas aeruginosa } \\
\text { Proteus vulgaris } \\
\text { Staphylococcus aureus } \\
\text { Bacillus subtilis }\end{array}$ & $\begin{array}{l}180 \\
160 \\
>1000 \\
>1000 \\
64 \\
60\end{array}$ & [115] \\
\hline 7.7\%AgNPs/ZnO & $\begin{array}{l}10^{3} \text { (length) of } \mathrm{ZnO} \\
\text { nanorods }\end{array}$ & $\begin{array}{l}\text { Dispersion of AgNPs on } \\
\text { ZnO nanorods }\end{array}$ & $\begin{array}{l}\text { Microwave-assited } \\
\text { solvothermal \& } \\
\text { deposition }\end{array}$ & $\begin{array}{l}\text { Escherichia coli } \\
\text { Salmonella typhimurium } \\
\text { Pseudomonas aeruginosa } \\
\text { Proteus vulgaris } \\
\text { Staphylococcus aureus } \\
\text { Bacillus subtilis }\end{array}$ & $\begin{array}{l}40 \\
60 \\
200 \\
60 \\
16 \\
20\end{array}$ & [115] \\
\hline 5\%AgNPs/ZnO & $\begin{array}{l}\text { 180-220 (diameter); } \\
70-80 \text { (thickness) }\end{array}$ & Prismatic nanoplates & Hydrothermal & $\begin{array}{l}\text { Escherichia coli } \\
\text { Staphylococcus aureus }\end{array}$ & $\begin{array}{l}38 \\
40\end{array}$ & [28] \\
\hline $5 \% \mathrm{Cu} / \mathrm{ZnO}$ & $\begin{array}{l}\text { 250-350 (diameter); } \\
60-80 \text { (thickness) }\end{array}$ & Prismatic nanoplates & Hydrothermal & $\begin{array}{l}\text { Escherichia coli } \\
\text { Staphylococcus aureus }\end{array}$ & $\begin{array}{l}72 \\
62\end{array}$ & [28] \\
\hline $\mathrm{GO} / \mathrm{ZnO}$ & ZnO: 170 & $\begin{array}{l}\text { Dispersion of } \mathrm{ZnO} \text { NPs } \\
\text { on GO sheet }\end{array}$ & Solution mixing & $\begin{array}{l}\text { Escherichia coli } \\
\text { Salmonella typhimurium } \\
\text { Bacillus subtilis } \\
\text { Enterococcus faecalis }\end{array}$ & $\begin{array}{l}6.25 \\
6.25 \\
12.5 \\
25\end{array}$ & [240] \\
\hline
\end{tabular}


Zhong and Yun reported that GO/ZnO hybrid had very low MIC values toward several bacterial strains including E. coli, Salmonella typhimurium, Enterococcus faecalis and B. subtilis. In particular, $\mathrm{GO} / \mathrm{ZnO}$ hybrid had the lowest MIC value of $6.25 \mu \mathrm{g} / \mathrm{mL}$ against both E. coli and S. typhimurium strains. In contrast, GO sheet and ZnO NPs exhibited a higher MIC value of 12.5 and $50 \mu \mathrm{g} / \mathrm{mL}$ respectively against $E$. coli and S. typhimurium. In other words, $\mathrm{GO} / \mathrm{ZnO}$ hybrid caused more damage to E. coli and S. typhimurium than GO and $\mathrm{ZnO}$ NPs alone [240]. Excellent antibacterial activity of GO/ZnO hybrid was attributed to the synergistic effects of GO and ZnO NPs. Generally, graphene sheet showed three modes of bactericidal activity, i.e., membrane lipid peroxidation, nano- knife and wrapping effects. Graphene sheets were capable of oxidizing and extracting unsaturated lipids from bacterial membranes, leading to LPO. The sharp edges of graphene sheets acted as a nano-knife to cut and damage bacterial membranes. Furthermore, graphene sheets with a lateral dimension of several micrometers served as a blanket to wrap bacteria completely, thus isolating bacterial strains from external environment and limiting their access to nutrients [13]. In this respect, finely dispersed $\mathrm{ZnO}$ NPs on GO inactivated those bacterial strains through the release of $\mathrm{Zn}^{2+}$ ions and the production of ROS [240]. As such, GO sheet caused LPO while ZnO NPs induced ROS, resulting in the GO/ZnO hybrid with superior antibacterial activity (Table 1). Table 1 also summarized the MIC values of ZnO nanostructures prepared by different processes against various bacterial strains.

\subsubsection{Zone of Inhibition}

As mentioned, Chen and coworkers treated Gram positive (S. aureus, B. subtilis), Gram negative (E. coli, P. aeruginosa, and K. pneumoniae) strains with green ZnO NPs $(\sim 18 \mathrm{~nm})$. B. subtilis was the most susceptible bacteria with an MIC value of $7.8 \mu \mathrm{g} / \mathrm{mL}$, while K. pneumoniae was the least susceptible strain having an MIC value of $125 \mu \mathrm{g} / \mathrm{mL}$ [31]. Figure 26 showed the growth inhibition zones for those bacterial strains were dependent on ZnO NPs concentrations. Gram-positive S. aureus and B. subtilis exhibited larger values of growth inhibition zones than Gram-negative bacterial strains. At ZnO NPs doses of 500 and $1000 \mu \mathrm{g} / \mathrm{mL}$, the greatest values of the growth inhibition zones were observed in $B$. subtilis, so ZnO NPs being the most efficient materials against this bacterial strain.

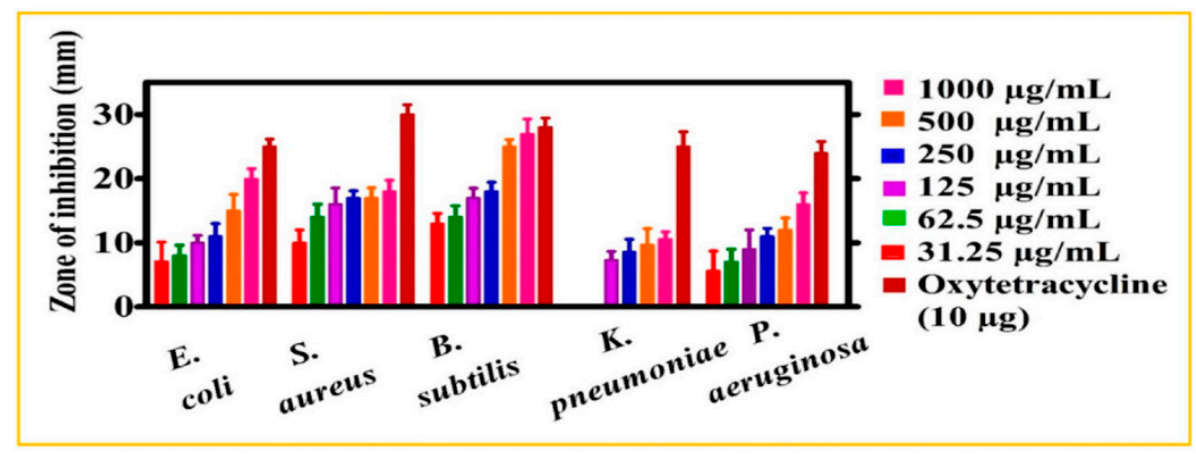

Figure 26. Growth inhibition zones for various bacterial strains exposed to green $\mathrm{ZnO}$ NPs of different concentrations. Oxytetracycline was used as a positive control. Reproduced from [31] under a Creative Commons Attribution License.

Zare et al. biosynthesized AgNPs/ZnO nanohybrid hydrothermally using Thymus vulgaris leaf extract, zinc nitrate, silver nitrate and sodium hydroxide reagents. The hydroxyl groups in flavonoids and phenols of leaf extract were effective to reduce zinc ions into ZnO NPs [282]. The antimicrobial activity of AgNPs/ZnO hybrid against E. coli and S. aureus was dose dependent (Figure 27a,b). The bacterial viability decreased with increasing nanohybrid doses, especially for $S$. aureus. At a dose of $50 \mu \mathrm{g} / \mathrm{mL}$, the viability of $S$. aureus was considerably lower than that of E. coli. The features of bacterial colonies on agar plates, and the zone of inhibition determined from the disk diffusion assay were shown in Figure 27c,d, respectively. For a given bacterial strain, the diameter of zone of inhibition (ZOI) of AgNPs/ZnO nanohybrid was larger than that of pure ZnO NPs. In this respect, doped 
$\mathrm{ZnO}$ hybrid showed a higher antimicrobial activity than undoped $\mathrm{ZnO}$. Furthermore, AgNPs/ZnO hybrid exhibited a stronger bactericidal effect against $S$. aureus compared to E. coli. The ZOI values of AgNPs/ZnO hybrid against $S$. aureus and E. coli were $18 \pm 0.24$ and $15 \pm 0.21 \mathrm{~mm}$, respectively. From the literature, susceptible organisms displayed relatively larger ZOI, while resistant bacterial strains had smaller or no ZOI upon exposure to nanomaterials [23]. Apparently, released $\mathrm{Ag}^{+}$ions from $\mathrm{AgNPs}$ and $\mathrm{Zn}^{2+}$ ions from $\mathrm{ZnO}$ of AgNPs/ZnO hybrid in the culture medium were responsible for bactericidal activity. Gram-negative E. coli was less susceptible to AgNPs/ZnO than S. aureus owing to impermeable outer membrane consisting of LPS. Very recently, Chauhan et al. prepared green AgNPs/ZnO nanoparticles $(38 \mathrm{~nm})$ using Cannabis sativa leaf extract and zinc acetate. The composite nanoparticles also exhibited excellent bactericidal activity against MRSA and S. aureus. From the agar diffusion test results, the diameters of zone of inhibition for MRSA $(16 \pm 0.404 \mathrm{~mm})$ and S. aureus $(16 \pm 0.818 \mathrm{~mm})$ were larger than those of $E$. coli $(14 \pm 0.568 \mathrm{~mm})$, P. aeruginosa $(13 \pm 0.458 \mathrm{~mm})$ and $K$. pneumoniae $(14 \pm 0.36 \mathrm{~mm})$. In another study, this same group also demonstrated that Gram-negative E. coli, P. aeruginosa and K. pneumoniae were more resistant to green $\mathrm{ZnO}$ nanoflowers $(54.1 \mathrm{~nm})$ than Gram-positive MRSA and S. aureus [283]. In the case of transition metal doped ZnO NPs, the Cr dopant also improved antibacterial activity of ZnO NPs against K. pneumoniae and P. aeruginosa on the basis of ZOI results [104].

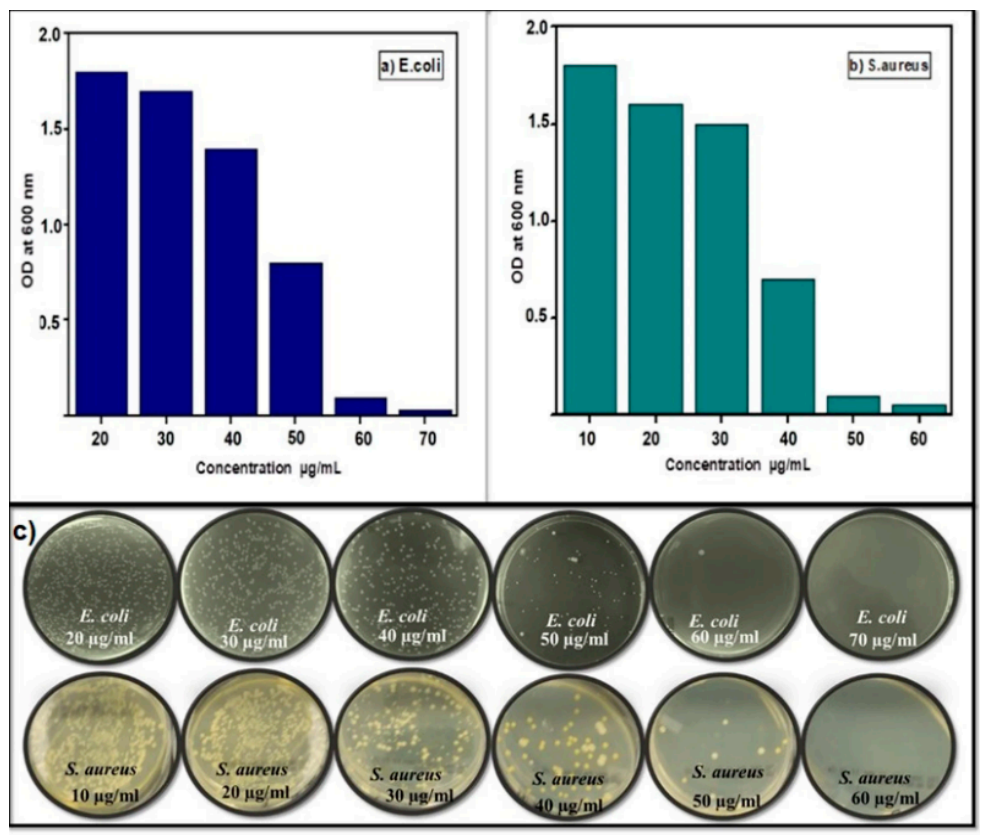

d)

\begin{tabular}{|c|ll|ll|}
\hline \multirow{2}{*}{$\begin{array}{c}\text { Sample } \\
\left(20 \mu \mathrm{g} \mathrm{ml}^{-1}\right)\end{array}$} & \multicolumn{3}{|c|}{ Zone of Inhibition (in mm) } \\
\cline { 2 - 5 } ZnO NPs & $11 \pm 0.23$ & & \multicolumn{2}{|c|}{ S. aureus } \\
\hline ZnO-Ag NC & $15 \pm 0.21$ & & $18 \pm 0.21$ & \\
\hline & & & & \\
\hline Gentamicin & $20 \pm 0.16$ & & $22 \pm 0.20$ & 0 \\
\hline
\end{tabular}

Figure 27. Effect of AgNPs/ZnO concentrations on the viability of (a) E. coli, (b) S. aureus, and (c) bacterial colony features cultured on agar plates. (d) Inhibition zone of AgNPs/ZnO nanocomposite (NC), $\mathrm{ZnO}$ NPs and Gentamicin. Gentamicin is an antibiotic specifically used for treating bacterial infections. OD in (a) denotes optical density. Reproduced from [282] under a Creative Commons Attribution 4.0 International License. 


\subsubsection{Bactericidal Efficacy}

One-dimensional $\mathrm{ZnO}$ nanorods/nanowires show potential applications as a bioimaging material, theranostic agent, antibacterial agent and biosensor in biomedical sector [284-287]. Jeong et al. hydrothermally synthesized $\mathrm{ZnO}$ nanorod arrays of different lengths ranging from 0.5 to $4 \mu \mathrm{m}$ using $\mathrm{ZnO}$ seeded silicon wafers [288]. They reported that the array with long nanorods $(4 \mu \mathrm{m})$ exhibit excellent inactivation efficiency against $E$. coli up to $94.2 \%$ in the dark for $30 \mathrm{~min}$ (Figure 28a). In contrast, short nanorods $(0.5 \mu \mathrm{m})$ exhibit lower inactivation efficiency of $63.5 \%$. The bactericidal potency of $\mathrm{ZnO}$ nanorods is attributed mainly to their mechanical piercing effect. $\mathrm{ZnO}$ nanorods attached to bacterial cell wall can pierce through the membrane completely, leading to the membrane rupture, and releasing intracellular contents; the direct contact killing is revealed by the SEM images. Meanwhile, $\mathrm{ZnO}$ nanorods also release zinc ions upon attachment on bacterial cell wall, and generate ROS for antibacterial activity. As mentioned, oxygen vacancies form easily in $\mathrm{ZnO}$ nanorods [20,21,289-291]. Those vacancies act as electron donors for the conduction band of $\mathrm{ZnO}$, thus facilitating the ROS generation [277]. The ROS level can be further increased by irradiating with UV light. As such, $\mathrm{ZnO}$ nanorods absorb UV radiation to create reactive radicals as a result of electron-hole pair generation. The bactericidal efficiency of short nanorods $(0.5 \mu \mathrm{m})$ reaches $73.1 \%$, while that of long nanorods $(4 \mu \mathrm{m})$ approaches $96.2 \%$ under UV irradiation (Figure 28a). When the nanorod arrays are coated with $\mathrm{Al}_{2} \mathrm{O}_{3}$ layer of different thicknesses, the inactivation efficiency is markedly decreased, especially for those with a thicker alumina layer. Thus alumina layer can suppress both the ROS generation and $\mathrm{Zn}^{2+}$ ion release effectively (Figure 28b). From these results, antibacterial efficacy of $\mathrm{ZnO}$ nanorod arrays in the dark condition derives mainly from the membrane rupture effect, followed by the ROS generation and released $\mathrm{Zn}^{2+}$ ions from nanorods. In other words, antibacterial activity of $\mathrm{ZnO}$ nanorod array is mainly due to the attachment of $\mathrm{ZnO}$ array to bacterial cell wall, leading to the membrane piercing effect and the release of $\mathrm{Zn}^{2+}$ ions as shown in Figure 28c.

Bhuyan et al. studied antibacterial activity of pristine $\mathrm{ZnO}$ and $\mathrm{Cu}$-doped $\mathrm{ZnO}$ nanorods (CZN) prepared by mechanochemical process against E. coli by means of shake flask method [103]. In the process, those samples were dispersed in bacterial suspensions and placed in an incubator shaker at $37^{\circ} \mathrm{C}$ for different time periods. The results are depicted in Figure 29. Apparently, Cu-doped $\mathrm{ZnO}$ nanorods exhibit higher antimicrobial activity than pristine $\mathrm{ZnO}$ nanorods against $\mathrm{S}$. aureus, Streptococcus pyogenes and E. coli. The improved bactericidal effect derives from the release of $\mathrm{Cu}^{2+}$ ions from $\mathrm{Cu}$-doped $\mathrm{ZnO}$. The killing effect of $\mathrm{Cu}$-doped $\mathrm{ZnO}$ is more effective against $\mathrm{S}$. aureus than E. coli. In addition, Gram-positive S. pyogenes appears to be more resistant to the attack of doped ZnO. S. pyogenes is a pathogen responsible for pharyngitis, impetigo, rheumatic fever, and acute glomerulonephritis [292].The cell wall structure of S. pyogenes consists of complex polysaccharides and proteins, i.e., peptidoglycan layer is overlaid with $\mathrm{M}$ protein and an outer hyaluronic acid capsule. The capsule is more resistant to the attack of ROS than peptidoglycan [293]. 


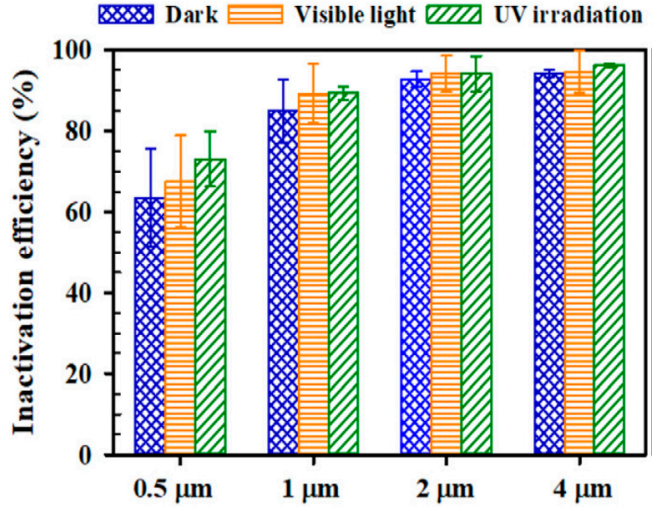

(a)

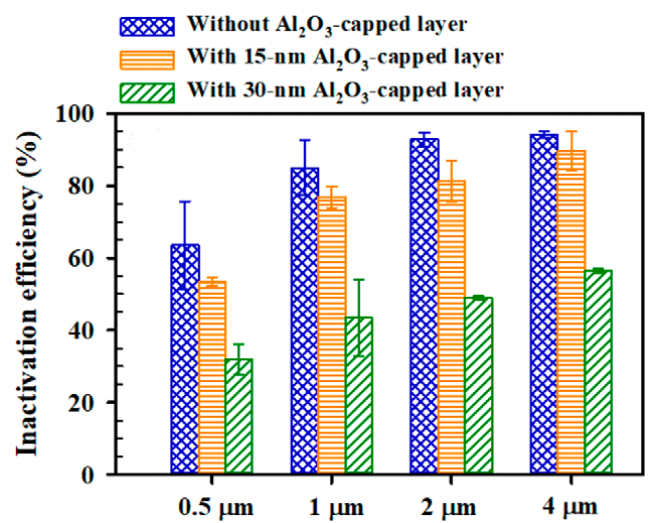

(b)

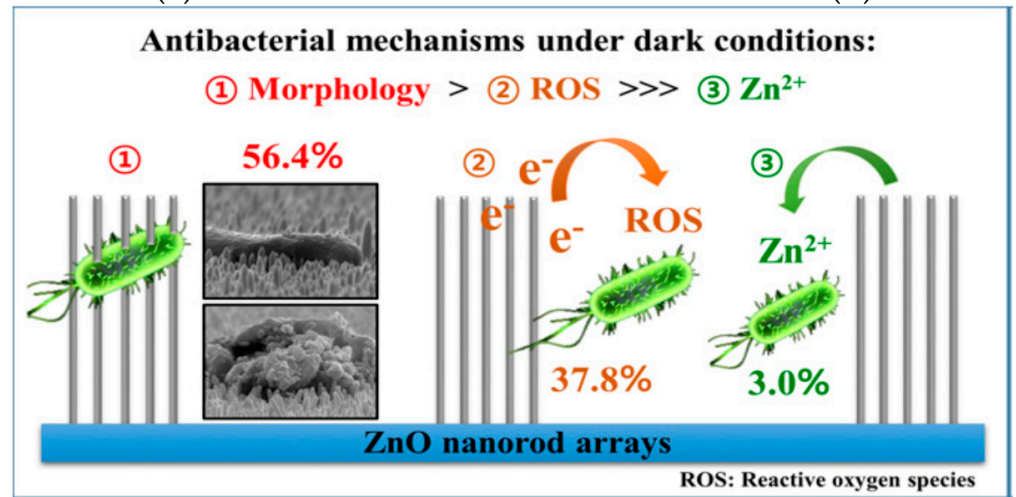

(c)

Figure 28. (a) Inactivation efficiency of $E$. coli treated with $\mathrm{ZnO}$ nanorod arrays of various lengths $(0.5-4 \mu \mathrm{m})$ for $30 \mathrm{~min}$ under different conditions (dark, visible light, and UV irradiation). (b) Inactivation efficiency of $E$. coli treated with $\mathrm{ZnO}$ nanorod arrays of various lengths with different $\mathrm{Al}_{2} \mathrm{O}_{3}$ layer thicknesses for $30 \mathrm{~min}$ in the dark. The values are the average of triplicate measurements, and error bars denote the standard deviation. (c) Bactericidal mechanisms of $\mathrm{ZnO}$ nanorod arrays in the dark: membrane rupture due to the nanorod piercing (inset: SEM images) $>$ ROS generation $>$ released $\mathrm{Zn}^{2+}$ ions. Reproduced from [288] with permission of Elsevier.

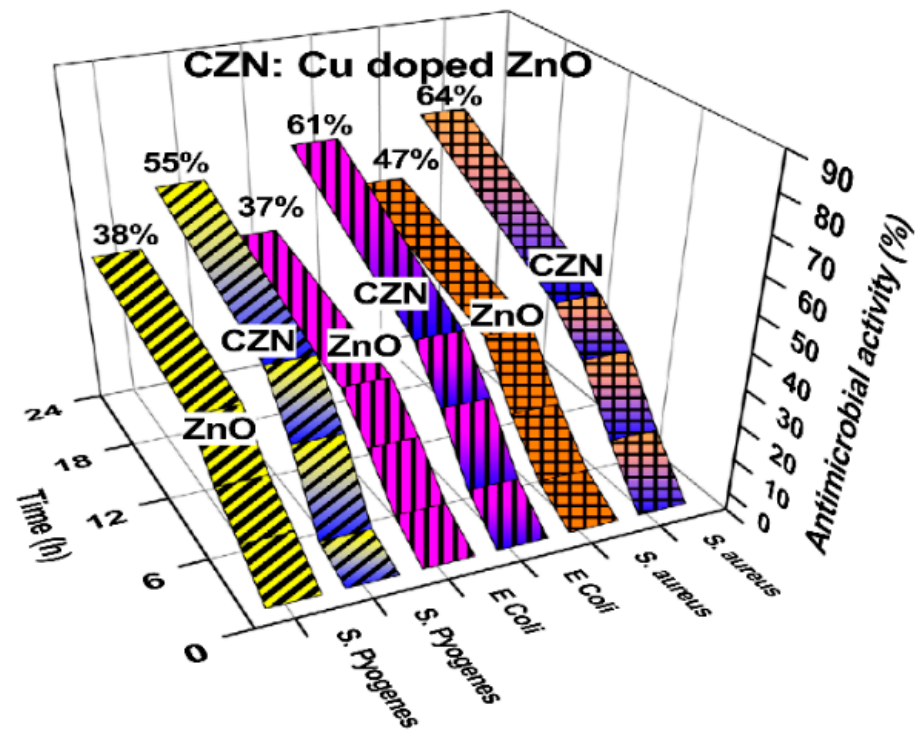

Figure 29. Antibacterial efficacy of pristine $\mathrm{ZnO}$ and $\mathrm{Cu}$-doped $\mathrm{ZnO}$ nanorods using shake flask method. Reproduced from [103] with permission of Springer. 
Agnihotri et al. studied bactericidal efficacy of AgNPs/ZnO nanorods against $E$. coli of different populations [235]. The time needed for full inactivation of E. coli at concentrations of $10^{3}$ and $10^{5}$ $\mathrm{CFU} / \mathrm{mL}$ was determined (Figure 30a). The time for complete bacterial inactivation was relatively shorter (i.e., $30 \mathrm{~min})$ by treating E. coli $\left(10^{3} \mathrm{CFU} / \mathrm{mL}\right)$ with $\mathrm{AgNPs} / \mathrm{ZnO}$ nanorods. Furthermore, $\mathrm{AgNPs} / \mathrm{ZnO}$ nanorods also exhibited better bactericidal performance when compared to pure $\mathrm{ZnO}$ nanorods, colloidal AgNPs, and AgNPs/silica samples (Figure 30b). In addition, antibacterial activity and released $\mathrm{Ag}^{+}$ions from the $\mathrm{AgNPs} / \mathrm{ZnO}$ nanorods reused for several runs were also evaluated. The full bacterial inactivation time increased with increasing reused test runs due to a decline in silver ions released from the AgNPs/ZnO nanorods (Figure 31a,b). The AgNPs were found to translocate across the cell membrane under TEM examination (Figure 31c). Internalization of AgNPs facilitated the generation of ROS, dysfunction of cell respiration, and disruption of DNA replication of E. coli. Overall, they attributed good antimicrobial efficacy of $\mathrm{AgNPs} / \mathrm{ZnO}$ nanorods to the contact killing and released $\mathrm{Ag}^{+}$ions since $\mathrm{Zn}^{2+}$ ions were not detected in treated bacterial cells.
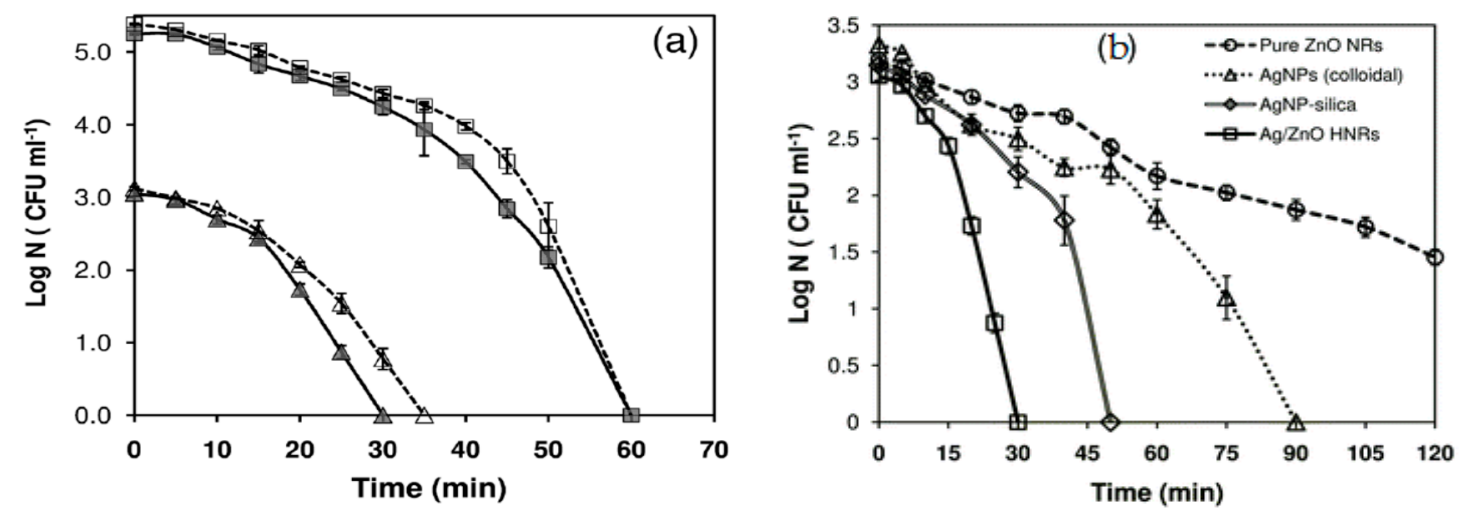

Figure 30. (a) The growth of bacterial populations as expressed by the logarithm of the number of cells $(\mathrm{N})$ versus time. The unit of $\mathrm{N}$ is given as the colony forming unit (CFU) per $\mathrm{mL}$. Bactericidal activity of AgNPs/ZnO nanorods against $E$. coli tested at an initial bacterial concentration of $10^{3} \mathrm{CFU} / \mathrm{mL}$ (triangle) and $10^{5} \mathrm{CFU} / \mathrm{mL}$ (square) in both deionized water (continuous line) and phosphate buffer medium (dashed line), respectively. (b) Bactericidal activity of AgNPs/ZnO nanorods, pure $\mathrm{ZnO}$ nanorods, colloidal AgNPs and AgNPs/silica against E. coli tested at an initial bacterial concentration of $10^{3}$ $\mathrm{CFU} / \mathrm{mL}$. Four independent tests were performed against E. coli, and the average values reported. Reproduced from [235] under a Creative Commons Attribution 3.0 Unported License.
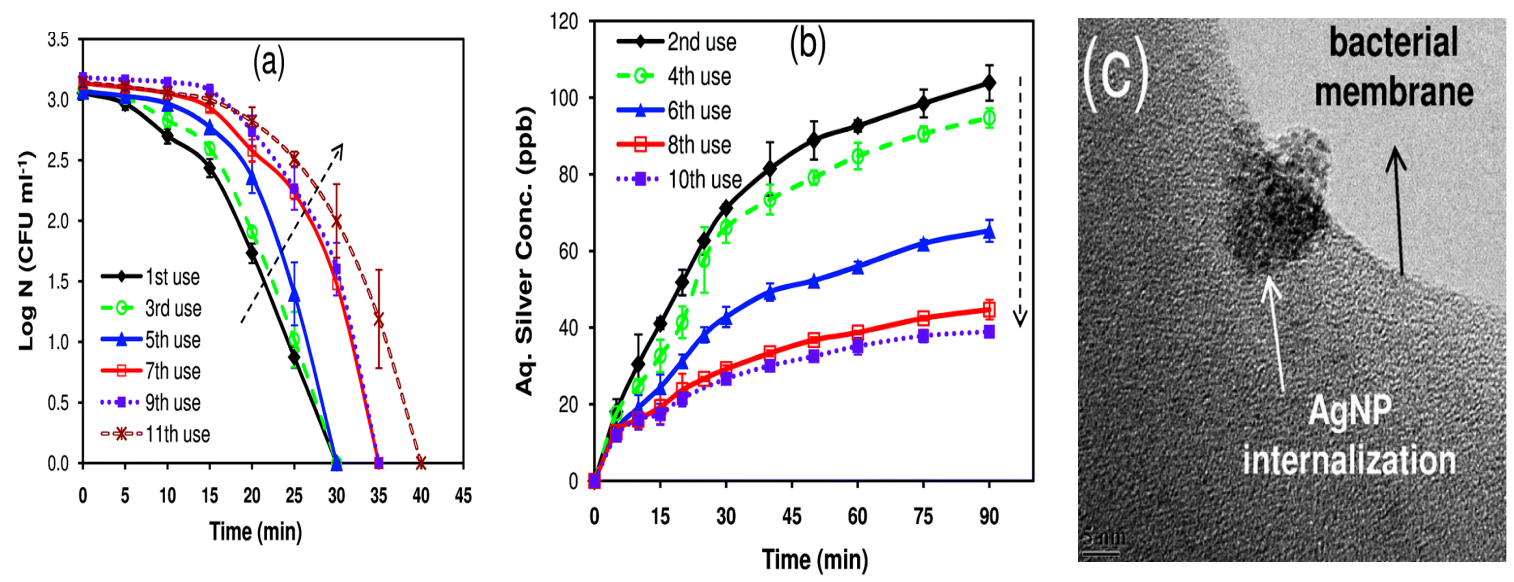

Figure 31. (a) Disinfection performance of AgNPs/ZnO nanorods after reusing for 11 runs against $E$. coli $\left(10^{3} \mathrm{CFU} / \mathrm{mL}\right)$. (b) The corresponding released silver ions vs time profiles after every usage. (c) TEM image showing internalization of AgNP by E. coli. Reproduced from [235] under a Creative Commons Attribution 3.0 Unported License. 
As mentioned, graphene oxide sheet with a lateral dimension of several micrometers serves as a template for anchoring $\mathrm{ZnO} N P s$ on its surface to form $\mathrm{GO} / \mathrm{ZnO}$ nanohybrid (Figure 23). Thus $\mathrm{ZnO}$ NPs of nanohybrid inactivate pathogens through direct contact killing effect by releasing zinc ions and generating ROS [240]. GO also contributes to bactericidal activity by inducing lipid peroxidation [13]. Moreover, GO sheet with a large lateral size can wrap bacteria completely, thereby cutting off the supply of nutrients from the growth environment $[13,294]$. Accordingly, GO/ZnO hybrid exhibits low MIC values against several bacterial strains, i.e., E. coli, S. typhimurium and B. subtilis as listed in Table 1.

In a recent study of Prema et al., ZnO NPs prepared by co-precipitation process are added to GO solution to form GO/ZnO nanohybrid [246]. Figure 32a shows the ROS level in E. coli, P. aeruginosa, $S$. tryphi, and Shigella flexneri treated with pristine GO and GO/ZnO nanohybrid. Pristine GO induces a moderate ROS level in those Gram-negative bacteria. Meanwhile, $\mathrm{ZnO}$ NPs of nanohybrid release $\mathrm{Zn}^{2+}$ ions when they come in contact with all bacterial strains. Therefore, $\mathrm{GO} / \mathrm{ZnO}$ hybrid exhibits a higher ROS level than pure GO as expected. The induction of ROS in Gram-negatives leads to the membrane disruption, resulting in the leakage of cytoplasmic enzymes as revealed by lactate dehydrogenase (LDH) assay (Figure 32b). LDH is a biomarker of damaged cell membrane integrity showing the percentage level of enzyme leakage from the cytoplasm.

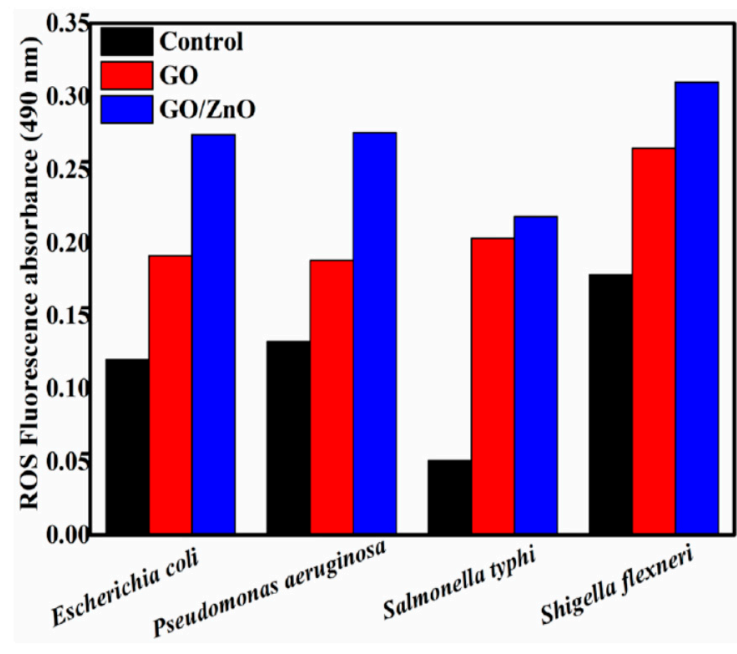

(a)

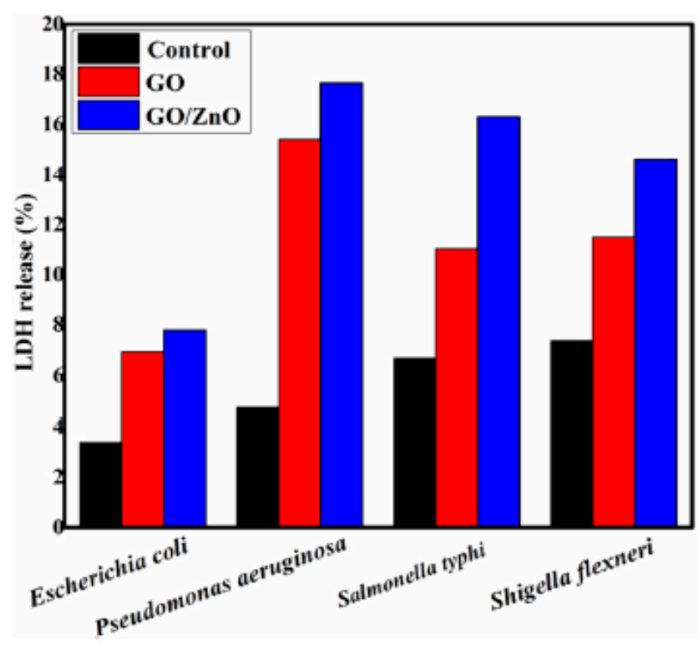

(b)

Figure 32. (a) ROS and (b) lactate dehydrogenase (LDH) levels of different Gram-negative bacteria strains treated with pure GO and GO/ZnO nanohybrid. Reproduced from [246] with permission of Springer Nature.

Recently, Wang et al. synthesized GO/ZnO nanohybrids solvothermally with different GO/ZnO mass ratios of 1:3 (denoting as GO-1/ZnO) and 1:2 (denoting as GO-2/ZnO). In nanohybrids, $\mathrm{ZnO} N P s$ with a size of about $4 \mathrm{~nm}$ were homogeneously anchored onto GO sheets [242]. Figure 33a,b show the growth curves over time of $E$. coli treated with both nanohybrids of different concentrations. The curves are obtained by monitoring the changes in optical density (OD) at $600 \mathrm{~nm}$. Typical sigmoidal curves with three different stages (phases), i.e., a lag phase, an exponential (logarithmic) phase, and a plateau phase, can be readily seen for the growth of bacterial populations. At a low dose of $2.5 \mu \mathrm{g} / \mathrm{mL}$, the lag phase is relatively short $(4 \mathrm{~h})$, after which $E$. coli populations grow rapidly with time in the exponential phase by treating with $\mathrm{GO}-1 / \mathrm{ZnO}$ and $\mathrm{GO}-2 / \mathrm{ZnO}$ hybrids. Both hybrids can suppress microbial growth more effectively by increasing the doses, especially at a high concentration of $10.0 \mu \mathrm{g} / \mathrm{mL}$. The lag phase time is delayed by $16 \mathrm{~h}$ and $12 \mathrm{~h}$, respectively at a dose of $10.0 \mu \mathrm{g} / \mathrm{mL}$, which is followed by the exponential stage and final plateau phase with low bacterial popupations. Meanwhile, the close contact of homogeneously dispersed ZnO NPs with E. coli favors the release of zinc ions from nanohybrids 
(Figure 33c). The bactericidal efficacy derives from the synergistic effect of released zinc ions from the $\mathrm{ZnO} / \mathrm{GO}$ nanohybrids, and the wrapping of graphene sheet around E. coli (Figure 33d).
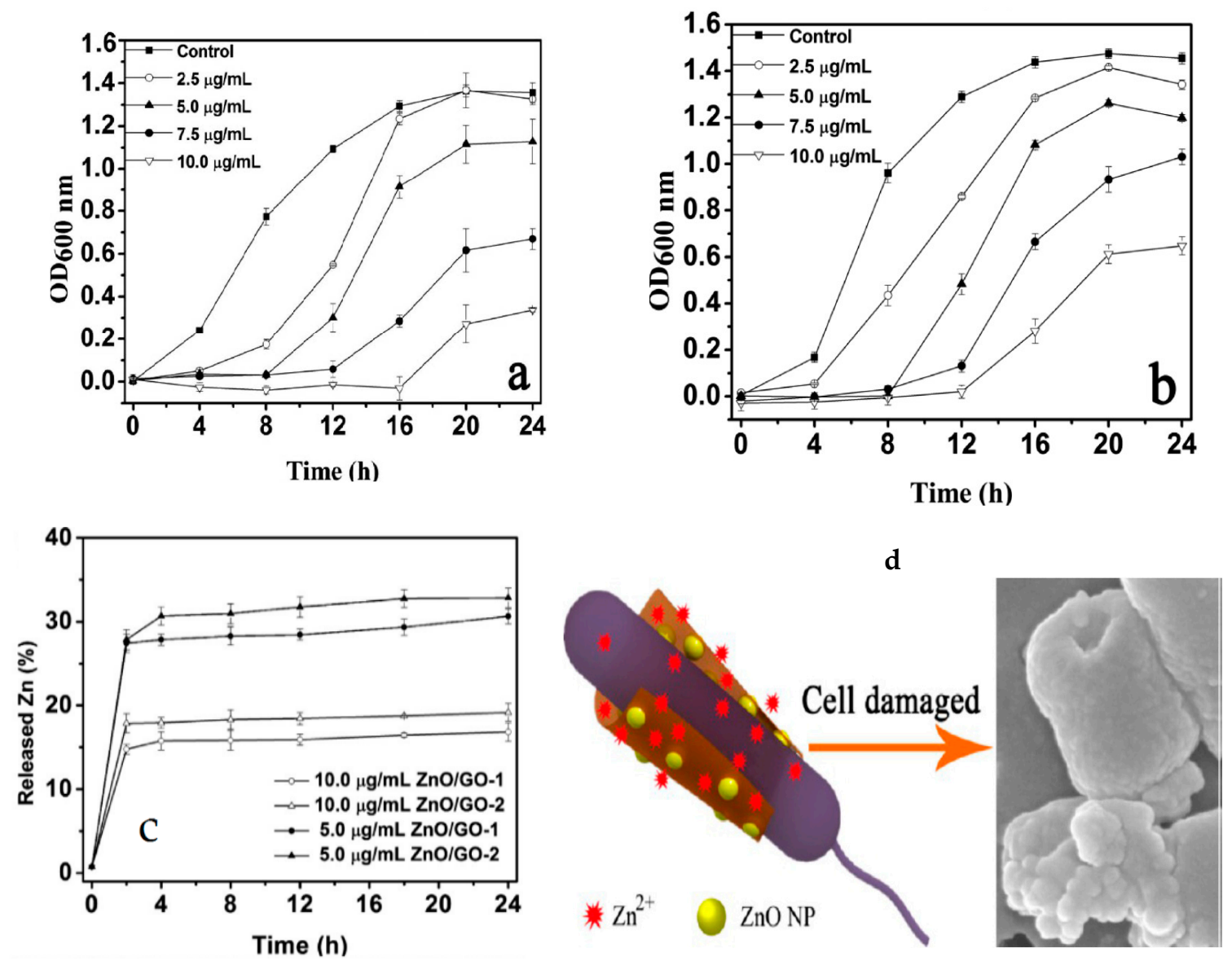

Figure 33. Growth curves of E. coli treated with (a) GO-1/ZnO and (b) GO-2/ZnO hybrids of different doses; (c) Zinc released from GO/ZnO composites; (d) Wrapping of graphene sheet around E. coli and released $\mathrm{Zn}^{2+}$ ions led to bacterial cell membrane damage. The experiments were performed in triplicates, and the results were given as mean \pm standard deviation. Reproduced from [242] with permission of the American Chemical Society.

\subsection{Bactericidal Activity under Visible Light}

\subsubsection{Metal Doping}

The bactericidal performance of $\mathrm{ZnO}$ nanostructures can be further enhanced by irradiating with electromagnetic waves. In general, photocatalytic ROS generation is mainly responsible for bactericidal activity of $\mathrm{ZnO}$ nanostructures with a wide bandgap under UV irradiation [295]. The bandgap of $\mathrm{ZnO}$ nanostructures can be greatly reduced by doping with transition metals. As such, $\mathrm{ZnO}$ can absorb photons of longer wavelength, thereby shifting its optical absorption edge from UV to visible region. Therefore, bactericidal activity of nano- $\mathrm{ZnO}$ under visible light can be improved by doping with metals [296-299]. More recently, Qi et al. synthesized pure ZnO NPs, and Cu-doped ZnO nanorods using co-precipitation process (Figure 34a) [298]. The antibacterial activity of nano- $\mathrm{ZnO}$ under simulated solar light was investigated. The bandgap of $\mathrm{ZnO} N P s$ was $3.20 \mathrm{eV}$, and reduced to $2.81 \mathrm{eV}$ by doping with $\mathrm{Cu}$. The $\mathrm{Cu} / \mathrm{ZnO}$ nanorods exhibited better antibacterial activity than $\mathrm{ZnO}$ NPs under simulated sunlight illumination (Figure 34b). This was attributed to the generation of ROS on $\mathrm{Cu} / \mathrm{ZnO}$ nanorods under sunlight. Copper dopant improved photocatalytic activity of $\mathrm{ZnO}$ by introducing midgap states below the $\mathrm{CB}$ of $\mathrm{ZnO}$ (Figure 34c). In this respect, photogenerated electrons 
were readily excited from the $\mathrm{VB}$ of $\mathrm{ZnO}$ to localized $\mathrm{Cu}$ midgap states, leading to the formation of superoxide anion and hydroxyl radicals for bactericidal activity. From Figure 34b, pure ZnO NPs displayed a sharp increase in bactericidal activity under solar light illumination for $4 \mathrm{~h}$. This was presumably caused by the presence of oxygen vacancies in ZnO NPs, thereby reducing the band-gap and enhancing solar light photocatalytic effect.

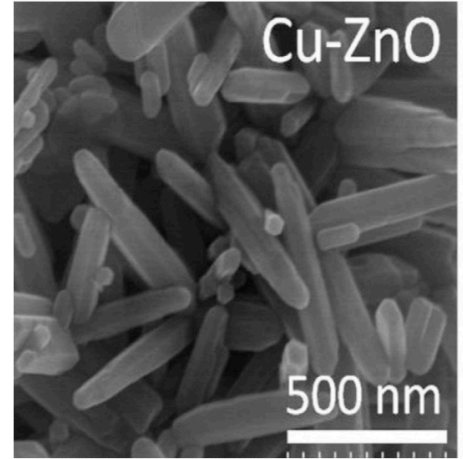

(a)

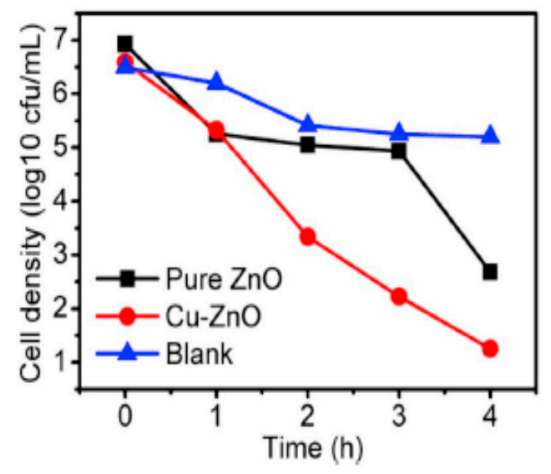

(b)

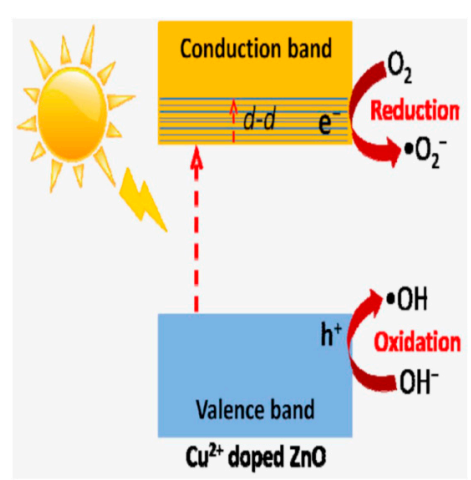

(c)

Figure 34. (a) SEM image showing morphology of Cu-doped $\mathrm{ZnO}$ nanorods; (b) Photocatalytic efficiency of $\mathrm{ZnO} N P$ s and $\mathrm{Cu} / \mathrm{ZnO}$ nanorods against $E$. coli under simulated solar light irradiation; (c) Photocatalytic mechanism of $\mathrm{Cu} / \mathrm{ZnO}$ nanorods under solar light. Reproduced from [298] with permission from Elsevier.

Gupta and Bahadur synthesized $\mathrm{Cu}$-doped $\mathrm{ZnO}$ nanocomposites through hydrolysis and condensation of zinc acetate and copper acetate in a polyol medium, i.e., diethylene glycol (DEG) at $170-180{ }^{\circ} \mathrm{C}$ for $1 \mathrm{~h}$. Based on the nominal concentration of $\mathrm{Cu}$, the resulting nanocomposites were designated as $\mathrm{Cu}_{5} / \mathrm{ZnO}(5 \% \mathrm{Cu})$ and $\mathrm{Cu}_{10} / \mathrm{ZnO}$, respectively [102]. Figure 35a,c summarize the live/dead staining, ROS and malonaldehyde (MDA) results of $E$. coli treated with different $\mathrm{Cu}_{5} / \mathrm{ZnO}$ concentrations. A marked decline in green fluorescence at $\mathrm{Cu}_{5} / \mathrm{ZnO}$ concentrations $\geq 100 \mu \mathrm{g} / \mathrm{mL}$ demonstrates the excellent efficacy against $E$. coli. As recognized, a mixture of SYTO9 and propidium iodide (PI) fluorescent dyes is used in the live/dead assay to distinguish viable bacterial cells with intact plasma membranes from dead cells with damaged membranes. SYTO9 dye can penetrate cell membranes of both viable and dead cells, giving rise to green fluorescence. However, PI only penetrates cell membranes of dead cells, producing red fluorescence. Moreover, $\mathrm{Cu}_{5} / \mathrm{ZnO}$ also induces $\mathrm{ROS}$ and membrane lipid peroxidation in E. coli, resulting in the loss of membrane integrity (Figure 35b,c). Both ROS and MDA levels increase markedly as the $\mathrm{Cu}_{5} / \mathrm{ZnO}$ content increases. MDA is a biomarker for revealing lipid membrane peroxidation. Figure $36 \mathrm{a}, \mathrm{b}$ show the effect of solar light irradiation on bactericidal potency of $\mathrm{Cu}_{5} / \mathrm{ZnO}(200 \mu \mathrm{g} / \mathrm{mL})$ against $E$. coli as determined by OD600 and colony counting methods. A large amount of $E$. coli is inactivated due to the creation of ROS under solar light irradiation. From Figure 36b, inactivation of E. coli by $\mathrm{Cu}_{5} / \mathrm{ZnO}$ to a small extent in the dark can be readily seen. As mentioned, nano- $\mathrm{ZnO}$ possesses intrinsic oxygen vacancies that facilitate the formation of superoxide anion, hydroxyl radicals, singlet oxygen and $\mathrm{H}_{2} \mathrm{O}_{2}$ in the dark [20,21,300-302]. The amount of oxygen vacancies in $\mathrm{ZnO}$ NPs can be somewhat increased by doping with $\mathrm{Cu}$ [303]. Thus oxygen vacancies, released $\mathrm{Cu}$, and $\mathrm{Zn}$ ions from $\mathrm{Cu}_{5} / \mathrm{ZnO}$ in the culture medium [22], are contributed to bactericidal activity to a certain degree in the dark. In another study, Gupta et al. also reported that $\mathrm{Ag}_{5} / \mathrm{ZnO}$ nanospheres exhibit superior bactericidal effect against $E$. coli under solar light [304]. The photocatalytic bactericidal effect derives from the creation of superoxide anion and hydroxyl radicals due to the surface plasmon effect of AgNPs under solar light as shown in Figure 5A. Both reactive species can damage bacterial cell membrane leading to cell death after $30 \mathrm{~min}$ of solar light illumination. 


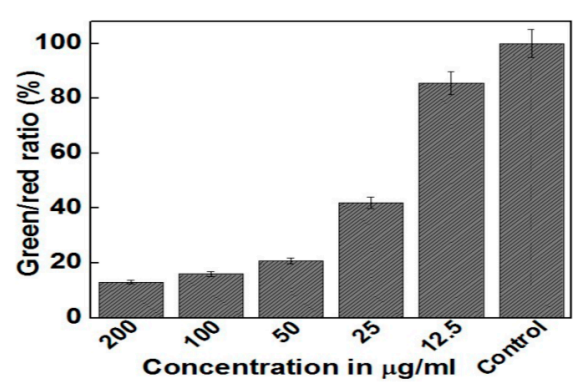

(a)

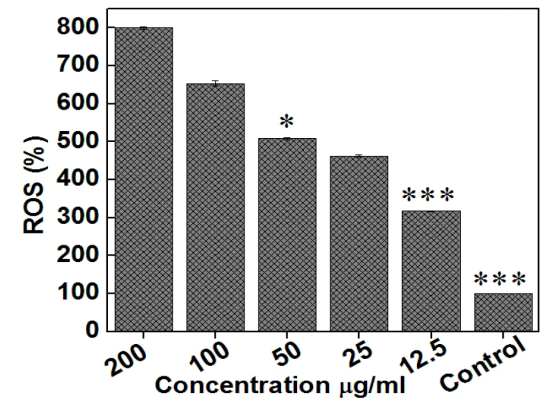

(b)

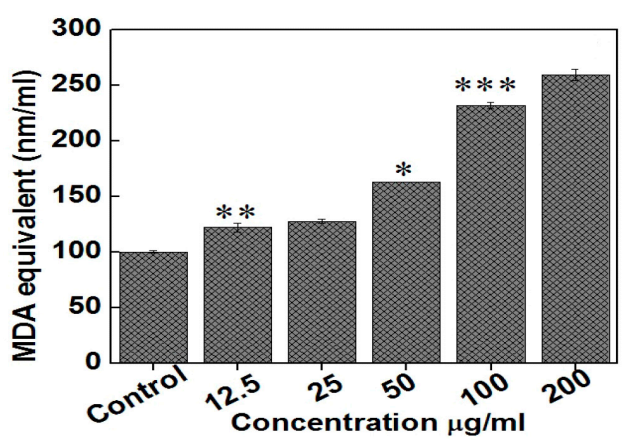

(c)

Figure 35. (a) Change in fluorescence intensity of green/red ratio of live/dead assay, (b) ROS and (c) MDA levels of E.coli treated with different $\mathrm{Cu}_{5} / \mathrm{ZnO}$ concentrations. The data were expressed as the mean \pm SD (standard deviation) for three independent experiments $(n=3) . p<0.05\left(^{*}\right), 0.001\left(^{* *}\right)$ and $\left.0.0001{ }^{* * *}\right)$ were measured significant as compared to control. Reproduced from [102] with permission of the American Chemical Society.
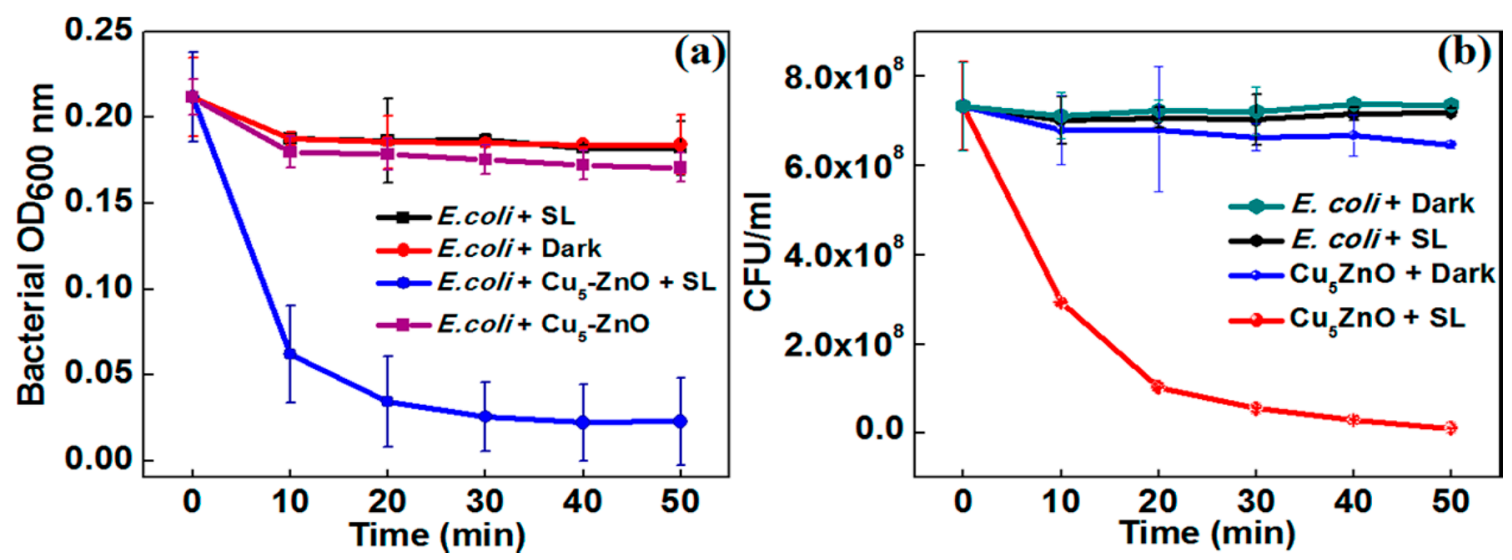

Figure 36. Photoinactivation of E. coli treated with $\mathrm{Cu} 5 / \mathrm{ZnO}(200 \mu \mathrm{g} / \mathrm{mL})$ under solar light (SL). The plots of (a) OD600 and (b) CFU/mL as a function of time. The experiments were performed in triplicates and data were expressed as the mean \pm SD. Reproduced from [102] with permission of the American Chemical Society.

For AuNPs/ZnO nanocomposites, hot electrons are injected from noble AuNPs into the CB of $\mathrm{ZnO}$ for reacting with adsorbed oxygen molecules to create ROS under visible light irradiation due to plasmonic oscillation. He et al. deposited 2-20\% AuNPs (1-3 nm) onto ZnO NPs (30-40 nm), and reported a dramatic increase in the production of hydroxyl, superoxide and singlet oxygen radicals on the nanocomposites under simulated sunlight irradiation (Figure 37a,b) [305]. As a result, AuNPs/ZnO nanocomposite with a dose of $0.05 \mathrm{mg} / \mathrm{mL}$ exhibited good antibacterial activity against $S$. aureus under simulated sunlight exposure for $10 \mathrm{~min}$. At a dose of $0.1 \mathrm{mg} / \mathrm{mL} \mathrm{AuNPs} / \mathrm{ZnO}$, the percentage of survival of $S$. aureus decreased significantly due to the ROS generation (Figure 37c). 


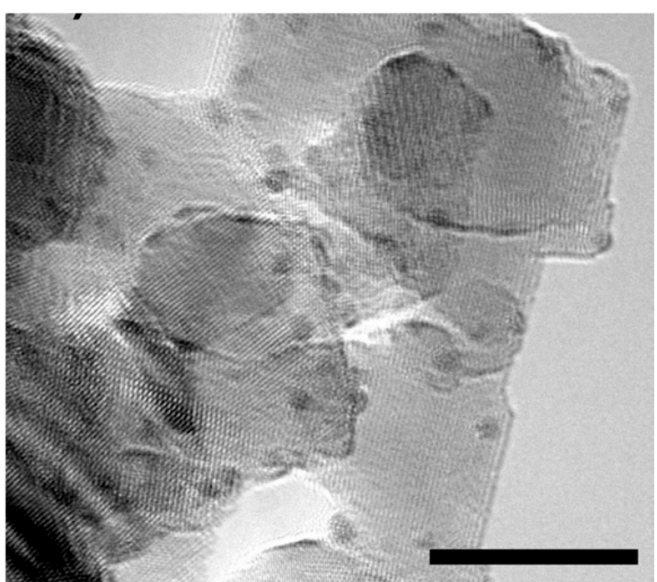

(a)

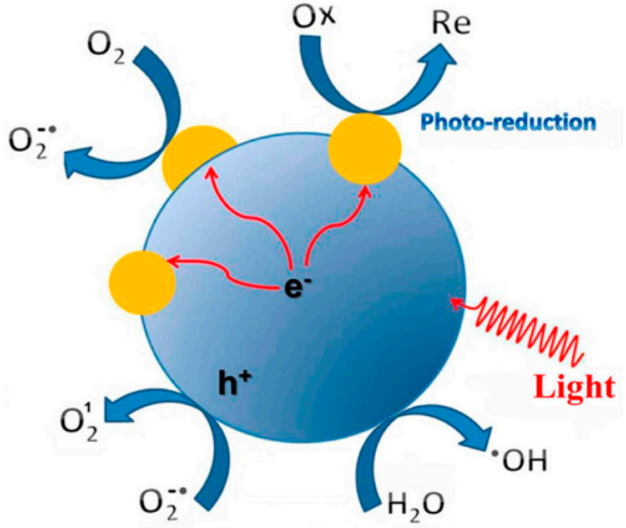

(b)

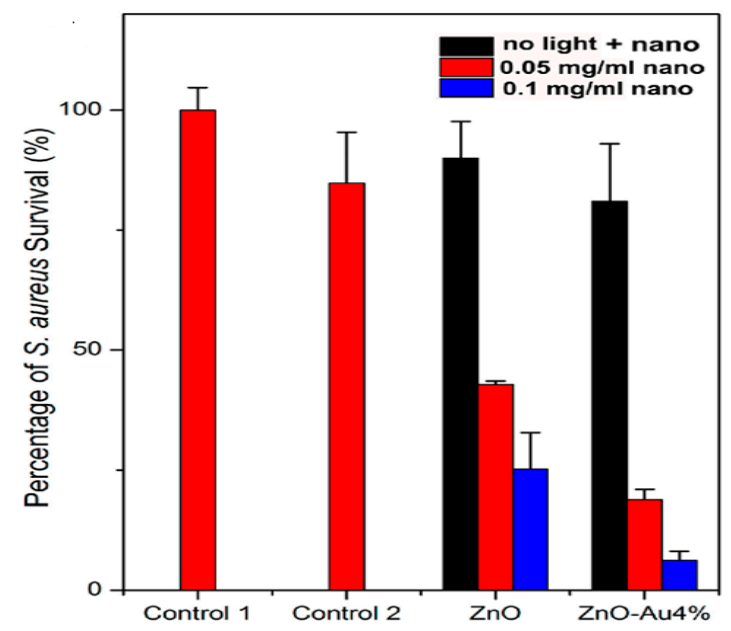

(c)

Figure 37. (a) TEM image and (b) schematic illustration of the production of hydroxyl, superoxide anion and singlet oxygen radicals on $4 \%$ AuNPs/ZnO exposed to simulated sunlight. Fine grey circles in (a) are AuNPs; scale bar is $20 \mathrm{~nm}$. (c) A bar graph showing staphylococcus aureus survival upon exposure to $\mathrm{ZnO}$ NPs and $4 \%$ AuNPs/AgNPs at doses of 0.05 and $0.1 \mathrm{mg} / \mathrm{mL}$ without (black column) and with simulated sunlight illumination for $10 \mathrm{~min}$. Control 1 is bacteria exposed to neither NPs nor light. Control 2 denotes bacteria exposed to simulated sunlight for $10 \mathrm{~min}$ in the absence of NPs. All tests are conducted in triplicates and repeated at least twice to obtain reproducibility. Reproduced from [305] with permission of the American Chemical Society.

Das et al. investigated solar-photocatalytic disinfection (PCD) of spherical Fe-doped ZnO NPs against MDR E. coli isolated from wastewater of a rural healthcare center [306]. Fe-doped ZnO NPs with sizes of 80-100 nm were synthesized by chemical precipitation process. MDR E. coli was the main bacteria causing urinary tract infections and water borne diseases. Figure 38a shows the time dependent disinfection of MDR E. coli as a function of Fe/ZnO NPs doses under solar light. Apparently, bactericidal efficiency increases with increasing Fe/ZnO NPs dose up to $750 \mu \mathrm{g} / \mathrm{mL}$; (Note that mg/L $=\mu \mathrm{g} / \mathrm{mL})$. At an optimal dose of $500 \mu \mathrm{g} / \mathrm{mL}$, the time for complete disinfection for Fe/ZnO NPs was relatively shorter (i.e., $80 \mathrm{~min}$ ) when compared to undoped $\mathrm{ZnO}(120 \mathrm{~min})$ and $\mathrm{TiO}_{2}(180 \mathrm{~min})$ as shown in Figure 38b (inset). By doping with $\mathrm{Fe}, \mathrm{Fe}^{3+}$ ions replaced $\mathrm{Zn}^{2+}$ ions at tetrahedral sites of $\mathrm{ZnO}$ [307]. Under solar light irradiation, $\mathrm{Fe}^{3+}$ ions acted as the hole and electron traps, thus promoting the ROS generation. The photocatalytic reactions were given by [308],

$$
\mathrm{Fe}^{3+}+\mathrm{e}^{-} \rightarrow \mathrm{Fe}^{2+} \text { (electron trap) }
$$




$$
\begin{aligned}
& \mathrm{Fe}^{2+}+\mathrm{O}_{2(\mathrm{ads})} \rightarrow \mathrm{Fe}^{3+}+\bullet \mathrm{O}_{2}^{-} \\
& \mathrm{Fe}^{3+}+\mathrm{h}^{+} \rightarrow \mathrm{Fe}^{4+} \text { (hole trap) } \\
& \mathrm{Fe}^{4+}+\mathrm{OH}^{-}{ }_{(\text {ads })} \rightarrow \mathrm{Fe}^{3+}+\bullet \mathrm{OH}
\end{aligned}
$$

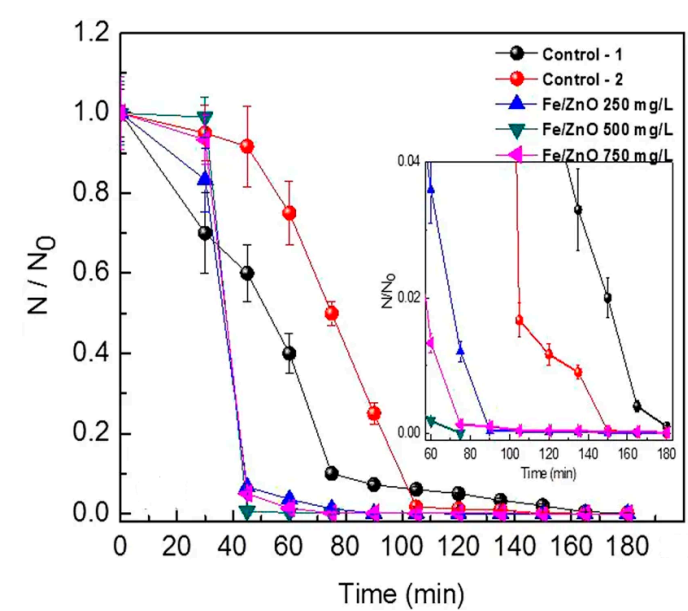

(a)

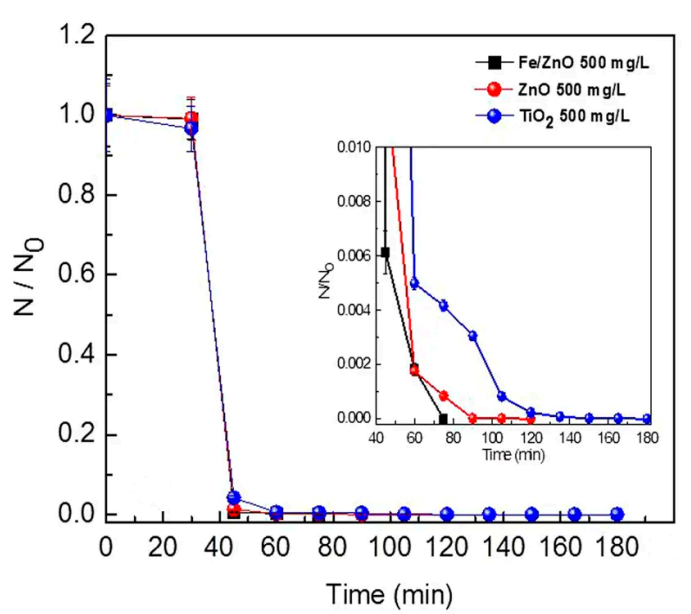

(b)

Figure 38. (a) Effect of Fe/ZnO NPs concentrations on solar-photocatalytic disinfection (PCD) kinetics of multidrug-resistant (MDR) E. coli. Control-1: bacteria exposed to Fe/ZnO NPs in the dark; Control-2: bacteria without Fe/ZnO NPs under solar irradiation. (b) Effect of different catalysts on the solar-PCD kinetics of MDR E. coli at a catalyst concentration of $500 \mathrm{mg} / \mathrm{L}$. Initial MDR E. coli concentration = $1.2 \times 10^{7} \mathrm{CFU} / \mathrm{mL}$, temperature $=35 \pm 2{ }^{\circ} \mathrm{C}, \mathrm{pH}=6.5$. Error bars indicate standard deviation of replicates $(n=3)$. Reproduced from [306] under a Creative Commons Attribution 4.0 International License.

The decline in bacterial populations due to $\mathrm{Fe} / \mathrm{ZnO}$ NPs was attributed to the generation of superoxide and hydroxyl radicals, leading to membrane lipid peroxidation as revealed by the MDA results (Figure 39a), and the leakage of of $\mathrm{K}^{+}$ion from MDR E. coli (Figure 39b). Figure 40 is a schematic showing solar-photocatalytic disinfection of Fe/ZnO NPs against MDR E. coli (left panel), leading to the membrane damage due to lipid peroxidation and the leakage of $\mathrm{K}^{+}$ions from cytoplasm (right panel).
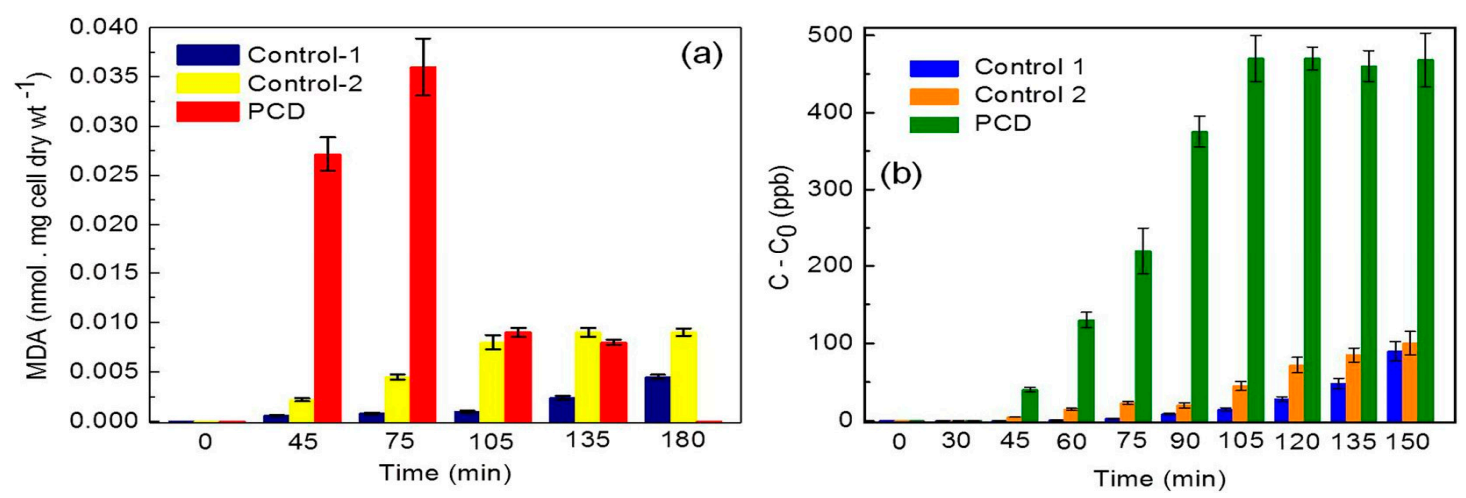

Figure 39. Plots of (a) malondialdehyde (MDA) content vs time and (b) leakage of $\mathrm{K}^{+}$ion vs time for MDR E. coli treated with Fe/ZnO NPs. Initial MDR E. coli concentration $=1.2 \times 10^{7} \mathrm{CFU} / \mathrm{mL}$, Temperature $=35 \pm 2{ }^{\circ} \mathrm{C}, \mathrm{pH}=6.5,[\mathrm{Fe} / \mathrm{ZnO} \mathrm{NPs}]=500 \mathrm{mg} / \mathrm{L}$. Error bars indicate standard deviation of replicates $(n=3)$. Reproduced from [306] under a Creative Commons Attribution 4.0 International License. 

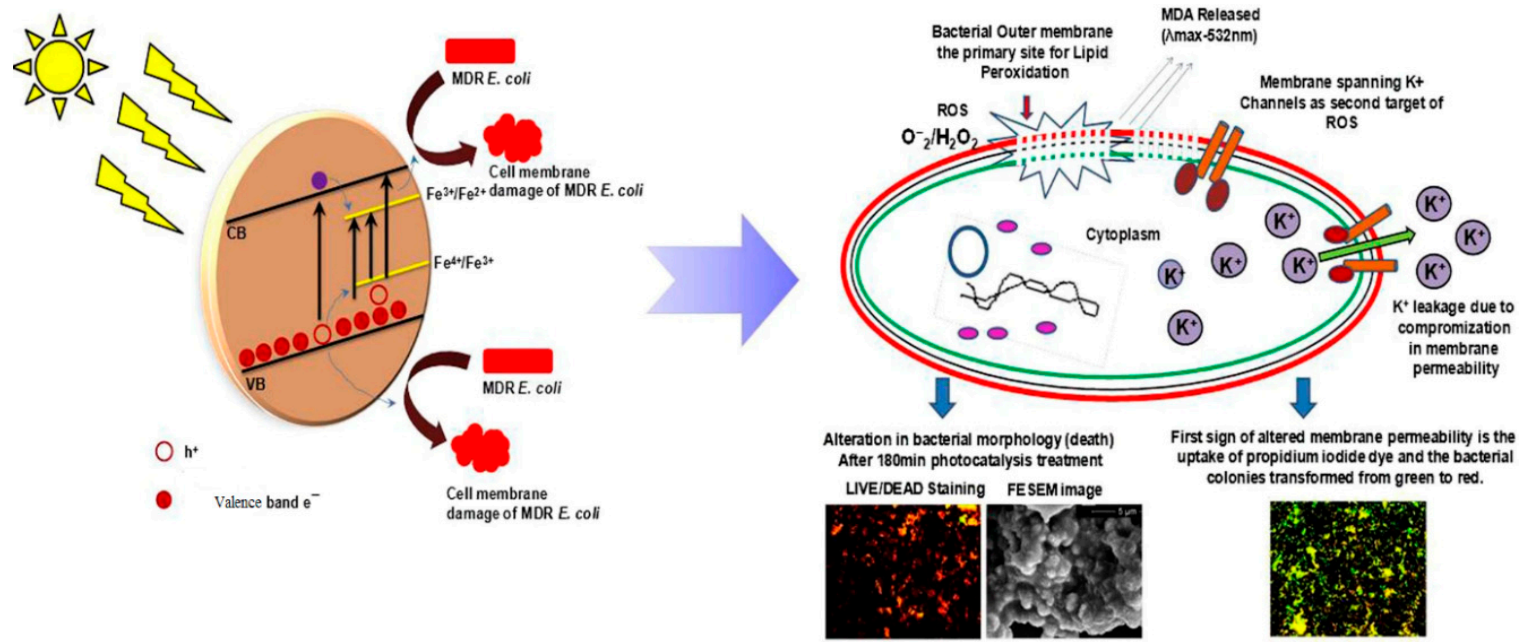

Figure 40. Schematic view of visible-light photocatalytic bactericidal activity of Fe/ZnO NPs against MDR E. coli. Reproduced from [306] under a Creative Commons Attribution 4.0 International License.

\subsubsection{Non-Metal Doping}

Non-metal dopants can effectively extend the absorption band edge of $\mathrm{ZnO}$ to visible light region by introducing an intermediate energy level just above the $\mathrm{VB}$ of $\mathrm{ZnO}$. The dopants narrow the bandgap and facilitate the separation of eletron-hole pairs [309]. Podporska-Carroll et al. studied antimicrobial behavior of F-doped $\mathrm{ZnO}$ nanopowders against $E$. coli and S. aureus under visible light illumination. F-doped ZnO NPs with two different molar ratios of ZnO: trifluoroacetic acid (TFA), i.e., ZnO:TFA 1:1 and ZnO:TFA 1:2, were prepared by the sol-gel process [310]. Figure 41A displays the bactericidal activity of undoped $\mathrm{ZnO}$ (ZnO SG), ZnO:TFA 1:1 and ZnO:TFA 1:2 nanopowders against $E$. coli in the dark. A few log reduction in bacterial density can be readily seen in these samples after testing for $3 \mathrm{~h}$ and $6 \mathrm{~h}$. This is ascribed to the direct contact killing of undoped $\mathrm{ZnO}$ and F-doped $\mathrm{ZnO}$ through the release of $\mathrm{Zn}^{2+}$ ions and ROS generation. Under visible light irradiation for $6 \mathrm{~h}$, ZnO:TFA 1:1 produces a $2.88 \log$ reduction $(99.87 \%$ ) in E. coli population, while it yields a $4.62 \log$ reduction (over $99.99 \%$ ) in S. aureus population (Figure $41 \mathrm{~B}, \mathrm{C}$ ). The visible-light photocatalytic bactericidal activity derives from the generation of additional ROS as expected [310].
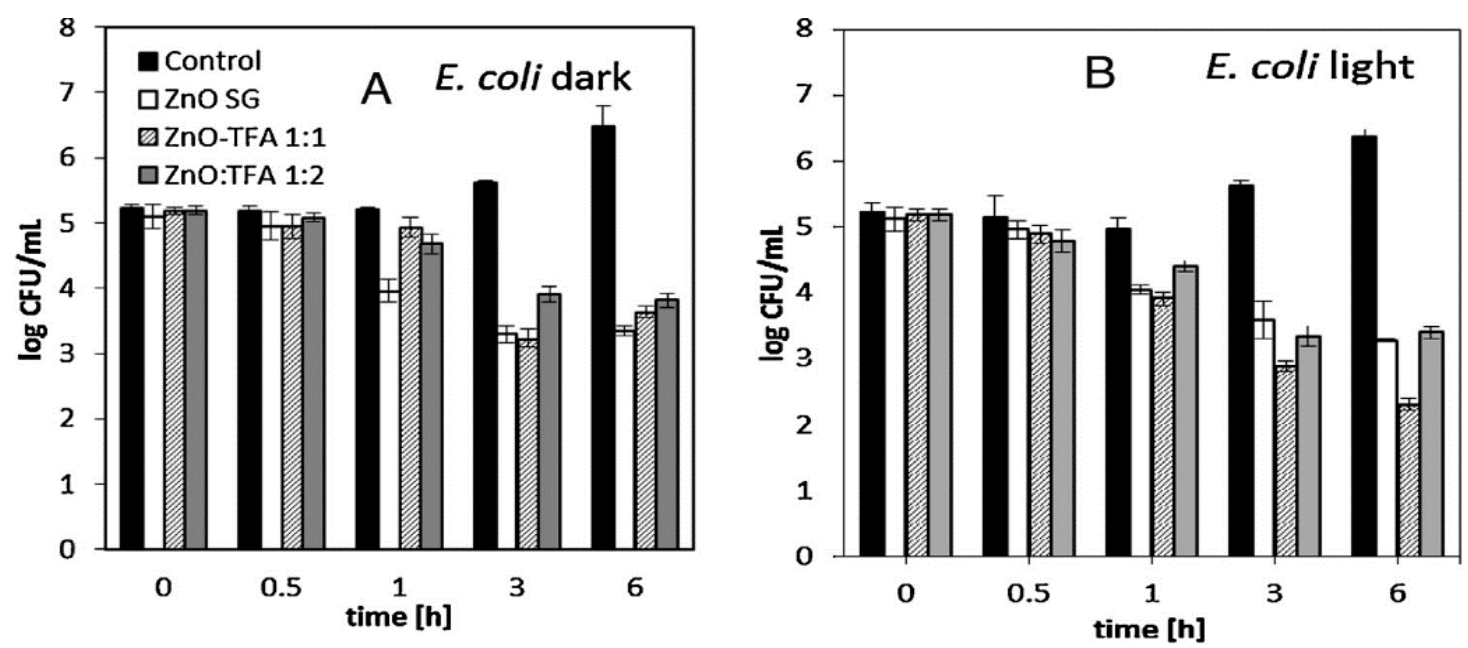

Figure 41. Cont. 


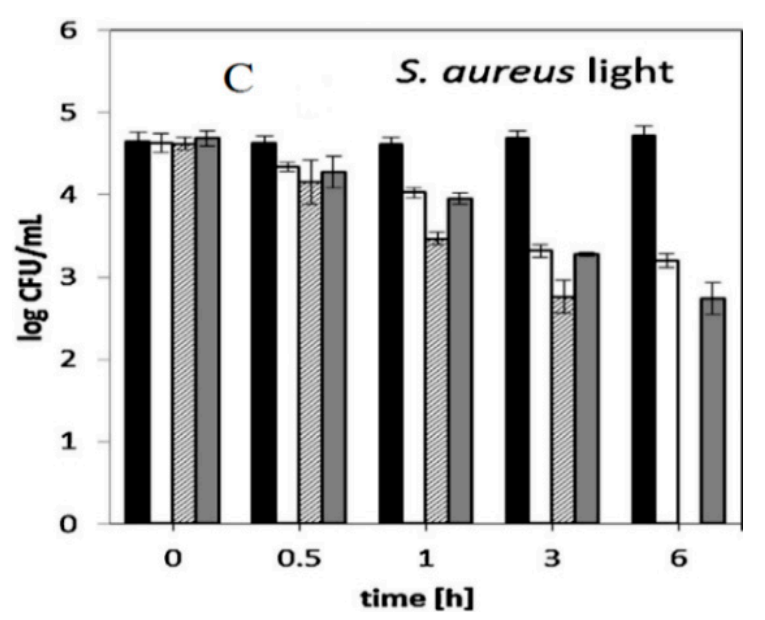

Figure 41. Log reduction of E. coli treated with undoped ZnO SG, ZnO:TFA 1:1 and ZnO:TFA 1:2 under (A) the dark and (B) visible light conditions. (C) Bactericidal activity of those samples against $S$. aureus under visible light. All tests were conducted in triplicates. Reproduced from [310] with permission of Elsevier.

\subsubsection{Coupled Metal Oxide Semiconductors}

Coupling nano- $\mathrm{ZnO}$ with $\mathrm{CuO}$ of a relatively narrow bandgap $(\sim 1.35-2.00 \mathrm{eV})$ can yield $\mathrm{CuO} / \mathrm{ZnO}$ nanocomposite heterostructures with enhanced photocatalytic activity [311,312]. Liu et al. carried out antimicrobial study of pristine $\mathrm{ZnO}$ and $\mathrm{CuO} / \mathrm{ZnO}$ nanocomposite membranes against $E$. coli. The composite membrane was prepared by mixing hydrothermally grown $\mathrm{ZnO}$ nanorods with an aqueous solution of copper sulfate and $\mathrm{NaCl}$. The resulting $\mathrm{ZnO}$ nanorods were decorated with $\mathrm{CuO}$ NPs ( $100 \mathrm{~nm})$, showing a corn-like feature (Figure 42a) [313].Under dark condition, ZnO nanorod exhibited limited bactericidal activity associated with direct contact killing effect and the generation of a certain amount of ROS. The presence of intrinsic oxygen vacancies in $\mathrm{ZnO}$ nanorod favored the formation of superoxide anion, hydroxyl radicals, singlet oxygen and $\mathrm{H}_{2} \mathrm{O}_{2}$ in the dark [20,21,302]. As such, $\mathrm{ZnO}$ nanorod inactivated $E$. coli around $15 \%$ in the dark after $30 \mathrm{~min}$. In the case of $\mathrm{CuO} / \mathrm{ZnO}$ under dark condition, the nanocomposite would kill around $40 \%$ E. coli after $30 \mathrm{~min}$ due to released $\mathrm{Zn}^{2+}$ ions, $\mathrm{Cu}^{2+}$ ions and the $\mathrm{ROS}$ generation. However, $\mathrm{CuO} / \mathrm{ZnO}$ membrane inactivated E. coli completely after $25 \mathrm{~min}$ irradiation of visible light (Figure 42b). This was ascribed to the high generation of superoxide and hydroxyl radicals for killing E. coli. As mentioned previously, electrons were excited from the $\mathrm{VB}$ to $\mathrm{CB}$ of $\mathrm{CuO}$ under visible light illumination due to its small bandgap. Photoexcited electrons from the $\mathrm{CB}$ of $\mathrm{CuO}$ were then transferred to the $\mathrm{CB}$ of $\mathrm{ZnO}$ for producing superoxide anions, while the holes from the $\mathrm{VB}$ of $\mathrm{ZnO}$ were moved to the $\mathrm{VB}$ of $\mathrm{CuO}$ for creating hydroxyl radicals (Figure 10b). 


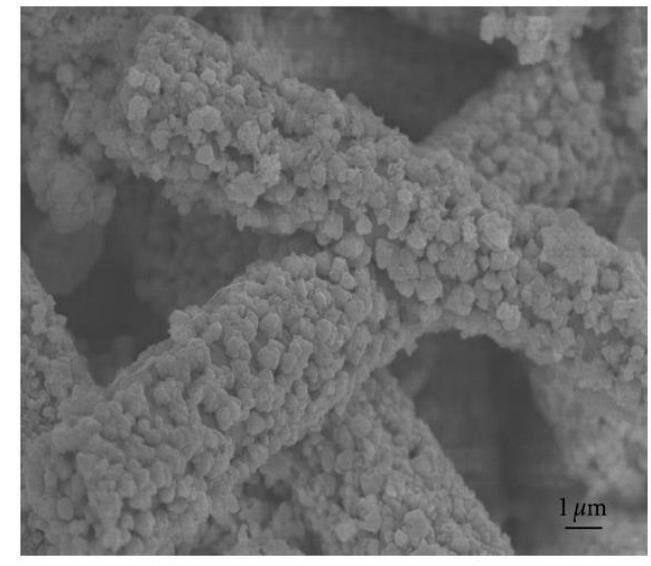

(a)

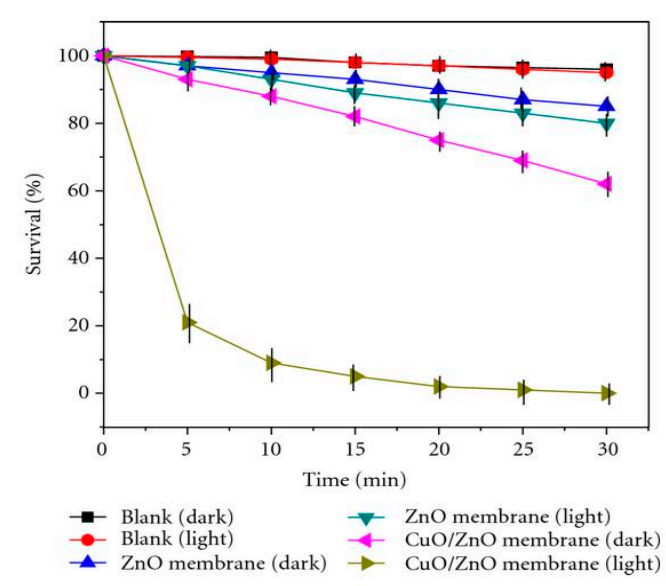

(b)

Figure 42. (a) SEM image showing $\mathrm{ZnO}$ nanorods decorated with $\mathrm{CuO}$. (b) Survival rate vs visible light irradiation time curves of $E$. coli treated with $\mathrm{CuO} / \mathrm{ZnO}$ membrane and $\mathrm{ZnO}$ membrane. Reproduced from [313] under the Creative Commons Attribution License.

\subsubsection{GO/ZnO Nanocomposites}

As mentioned, photocorrosion of $\mathrm{ZnO}$ nanostructures can be prevented by modifying with carbonaceous nanomaterials such as graphene sheet and CNTs [89,160-162,314]. Furthermore, the optical absorption edge of nano- $\mathrm{ZnO}$ is red-shifted to the visible region by modifying with carbonaceous nanomaterials due to a significant decrease in their bandgap energy $[172,314]$. The main drawbacks of CNTs for fabricating CNTs/ZnO nanocomposites include the lack of solubility in aqueous media, and the absence of oxygenated functional groups for reacting with $\mathrm{ZnO}$. By contrast, negatively charged oxygenated groups of GO react readily with released $\mathrm{Zn}^{2+}$ ions from the zinc salt precursor to produce $\mathrm{GO} / \mathrm{ZnO}$ nanocomposites. This leads to the formation of finely dispersed $\mathrm{ZnO} N P s$ on graphene [242].

Wu et al. hydrothermally synthesized $\mathrm{GO} / \mathrm{ZnO}$ hybrid using an aqueous solution of $\mathrm{GO}$ and $\mathrm{ZnO}$, and reported its visible-light photocatalytic bactericidal activity [173]. Under visible light illumination, total inactivation of $E$. coli requires $60 \mathrm{~min}$, with a 7-log reduction in bacterial cell density (Figure 43a). As such, electrons are injected from the graphene sheet into the $\mathrm{CB}$ of $\mathrm{ZnO}$, generating superoxide anion on the $\mathrm{GO} / \mathrm{ZnO}$ nanocomposite (Figure 8). Meanwhile, $\mathrm{H}_{2} \mathrm{O}_{2}$ is formed by the reduction of superoxide anion. Figure $43 \mathrm{~b}$ shows the creation of $\mathrm{H}_{2} \mathrm{O}_{2}$ from $\mathrm{GO} / \mathrm{ZnO}$ during the photocatalytic inactivation process under visible light illumination. The hydrogen peroxide content can reach as high as $80 \mu \mathrm{M}$ within $60 \mathrm{~min}$, leading to remarkable photocatalytic bactericidal activity accordingly. In general, negatively charged superoxides and hydroxyl radicals cannot pass through bacterial cell membrane with a negative surface charge. Therefore, these radicals reside mainly on the surface of bacterial cell wall for bacterial killing. However, neutral $\mathrm{H}_{2} \mathrm{O}_{2}$ molecule permeates the cell wall readily, which is followed by the subsequent oxidation of intracellular components. 

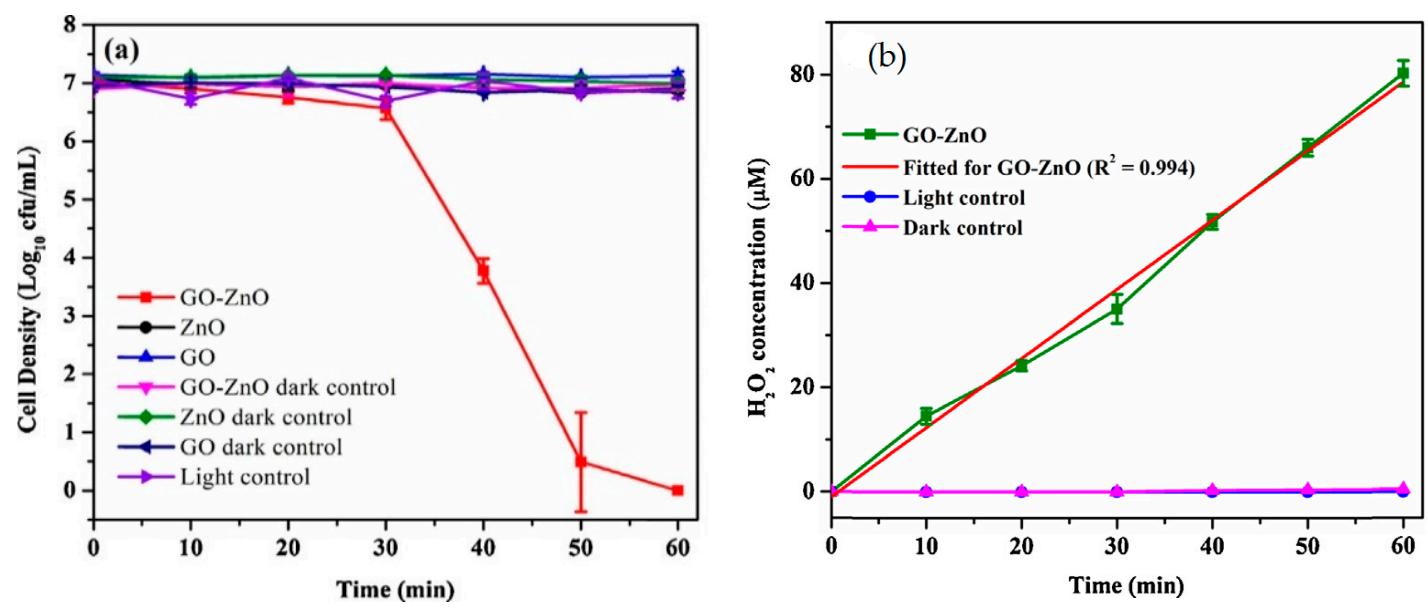

Figure 43. (a) Visible-light photocatalytic inactivation efficiency of E. coli $\left(1 \times 10^{7} \mathrm{CFU} / \mathrm{mL}\right)$ treated with $\mathrm{GO} / \mathrm{ZnO}$ composite, $\mathrm{GO}$ and $\mathrm{ZnO}$; (b) $\mathrm{H}_{2} \mathrm{O}_{2}$ generation from $\mathrm{GO} / \mathrm{ZnO}$ during the photocatalytic inactivation process under visible light. All the experiments and controls were conducted in triplicates. Reproduced from [173] with permisiion of Elsevier.

\section{Hemolysis}

Malaria is caused by protozoa of the genus Plasmodium through the bites of female Anopheles mosquitoes. Protozoa are single celled organisms having membrane-bound nuclei. In particular, Plasmodium falciparum is the deadliest parasite causing human fatality globally. Those parasites invade mammalian erythrocytes (red blood cells), causing rupture of infected cells. So much efforts have been spent by the researchers to tackle this issue. Graphene and its derivatives GO/rGO have been reported to inhibit malaria invasion through physical barrier obstruction of P. falciparum parasites and nutrition depletion effects $[315,316]$. Recently, Paul et al. have employed CNT/ZnO hybrid for the detection of malaria biomarker, histidine rich protein II (HRP2) [317]. HRP2 is a $30 \mathrm{kDa}$ water-soluble protein found on the surface of infected red blood cells (RBCs) [318]. So CNT/ZnO hybrid facilitates not only the formation of ROS for killing bacteria, but also acts as an effective biosensor for detecting malaria.

\subsection{Red Blood Cells}

In a previous article, we have reviewed the cytotoxic effects of $\mathrm{ZnO}$ nanostructures on mammalian cells [67]. As mentioned, ZnO NPs are widely used in cosmetics, suncreams, UV-absorbing packaging films and fabrics for food and medical textile applications, as well as therapeutic agents for cancer treatment [42-46,67]. In addition, ZnO NPs have also been added to animal (e.g., chicken) feed to promote the growth performance of the animals [319]. So ZnO NPs could enter the human body by different routes including the circulatory system. Once ZnO NPs enter the circulatory system, they come in direct contact with RBCs, neutrophils and immune cells. As it is known, mature erythrocytes do not have nucleus and rough endoplasmic reticulum in order to accommodate a large amount of hemoglobin in the cells. In this respect, erythrocytes are incapable of replacing damaged proteins and undergoing mitosis. However, camels, birds, and fish have nucleated red blood cells. By contacting $\mathrm{RBC}, \mathrm{ZnO}$ nanoparticles would anchor on their surfaces and penetrate through the cell membranes, resulting in the generation of ROS. In this respect, RBCs are vulnerable to oxidative stress damage. This leads to the disruption of erythrocyte membranes, which causes the leak of hemoglobin into surrounding medium. This is generally referred to as hemolysis (Figure 44) [320]. 


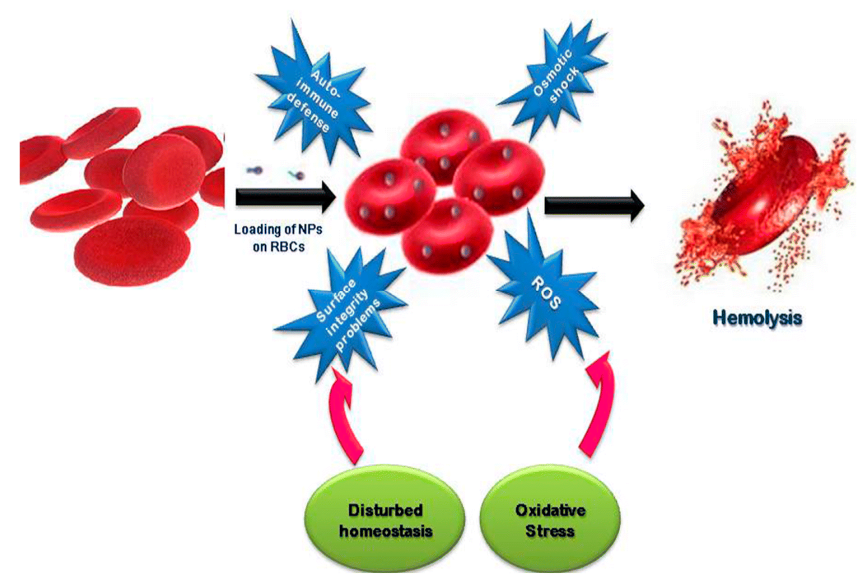

Figure 44. Hemolysis is caused by the binding or encapsulation of nanoparticles (NPs) in red blood cells (RBCs) leading to the generation of ROS, oxidative stress, and disturbed homeostasis as a result of osmotic shock and surface integrity problems. Reproduced from [320] with permission of Springer Nature.

The biocompatibility of nanomaterials contacting blood in medical applications can be assessed using the ASTM standards. The hemoglobin released from damaged red blood cells due to nanomaterials is determined accordingly. From the ASTM E2524-08 standard, nanoparticulate materials cause damage to RBCs when hemolysis exceeds 5\% [321]. ASTM F756 standard further describes hemolytic criteria of blood-contacting nanoparticulate materials, i.e., $<2 \%$ as non-hemolytic, $2-5 \%$ as slightly hemolytic, and $>5 \%$ as hemolytic [322].

Preedia Babu et al. studied the cytotoxic effect of commercial ZnO NPs on erythrocytes. ZnO NPs of different sizes, i.e., $<50 \mathrm{~nm}, 50-100 \mathrm{~nm}$ and $>100 \mathrm{~nm}$ of were separated by means of density gradient centrifugation. The hemolytic effect of $\mathrm{ZnO} N P s(<50 \mathrm{~nm})$ in the presence of albumin and ferulic acid (FA) was examined [323]. FA is a natural phytochemical from the plants, showing good anti-inflammatory response and antioxidant activity [324]. Figure 45A shows the hymolysis rate of chicken RBCs treated with ZnO NPs $(<50 \mathrm{~nm})$ of 200 and $400 \mu \mathrm{g} / \mathrm{mL}$ concentrations. A significant hemolytic activity of around $24 \%$ and $38 \%$ can be readily observed. This is due to the internalization of small ZnO NPs by RBCs as observed by TEM, leading to the ROS generation. However, no hemolysis is observed in the presence of albumin. Furthermore, hemolytic activity is also assessed at different fetal bovine serum (FBS) concentrations ranging from 3.125\% to 25\% (Figure 45B). Apparently, hemolysis decreases with increasing percentage of serum. Thus antioxidant FA also reduces ZnO NPs induced hemolysis.

Khan et al. synthesized $\mathrm{ZnO}$ nanorods by means of combustion of zinc acetate and citric acid gel. The percentage hemolysis due to the nanorods at doses of 50,100 and $250 \mu \mathrm{g} / \mathrm{mL}$ was determined to be 20, 39.5 and $62.5 \%$, respectively [325]. Mahanta et al. prepared ZnO NPs (100-250 nm; average size of $200 \mathrm{~nm}$ ) using co-precipitation process, and then functionalized nanoparticles with a small protein

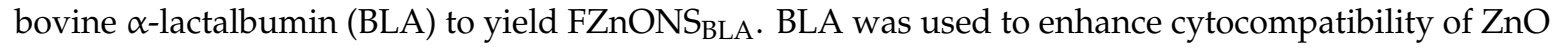
NPs (ZnONS) [326]. Hemocompatibility assay was employed to assess hemolytic behavior of human RBCs treated with ZnONS and FZnONS BLA of different concentrations. Minimal hemolysis $(<5 \%)$ was found at $\mathrm{ZnONS}$ doses below $300 \mu \mathrm{g} / \mathrm{mL}$. Hemolysis rate rose to $7.7 \%$ and $75.3 \%$ by increasing ZnONS doses to $300 \mu \mathrm{g} / \mathrm{mL}$ and $600 \mu \mathrm{g} / \mathrm{mL}$, respectively (Figure 46a). FZnONS BLA showed negligible hemolysis $(<3 \%)$ up to a concentration of $600 \mu \mathrm{g} / \mathrm{mL}$ ), implying hemocompatible of FZnONS BLA with doses from 5 to $600 \mu \mathrm{g} / \mathrm{mL}$ (Figure 46b). 

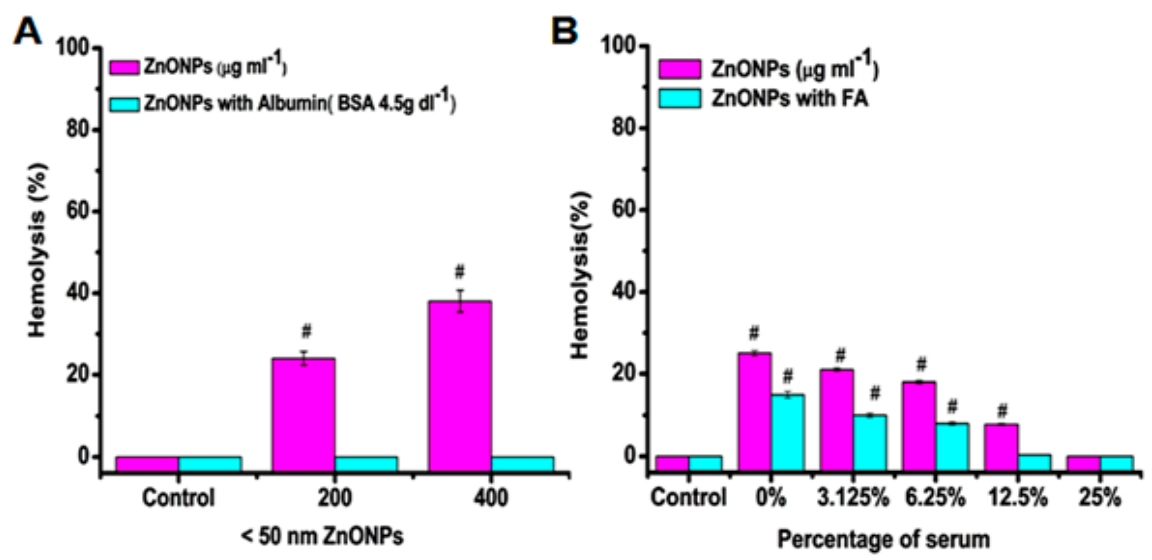

Figure 45. (A) Hemolytic effect of $\mathrm{ZnO}$ NPs $(<50 \mathrm{~nm})$ of two different doses with and without albumin $\left(4.5 \mu \mathrm{g} \mathrm{dl}^{-1}\right)$ on erythrocytes for $24 \mathrm{~h}$. \# denotes significant difference at $p \leq 0.05$ of the samples compared to control. (B) The effect of ZnO NPs ( $<50 \mathrm{~nm} ; 200 \mu \mathrm{g} / \mathrm{mL})$ and $\mathrm{ZnO}$ NPs with ferulic acid (FA) exposure on hemolysis in the presence of fetal bovine serum of different concentrations $(3.125 \%$, $6.25 \%, 12.5 \%$ and $25 \%$ ) for $24 \mathrm{~h}$. \# denotes significant difference at $p \leq 0.05$ of the samples compared to control. Reproduced from [323] under Creative Commons Attribution License.

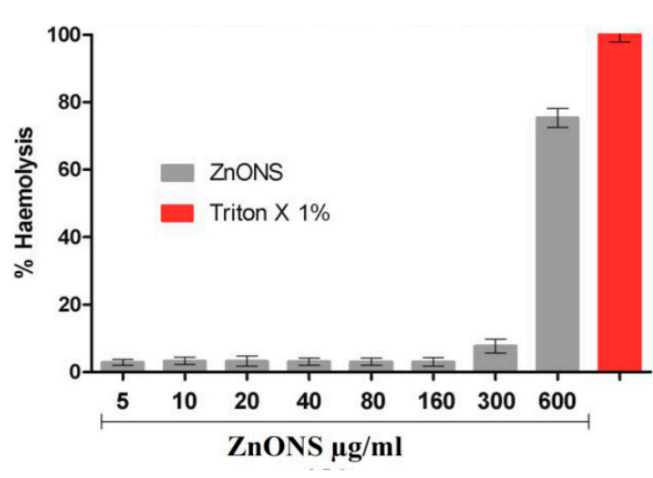

(a)

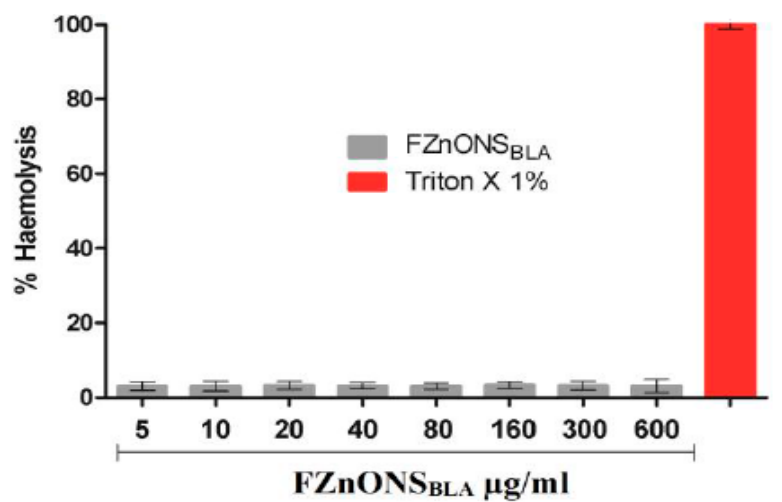

(b)

Figure 46. Hemocompatibility assay results of human erythrocytes treated with (a) $\mathrm{ZnO}$ nanostrucuture (ZnONS) and (b) bovine $\alpha$-lactalbumin (BLA) functionalized ZnONS of different concentrations. Trixton $\mathrm{X} 1 \%$ was employed as a control. All the data were expressed as mean \pm standard deviation, $n=3$. Reproduced from [326] with permission of Elsevier.

Inhibition of Hemolysis

As discussed in Figure 26, biosynthesized AgNPs/ZnO hybrid exhibits excellent antibacterial activity than pure ZnO NPs against S. aureus and E. coli, especially for former bacterial strain. This is evidenced by bacterial viability and the zone of inhibition results [282]. The excellent bactericidal activity of green AgNPs/ZnO NPs hybrid derives from the release of silver ions from AgNPs and $\mathrm{Zn}^{2+}$ ions from $\mathrm{ZnO}$ to the culture medium. However, released $\mathrm{Ag}^{+}$ions from AgNPs of the hybrid are also toxic to various mammalian cell lines [14]. Figure 47a shows the percentage hemolysis of $\mathrm{RBC}$ s upon exposure to bulk $\mathrm{ZnO}$, green $\mathrm{ZnO} \mathrm{NPs}$ and $\mathrm{AgNPs} / \mathrm{ZnO}$ nanocomposite for $2 \mathrm{~h}$. It is apparent that AgNPs/ZnO hybrid possesses higher hemolytic activity than ZnO NPs and bulk $\mathrm{ZnO}$. The hemolytic activity increases markedly with increasing AgNPs/ZnO doses, demonstrating dose-dependent hemolysis. Thus, AgNPs cause the lysis of RBCs rather than green $\mathrm{ZnO}$ from the hybrid. From the literature, AgNPs cause a dose-dependent hemolysis in RBCs due to the generation of ROS and oxidative stress [327]. In general, standalone ZnO NPs biosynthesized from the plant extracts are more effective to prevent hemolysis of RBCs than chemically prepared ZnO NPs. Very recently, Mahalakshmi et al. biosynthesized ZnO NPs using zinc acetate and Sesbania grandiflora leaf 
extract. In addition, $\mathrm{ZnO} N P s$ were also synthesized via co-precipitation method. They then treated human RBCs with green ZnO NPs and chemically prepared ZnO NPs [328]. The hemolytic activity of human RBCs exposed to both types of ZnO NPs was depicted in Figure 47b.

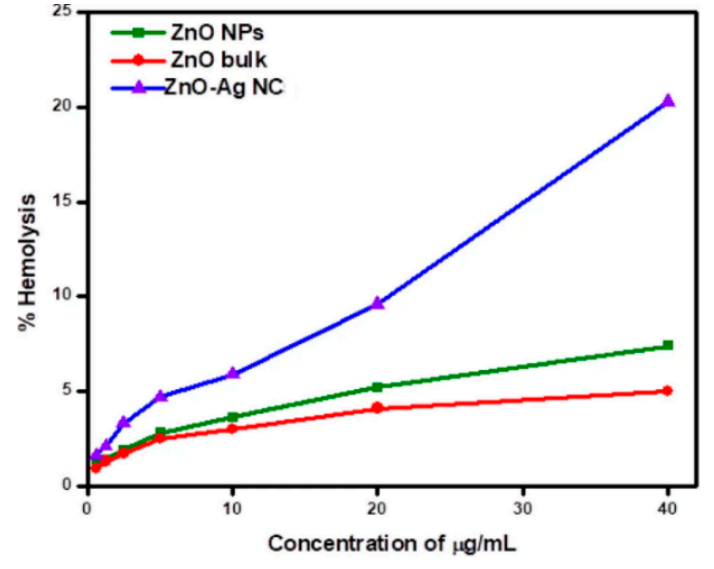

(a)

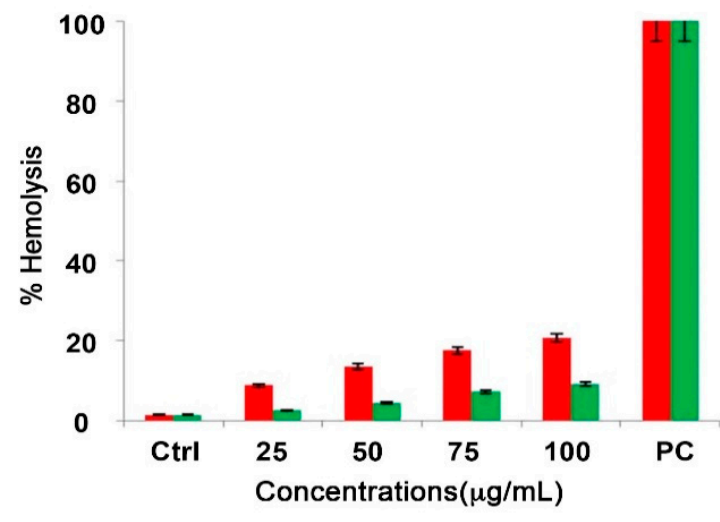

(b)

Figure 47. (a) The hemolytic activity of bulk $\mathrm{ZnO}$, biosynthesized $\mathrm{ZnO} \mathrm{NPs}$ and AgNPs/ZnO nanocomposite. Reproduced from [282] under the terms of Creative Commons License. (b) Percentage hemolysis of $\mathrm{ZnO}$ nanoparticles prepared by biosynthesis (green column) and co-precipitation (orange column). $0.1 \%$ Triton X-100 was employed as a positive control (PC). Reproduced from [328] with permission of Springer.

Jan et al. treated human erythrocytes with green ZnO NPs (19.58 nm); ZnO NPs were biosynthesized from zinc acetate dihydrate and leaf extract of Aquilegia pubiflora acting as an effective reducing and capping agent. The leaf extract contained several medicinal phytochemicals including flavonoids (orientin, isoorientin, isovitexin and vitexin), and hydroxycinnamic acid derivatives (ferulic acid, coumaric acid, and sinapic acid) [329]. The hemolytic activity of green $\mathrm{ZnO}$ NPs at doses of 50, 100,200 and $400 \mu \mathrm{g} / \mathrm{mL}$ was reported to be $0.48 \pm 0.23 \%, 0.73 \pm 0.1 \%, 1.05 \pm 0.12 \%$ and $1.24 \pm 0.14 \%$, respectively. Those phytochemicals rendered green $\mathrm{ZnO}$ NPs with insignificant hemolytic activity, i.e., biocompatible with erythrocytes. From a recent study of Rajapriya et al., spherical ZnO NPs (65.9 nm) synthesized from Cynara scolymus leaf extract at a dose of $100 \mu \mathrm{g} / \mathrm{mL}$ also had a low hemolytic activity of $0.5 \%$ for human RBCs [330]. Similarly, green ZnO NPs $(26.55 \mathrm{~nm})$ biosynthesized from aqueous zin acetate and Costus igneus leaf extract were biocompatible with goat RBCs as evidenced by low hemolytic activity. From hemolytic assay, the percentage hemolysis due to the nanoparticles at doses of 50, 100, 150 and $200 \mu \mathrm{g} / \mathrm{mL}$ was reported to be $0.536 \pm 0.005,0.583 \pm 0.005,0.595 \pm 0.003$, and $0.633 \pm 0.005$, respectively [331]. Overall, these results clearly demonstrate that ZnO NPs biosynthesized from the leaf extracts have no adverse effect towards RBCs. They can be classified as non-hemolytic on the basis of ASTM F756 standard, i.e., the percentage hemolysis is $<2 \%$ [322]. Table 2 summarizes the percentage hemolysis of RBCs upon exposure to nano- $\mathrm{ZnO}$ prepared from different processes. 
Table 2. The percentage hemolysis of erythrocytes treated with $\mathrm{ZnO}$ nanostructures.

\begin{tabular}{|c|c|c|c|c|c|c|}
\hline Material & Size, nm & Shape & $\begin{array}{l}\text { Synthetic } \\
\text { Process }\end{array}$ & $\begin{array}{c}\text { Dose, } \\
\mu \mathrm{g} / \mathrm{mL}\end{array}$ & $\begin{array}{l}\text { Percentage } \\
\text { Hemolysis }\end{array}$ & Ref. \\
\hline \multirow{2}{*}{$\mathrm{ZnO}$} & $<50$ & Particles & Commercial & 200 & 24 & [323] \\
\hline & $<50$ & Particles & Commercial & 400 & 38 & [323] \\
\hline $\mathrm{ZnO}+$ albumin & $<50$ & Particles & Commercial & 200 & $<2$ & [323] \\
\hline $\mathrm{ZnO}+$ albumin & $<50$ & Particles & Commercial & 400 & $<2$ & [323] \\
\hline \multirow{3}{*}{$\mathrm{ZnO}$} & $\begin{array}{l}47.8-52.5 \\
\text { (width) }\end{array}$ & Rod & Gel combustion & 50 & 20 & [325] \\
\hline & $\begin{array}{l}47.8-52.5 \\
\text { (width) }\end{array}$ & Rod & Gel combustion & 100 & 39.5 & [325] \\
\hline & $\begin{array}{c}47.8-52.5 \\
\text { (width) }\end{array}$ & Rod & Gel combustion & 250 & 65.2 & [325] \\
\hline \multirow{3}{*}{$\mathrm{ZnO}$} & 200 & Particles & Co-precipitation & 5 to 160 & $<5$ & [326] \\
\hline & 200 & Particles & Co-precipitation & 300 & 7.7 & [326] \\
\hline & 200 & Particles & Co-precipitation & 600 & 75.3 & [326] \\
\hline $\mathrm{FZnONS}_{\mathrm{BLA}}$ & 450 & Particles & Co-precipitation & 5 to 600 & $<3$ & [326] \\
\hline \multirow{4}{*}{$\mathrm{ZnO}$} & 19.58 & Particles & Green & 50 & $0.48 \pm 0.23$ & [329] \\
\hline & 19.58 & Particles & Green & 100 & $0.73 \pm 0.1$ & [329] \\
\hline & 19.58 & Particles & Green & 200 & $1.05 \pm 0.12$ & [329] \\
\hline & 19.58 & Particles & Green & 400 & $1.24 \pm 0.14$ & [329] \\
\hline $\mathrm{ZnO}$ & 65.9 & Particles & Green & 100 & 0.5 & [330] \\
\hline \multirow{4}{*}{$\mathrm{ZnO}$} & 26.55 & Particles & Green & 50 & $0.536 \pm 0.005$ & [331] \\
\hline & 26.55 & Particles & Green & 100 & $0.583 \pm 0.005$ & [331] \\
\hline & 26.55 & Particles & Green & 150 & $0.595 \pm 0.003$ & [331] \\
\hline & 26.55 & Particles & Green & 200 & $0.633 \pm 0.005$ & [331] \\
\hline \multirow{3}{*}{$\begin{array}{c}\text { AgNPs/ZnO } \\
\text { hybrid }\end{array}$} & 5 (AgNPs) & Particles & Bio-hydrothermal & 10 & $\sim 6.0$ & [282] \\
\hline & 5 (AgNPs) & Particles & Bio-hydrothermal & 20 & $\sim 9.1$ & [282] \\
\hline & 5 (AgNPs) & Particles & Bio-hydrothermal & 40 & $\sim 20.5$ & [282] \\
\hline
\end{tabular}

Finally, phytochemicals capped on ZnO NPs are also beneficial for reducing hemolysis of S. aureus infected RBCs. Very recently, Ahmar Rauf et al. biosynthesized ZnO NPs (10-50 nm) using zinc acetate and Bougainvillea flower extract. They then exposed RBCs to either green ZnO NPs, S. aureus, or combined S. aureus with ZnO NPs [332]. The virulence factor of $S$. aureus produces $\alpha$-hemolysin, leading to the pore formation in the plasma membranes of RBCs (Figure 48a). As such, S. aureus infected RBCs undergo a high hemolysis rate of $61 \%$. The hemolysis of RBCs reduces markedly to about $21 \%$ by co-culturing green $\mathrm{ZnO} N P$ s at a dose of $100 \mu \mathrm{g} / \mathrm{mL}$ with $S$. aureus. A further reduction in hemolysis of $S$. aureus infected RBCs can be achieved by treating with ZnO NPs at a dose of $300 \mu \mathrm{g} / \mathrm{mL}$ (Figure 48b). 

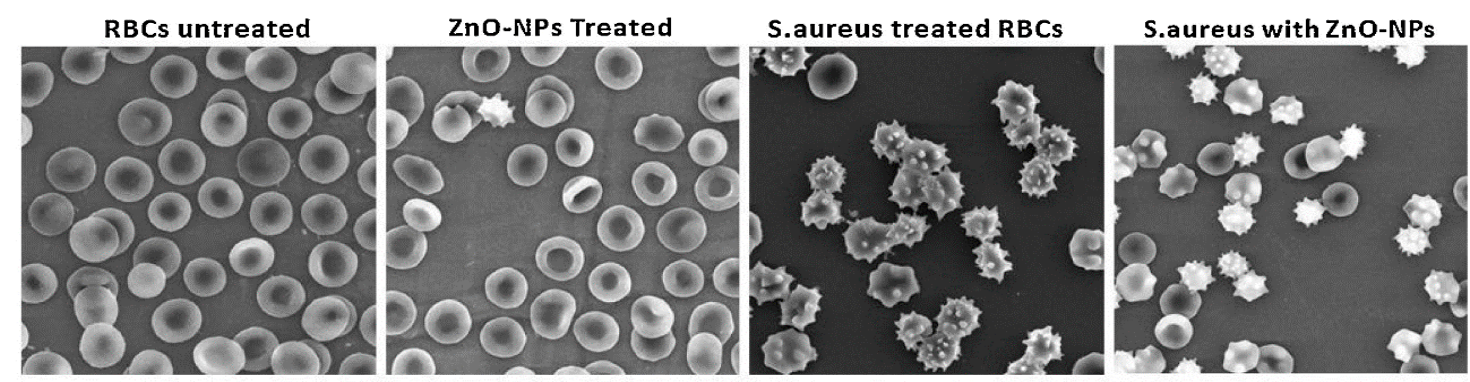

(a)

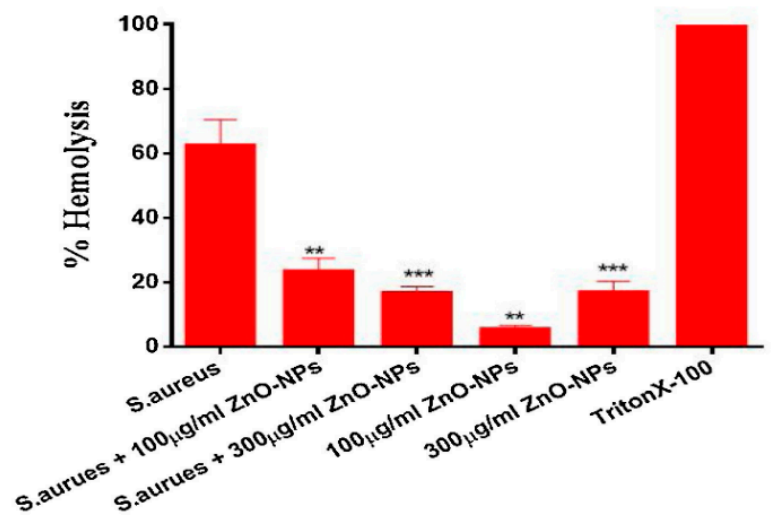

(b)

Figure 48. (a) SEM images showing lysis of RBCs by S. aureus and their inhibition by green ZnO NPs. Images from left to right: untreated RBCs, ZnO NPs treated RBCs, S. aureus infected RBCs, and RBCs co-cultured with S. aureus and ZnO NPs. (b) Inhibition of hemolysis in S. aureus infected RBCs by ZnO NPs. All data are expressed as the mean \pm standard deviation. ${ }^{* * *}$ for $p \leq 0.001$; $^{* *}$ for $p \leq 0.01$. Reproduced from [332] under a Creative Commons License.

\section{Immune Cells}

When $\mathrm{ZnO}$ NPs enter human body, they also come in direct contact with immune cells like macrophages, neutrophils, B-cells, T-cells, etc. The macrophages play an important role in innate and adaptive immunity for defending the host immune against foreign antigens through the recognition, processing and elimination. Macrophages remove foreign antigens from the tissues by means of phagocytosis [333]. In this respect, ZnO NPs with nanoscale dimension are phagocyted readily by macrophages and dissolved in lysosomes, releasing zinc ions accordingly. ZnO NPs can interact with white blood cells to activate innate immune system by triggering inflammatory responses and releasing pro-inflammatory cytokines such as tumor necrosis factor-alpha (TNF- $\alpha$ ), interleukin-6 (IL-6), and interleukin-1 $\beta$ (IL-1 $\beta$ ). The IL- $1 \beta$ activates macrophages at the inflammation site. This is followed by the subsequent secretion of other cytokines including TNF- $\alpha$ and IL-6. For instance, Chang et al. reported that ZnO NPs can induce lung inflammation by releasingTNF- $\alpha$ and IL- 6 via toll-like receptor (TLR) signaling pathways. Instillation of ZnO NPs into the tracheas of mice causes increased neutrophils and macrophages in bronchoalveolar lavage fluid (BALF), bronchioles and peribronchiolar areas [334]. In a recent study, Alghsham et al. also reported that ZnO NWs induce the production of TNF- $\alpha$ and IL-6 in cultured mouse macrophage cell line (RAW 264.7) and bone marrow macrophages obtained from the mice hind legs. From in vivo mouse model results, $\mathrm{ZnO}$ NWs facilitated the recruitment of macrophages and eosinophils into the lung and air-pouch [335].

The mechanisms responsible for cytotoxicity of $\mathrm{ZnO}$ nanomaterials on immune cells include the generation of ROS, the release of zinc ions, and the membrane lipid peroxidation [336-339]. The extent of nanotoxicity depends on the size, shape and concentration of $\mathrm{ZnO}$ nanomaterials. 
In particular, spherical $\mathrm{ZnO}$ NPs (10-30 nm) are more toxic than $\mathrm{ZnO}$ nanorods as expected [337]. Johnson et al. indicated that release of $\mathrm{Zn}^{2+}$ ions from $\mathrm{ZnO}$ NPs triggers the generation of excessive intracellular ROS, resulting in autophagic death of immune cells [338]. Roy et al. treated mouse primary peritoneal macrophages with $\mathrm{ZnO} N P s(\sim 50 \mathrm{~nm})$, resulting in the induction of ROS and membrane lipid peroxidation. These activated autophagy and apoptosis as evidenced by the cleavage of apoptotic caspases-3, -8, and -9. Furthermore, the apoptotic and autophagic cell death were inhibited considerably by treating with $\mathrm{N}$-acetylcysteine (NAC) for blocking the generation of ROS [339]. NAC was reported to be an effective antioxidant for inhibiting ROS generation, thus acting as ROS scavenger for macrophages [340]. The cytotoxicity of ZnO NPs in human acute monocytic leukemia cell line (THP-1) was also reduced through surface modification with polyethylene glycols (PEGs). PEGylation of ZnO NPs led to a decreased uptake of modified nanoparticles in THP-1 monocytes and macrophages by inhibiting the binding of NPs to blood proteins and macrophages [341].

Apart from NAC and PEGylation, green ZnO NPs synthesized from the plant extracts exhibit excellent anti-inflammatory properties by reducing the secretion of proinflammatory cytokines dramatically [342-344]. The anti-inflammatory activity of ZnO NPs is comparatively higher than that of AgNPs with 79\% and 69.1\% respectively [343]. Meanwhile, green ZnO NPs synthesized from Vernonia amygdalina leaves show good anti-inflammatory properties in the mice model due to the presence of flavonoids and tannins in the plant extracts. As a result, the inflammatory activity and pro-inflammatory cytokine level in the mice are reduced substantially [344]. In this respect, green $\mathrm{ZnO}$ NPs with good antimicrobial and anti-inflammatory properties are promising nanomaterials for the treatment of bacterial infections. Considering $\mathrm{ZnO}$ as an additive to improve the flavor, color, nutritional value and shelf-life of food, and a source of zinc in supplements, the risks of using $\mathrm{ZnO}$ NPs can be minimized by using nanoparticles biosynthesized from natural plant derivatives.

\section{Conclusions}

This review presents a comprehensive summary of literature studies on the fabrication, antibacterial activity, and photocatalytic bacterial inactivation of $\mathrm{ZnO}$ heterostructures under visible light. $\mathrm{ZnO}$ nanostructures of different dimensions and shapes with hexagonal wurtzite lattice can be prepared by means of vapor-, liquid-, and solid-phase processing techniques. Among these, wet chemical processing techniques including co-precipitation, hydrothermal/solvothermal treatment, hydrolysis-condensation, and microemulsion are a facile route to synthesize $\mathrm{ZnO}$ nanomaterials on a large scale at lower temperatures and costs compared to vapor-phase method.

$\mathrm{ZnO}$ nanostructures with positive surface charge are able to adhere and attach on negatively charged membrane via electrostatic interaction when they come in contact with bacteria. This effect disrupts bacterial cell membrane function, interferes electron transport chain, and deactivates bacterial enzyme, leading to final cell death. Apart from contact killing effect, other mechanisms such as the ROS production and released zinc ions have also been reported to be responsible for bactericidal activity of $\mathrm{ZnO}$ nanomaterials. The antibacterial activity of $\mathrm{ZnO}$ nanorod arrays against $E$. coli derives from the combined effect of these three mechanisms in which direct contact killing effect predominates [288]. The antimicrobial activity of $\mathrm{ZnO}$ nanostructures is size-, shape-, and concentrationdependent. In particular, green $\mathrm{ZnO}$ nanoparticles have the lowest MIC values against Gram-positive and Gram-negative bacterial strains compared with ZnO NPs prepared by hydrothermal/solvothermal, sol-gel and polyol techniques (Table 1). This can be attributed to green ZnO NPs exhibiting high purity and possessing bioactive phytocompounds, such as flavonoids and polyphenols for bactericidal activity $[216,217,229]$. Furthermore, phytochemicals of the plant extracts are very effective to reduce hemolysis of $S$. aureus infected RBCs and inflammatory response of white blood cells.

The modifications in nano- $\mathrm{ZnO}$ can be employed to enhance photocatalytic activity for the ROS generation. $\mathrm{ZnO}$ heterostructures modified with metal/non-metal dopants, carbon nanomaterials and other semiconductors show excellent photocatalytic bacterial inactivation under visible light. In particular, coupling nano- $\mathrm{ZnO}$ with $\mathrm{CuO}$ can yield $\mathrm{CuO} / \mathrm{ZnO}$ nanocomposite with enhanced 
photocatalytic activity under visible light. As such, photoexcited electrons are injected from $\mathrm{CuO}$ to the conduction band of $\mathrm{ZnO} N P$ s for generating reactive radical species. Consequently, $100 \% \mathrm{E}$. coli inactivation under visible light takes only $25 \mathrm{~min}$ [313]. Moreover, GO/ZnO nanocomposite also exhibits excellent photocatalytic bactericidal activity, showing a complete inactivation of $E$. coli in 60 min, with a 7-log reduction in bacterial cell density under visible light illumination [173].

Author Contributions: S.C.T. conceived and directed the research. Y.L., C.L. and S.C.T. contributed to the writing and editing the draft of this article. All authors have read and agreed to the published version of the manuscript.

Funding: Natural Science Foundation of Shandong Province, China (Grant Number: ZR2019MB053) and National Youth Science Foundation, China (Grant Number: 21703096) provided funding for this research.

Conflicts of Interest: The authors declare no conflict of interest.

\section{References}

1. Fletcher, S. Understanding the contribution of environmental factors in the spread of antimicrobial resistance. Environ. Health Prev. Med. 2015, 20, 243-252. [CrossRef]

2. Gill, A.S.; Morrissey, H.; Rahman, A. A systematic review and meta-analysis evaluating antibiotic prophylaxis in dental implants and extraction procedures. Medicina 2018, 54, 95. [CrossRef] [PubMed]

3. Pang, Z.; Raudonis, R.; Glick, B.R.; Lin, T.J.; Cheng, Z. Antibiotic resistance in Pseudomonas aeruginosa: Mechanisms and alternative therapeutic strategies. Biotechnol. Adv. 2019, 37, 177-192. [CrossRef] [PubMed]

4. Levin-Reisman, I.; Brauner, A.; Ronin, I.; Balaban, N.Q. Epistasis between antibiotic tolerance, persistence, and resistance mutations. Proc. Nat. Acad. Sci. USA 2019, 116, 14734-14739. [CrossRef] [PubMed]

5. O'Gara, J.P. Into the storm: Chasing the opportunistic pathogen Staphylococcus aureus from skin colonisation to life-threatening infections. Environ. Microbiol. 2017, 19, 3823-3833. [CrossRef] [PubMed]

6. Li, B.; Webster, T.J. Bacteria antibiotic resistance: New challenges and opportunities for implant-associated orthopaedic infections. J. Orthop. Res. 2018, 36, 22-32. [CrossRef] [PubMed]

7. Craft, K.M.; Nguyen, J.M.; Berg, L.J.; Townsend, S.D. Methicillin-resistant Staphylococcus aureus (MRSA): Antibiotic-resistance and the biofilm phenotype. Med. Chem. Commun. 2019, 10, 1231-1241. [CrossRef] [PubMed]

8. Beyth, N.; Houri-Haddad, Y.; Domb, A.; Khan, W.; Hazan, R. Alternative antimicrobial approach: Nano-antimicrobial materials. Evid. Based Complement. Altern. Med. 2015, 2015, 246012. [CrossRef]

9. Hemeg, H.A. Nanomaterials for alternative antibacterial therapy. Int. J. Nanomed. 2017, 12, 8211-8225. [CrossRef]

10. Choudhari, P.; Das, S.K. Bio-reduced graphene oxide as a nanoscale antimicrobial coating for medical devices. ACS Omega 2019, 4, 387-397. [CrossRef]

11. Tjong, S.C.; Chen, H. Nanocrystalline materials and coatings. Mater. Sci. Eng. R Rep. 2004, 45, 1-88. [CrossRef]

12. Tjong, S.C. Nanocrystalline Materials: Their Synthesis-Structure-Property Relationships and Applications, 2nd ed.; Elsevier: London, UK, 2013; ISBN 9780124077966.

13. Liao, C.; Li, Y.; Tjong, S.C. Graphene nanomaterials: Synthesis, biocompatibility, and cytotoxicity. Int. J. Mol. Sci. 2018, 19, 3564. [CrossRef] [PubMed]

14. Liao, C.; Li, Y.; Tjong, S.C. Bactericidal and cytotoxic properties of silver nanoparticles. Int. J. Mol. Sci. 2019, 20, 449. [CrossRef] [PubMed]

15. Limo, M.J.; Sola-Rabada, A.; Boix, E.; Thota, V.; Westcott, J.C.; Puddu, V.; Perry, C.C. Interactions between metal oxides and biomolecules: From fundamental understanding to applications. Chem. Rev. 2018, 118, 11118-11193. [CrossRef] [PubMed]

16. Baptista, P.V.; McCusker, M.P.; Carvalho, A.G.; Ferreira, D.A.; Mohan, N.M.; Martins, M.; Fernandes, A.R. Nano-strategies to fight multidrug resistant bacteria-"A battle of the titans". Front. Microbiol. 2018, 9, 1441. [CrossRef]

17. Yan, X.; He, B.; Liu, L.; Qu, G.; Shi, J.; Hu, L.; Jiang, G. Antibacterial mechanism of silver nanoparticles in Pseudomonas aeruginosa: Proteomics approach. Metallomics 2018, 10, 557-564. [CrossRef]

18. Chatterjee, A.K.; Chakraborty, R.; Basu, T. Mechanism of antibacterial activity of copper nanoparticles. Nanotechnology 2014, 25, 135101. [CrossRef] 
19. Ansari, M.A.; Khan, H.M.; Khan, A.A.; Sultan, A.; Azam, A. Synthesis and characterization of the antibacterial potential of $\mathrm{ZnO}$ nanoparticles against extended-spectrum $\beta$-lactamases-producing Escherichia coli and Klebsiella pneumoniae isolated from a tertiary care hospital of North India. Appl. Microbiol. Biotechnol. 2012, 94, 467-477. [CrossRef]

20. Lipovsky, A.; Tzitrinovich, Z.; Friedmann, H.; Applerot, G.; Gedanken, A.; Lubart, R. EPR study of visible light-induced ROS generation by nanoparticles of ZnO. J. Phys. Chem. C 2009, 113, 15997-16001. [CrossRef]

21. Prasanna, V.L.; Vijayaraghavan, R. Insight into the mechanism of antibacterial activity of ZnO: Surface defects mediated reactive oxygen species even in the dark. Langmuir 2015, 31, 9155-9162. [CrossRef]

22. Joe, A.; Park, S.H.; Shim, K.D.; Kim, D.J.; Jhee, K.H.; Lee, H.W.; Heo, C.H.; Kim, H.M.; Jang, E.S. Antibacterial mechanism of $\mathrm{ZnO}$ nanoparticles under dark conditions. J. Ind. Eng. Chem. 2017, 45, 430-439. [CrossRef]

23. Chauhan, A.; Verma, R.; Kumari, S.; Sharma, A.; Sandilya, P.; Li, X.; Batoo, K.M.; Imran, A.; Kulshrestha, S.; Kumar, R. Photocatalytic dye degradation and antimicrobial activities of pure and Ag-doped ZnO using Cannabis sativa leaf extract. Sci. Rep. 2020, 10, 7881. [CrossRef] [PubMed]

24. Liao, C.; Li, Y.; Tjong, S.C. Visible-light active titanium dioxide nanomaterials with bactericidal properties. Nanomaterials 2020, 10, 124. [CrossRef] [PubMed]

25. Wang, L.; Hu, C.; Shao, L. The antimicrobial activity of nanoparticles: Present situation and prospects for the future. Int. J. Nanomed. 2017, 12, 1227-1249. [CrossRef]

26. Da Silva, B.L.; Caetano, B.L.; Chiari-Andréo, B.G.; Pietro, R.C.; Chiavacci, L.A. Increased antibacterial activity of $\mathrm{ZnO}$ nanoparticles: Influence of size and surface modification. Colloids Surf. B Biointerfaces 2019, 177, 440-447. [CrossRef]

27. Paduraru, A.; Ghitulica, C.; Trusca, R.; Surdu, V.A.; Neacsu, I.A.; Holban, A.M.; Birca, A.C.; Iordache, F.; Vasile, B.S. Antimicrobial wound dressings as potential materials for skin tissue regeneration. Materials 2019, 12, 1859. [CrossRef]

28. Abinaya, C.; Marikkannan, M.; Manikandan, M.; Mayandi, J.; Suresh, P.; Shanmugaiah, V.; Ekstrum, C.; Pearce, J.M. Structural and optical characterization and efficacy of hydrothermal synthesized $\mathrm{Cu}$ and Ag doped zinc oxide nanoplate bactericides. Mater. Chem. Phys. 2016, 184, 172-182. [CrossRef]

29. Dwivedi, S.; Wahab, R.; Khan, F.; Mishra, Y.K.; Musarrat, J.; Al-Khedhairy, A.A. Reactive oxygen species mediated bacterial biofilm inhibition via zinc oxide nanoparticles and their statistical determination. PLOS ONE 2014, 9, e111289. [CrossRef]

30. Elumalai, K.; Velmurugan, S. Green synthesis, characterization and antimicrobial activities of zinc oxide nanoparticles from the leaf extract of Azadirachta indica (L.). App. Surf. Sci. 2015, 345, 329-336. [CrossRef]

31. Abbasi, B.A.; Iqbal, J.; Ahmad, R.; Zia, L.; Kanwal, S.; Mahmood, T.; Wang, C.; Chen, J.-T. Bioactivities of Geranium wallichianum leaf extracts conjugated with zinc oxide nanoparticles. Biomolecules 2020, 10, 38. [CrossRef]

32. Paladini, F.; Pollini, M. Antimicrobial silver nanoparticles for wound healing application: Progress and future trends. Materials 2019, 12, 2540. [CrossRef] [PubMed]

33. Tarannum, N.; Gautam, Y.K. Facile green synthesis and applications of silver nanoparticles: A state-of-the-art review. RSC Adv. 2019, 9, 34926-34948. [CrossRef]

34. Gliga, A.R.; Skoglund, S.; Odnevall Wallinder, I.; Fadeel, B.; Karlsson, H.L. Size-dependent cytotoxicity of silver nanoparticles in human lung cells: The role of cellular uptake, agglomeration and Ag release. Part. Fibre Toxicol. 2014, 11, 11. [CrossRef] [PubMed]

35. Kandpal, K.; Gupta, N. Investigations on high-K dielectrics for low threshold voltage and low leakage zinc oxide thin-film transistor, using material selection methodologies. J. Mater. Sci. Mater. Electron. 2016, 27, 5972-5981. [CrossRef]

36. Janotti, A.; Van de Walle, C.G. Fundamentals of zinc oxide as a semiconductor. Rep. Prog. Phys. 2009, 72, 126501. [CrossRef]

37. Wang, B.; Huang, W.; Chi, L.; Al-Hashimi, M.; Marks, T.J.; Facchetti, A. High-k gate dielectrics for emerging flexible and stretchable electronics. Chem. Rev. 2018, 118, 5690-5754. [CrossRef]

38. Rauwel, E.; Galeckas, A.; Rauwel, P. Photoluminescent cubic and monoclinic $\mathrm{HfO}_{2}$ nanoparticles: Effects of temperature and ambient. Mater. Res. Express 2014, 1, 015035. [CrossRef]

39. Zou, Y.; Zhang, Y.; Hu, Y.; Gu, H. Ultraviolet detectors based on wide bandgap semiconductor nanowire: A review. Sensors 2018, 18, 2072. [CrossRef] 
40. Chen, C.; Zhou, P.; Wang, N.; Ma, Y.; San, H. UV-assisted photochemical synthesis of reduced graphene oxide/ZnO nanowires composite for photoresponse enhancement in UV photodetectors. Nanomaterials 2018, 8, 26. [CrossRef]

41. Wu, D.; Wang, X.; Cao, K.; An, Y.; Song, X.; Liu, N.; Xu, F.; Gao, Z.; Jiang, K. ZnO nanorods with tunable aspect ratios deriving from oriented-attachment for enhanced performance in quantum-dot sensitized solar cells. Electrochim Acta 2017, 231, 1-12. [CrossRef]

42. Ghamsari, M.S.; Alamdari, S.; Han, W.; Park, H.H. Impact of nanostructured thin ZnO film in ultraviolet protection. Int. J. Nanomed. 2016, 12, 207-216. [CrossRef] [PubMed]

43. Zhang, G.; Xiao, Y.; Yan, J.; Xie, N.; Liu, R.; Zhang, Y. Ultraviolet light-degradation behavior and antibacterial activity of polypropylene/ZnO nanoparticles fibers. Polymers 2019, 11, 1841. [CrossRef] [PubMed]

44. Fouda, A.; Hassan, S.E.D.; Salem, S.S.; Shaheen, T.I. In-vitro cytotoxicity, antibacterial, and UV protection properties of the biosynthesized Zinc oxide nanoparticles for medical textile applications. Microb. Pathog. 2018, 125, 252-261. [CrossRef] [PubMed]

45. Kim, I.; Viswanathan, K.; Kasi, G.; Sadeghi, K.; Thanakkasaranee, S.; Seo, J. Poly(lactic Acid)/ZnO bionanocomposite films with positively charged $\mathrm{ZnO}$ as potential antimicrobial food packaging materials. Polymers 2019, 11, 1427. [CrossRef] [PubMed]

46. Abbas, M.; Buntinx, M.; Deferme, W.; Peeters, R. (Bio)polymer/ZnO nanocomposites for packaging applications: A review of gas barrier and mechanical properties. Nanomaterials 2019, 9, 1494. [CrossRef]

47. Meng, Y.Z.; Tjong, S.C. Rheology and morphology of compatibilized polyamide 6 blends containing liquid crystalline copolyesters. Polymer 1998, 39, 99-107. [CrossRef]

48. Meng, Y.Z.; Tjong, S.C.; Hay, A.S.; Wang, S.J. Synthesis and proton conductivities of phosphonic acid containing poly-(arylene ether)s. J. Polym. Sci. A Polym. Chem. 2001, 39, 3218-3226. [CrossRef]

49. Tjong, S.C.; Meng, Y.Z. Morphology and mechanical characteristics of compatibilized polyamide 6-liquid crystalline polymer composites. Polymer 1997, 38, 4609-4615. [CrossRef]

50. Liu, C.; Chan, K.W.; Shen, J.; Liao, C.; Yeung, K.W.K.; Tjong, S.C. Polyetheretherketone hybrid composites with bioactive nanohydroxyapatite and multiwalled carbon nanotube fillers. Polymers 2016, 8, 425. [CrossRef]

51. Chan, K.W.; Liao, C.; Wong, H.M.; Yeung, K.W.K.; Tjong, S.C. Preparation of polyetheretherketone composites with nanohydroxyapatite rods and carbon nanofibers having high strength, good biocompatibility and excellent thermal stability. RSC Adv. 2016, 6, 19417-19429. [CrossRef]

52. Liao, C.; Li, K.; Wong, H.M.; Tong, W.Y.; Yeung, K.W.K.; Tjong, S.C. Novel polypropylene biocomposites reinforced with carbon nanotubes and hydroxyapatite nanorods for bone replacements. Mater. Sci. Eng. C 2013, 13, 1380-1388. [CrossRef] [PubMed]

53. Liao, C.; Wong, H.M.; Yeung, K.W.K.; Tjong, S.C. The development, fabrication and material characterization of polypropylene composites reinforced with carbon nanofiber and hydroxyapatite nanorod hybrid fillers. Int. J. Nanomed. 2014, 9, 1299-1310. [CrossRef]

54. Liu, C.; Wong, H.M.; Yeung, K.W.; Tjong, S.C. Novel electrospun polylactic acid nanocomposite fiber mats with hybrid graphene oxide and nanohydroxyapatite reinforcements having enhanced biocompatibility. Polymers 2016, 8, 287. [CrossRef] [PubMed]

55. Dimapilis, E.A.; Hsu, C.S.; Mendoza, R.M.; Lu, M.C. Zinc oxide nanoparticles for water disinfection. Sustain. Environ. Res. 2018, 28, 47-56. [CrossRef]

56. Tian, C.; Zhang, Q.; Wu, A.; Jiang, M.; Liang, Z.; Jiang, B.; Fu, H. Cost-effective large-scale synthesis of ZnO photocatalyst with excellent performance for dye photodegradation. Chem. Commun. 2012, 48, 2858-2860. [CrossRef]

57. Raji, R.; Gopchandran, K.G. ZnO nanostructures with tunable visible luminescence: Effects of kinetics of chemical reduction and annealing. J. Sci. Adv. Mater. Dev. 2017, 2, 51-58. [CrossRef]

58. Kumar, S.G.; Rao, K.S. Zinc oxide based photocatalysis: Tailoring surface-bulk structure and related interfacial charge carrier dynamics for better environmental applications. RSC Adv. 2015, 5, 3306-3351. [CrossRef]

59. Sang, Y.; Liu, H.; Umar, A. Photocatalysis from UV/vis to near-infrared light: Toward full solar-light spectrum activity. Chem CatChem 2015, 7, 559-573. [CrossRef]

60. Ong, C.B.; Ng, L.Y.; Mohammad, A.W. A review of ZnO nanoparticles as solar photocatalysts: Synthesis, mechanisms and applications. Renew. Sustain. Energy Rev. 2018, 81, 536-551. [CrossRef]

61. Saleh, R.; Djaja, N.F. Transition-metal-doped ZnO nanoparticles: Synthesis, characterization and photocatalytic activity under UV light. Spectrochim. Acta Part A 2014, 130, 581-590. [CrossRef] 
62. Cardoza-Contreras, M.N.; Vásquez-Gallegos, A.; Vidal-Limon, A.; Romo-Herrera, J.M.; Aguila, S.; Contreras, O.E. Photocatalytic and antimicrobial properties of Ga doped and Ag doped ZnO nanorods for water treatment. Catalysts 2019, 9, 165. [CrossRef]

63. Naskar, A.; Lee, S.; Kim, K.S. Antibacterial potential of Ni-doped zinc oxide nanostructure: Comparatively more effective against Gram-negative bacteria including multidrug resistant strains. RSC Adv. 2020, 10, 1232-1242. [CrossRef]

64. Azfar, A.K.; Kasim, M.F.; Lokman, I.M.; Rafaie, H.A.; Mastuli, M.S. Comparative study on photocatalytic activity of transition metals ( $\mathrm{Ag}$ and $\mathrm{Ni}$ )-doped $\mathrm{ZnO}$ nanomaterials synthesized via sol-gel method. R. Soc. Open Sci. 2020, 7, 191590. [CrossRef] [PubMed]

65. Papadaki, D.; Mhlongo, G.H.; Motaung, D.E.; Nkosi, S.S.; Panagiotaki, K.; Chrsitaki, E.; Assimakopoulos, M.N.; Papadimitriou, V.C.; Rosei, F.; Kiriakidis, G.; et al. Hierarchically porous Cu-, Co-, and $\mathrm{Mn}$-doped platelet-like $\mathrm{ZnO}$ nanostructures and their photocatalytic performance for indoor air quality control. ACS Omega 2019, 4, 16429-16440. [CrossRef] [PubMed]

66. Mohammadi-Aloucheh, R.; Habibi-Yangjeh, A.; Bayrami, A.; Latifi-Navid, S.; Asadi, A. Enhanced anti-bacterial activities of $\mathrm{ZnO}$ nanoparticles and $\mathrm{ZnO} / \mathrm{CuO}$ nanocomposites synthesized using Vaccinium arctostaphylos L. fruit extract. Artif. Cells Nanomed. B 2018, 46, 1200-1209. [CrossRef]

67. Liao, C.; Jin, Y.; Li, Y.; Tjong, S.C. Interactions of ZnO nanostructures with mammalian cells: Cytotoxicity and photocatalytic toxicity. Int. J. Mol. Sci. 2020, 21, 6305. [CrossRef]

68. Wang, Q.; Li, S.; He, Q.; Zhu, W.; He, D.; Peng, F.; Lei, L.; Zhang, L.; Zhang, Q.; Tan, L.; et al. Reciprocating compression of $\mathrm{ZnO}$ probed by $\mathrm{X}$-ray diffraction: The size efect on structural properties under high pressure. Inorg. Chem. 2018, 57, 5380-5388. [CrossRef]

69. Yan, X.; Dong, H.; Li, Y.; Lin, C.; Park, C.; He, D.; Yang, W. Phase transition induced strain in ZnO under high pressure. Sci. Rep. 2016, 6, 24958. [CrossRef]

70. Razavi-Khosroshahi, H.; Edalati, K.; Wu, J.; Nakashima, Y.; Arita, M.; Ikoma, Y.; Sadakiyo, M.; Inagaki, Y.; Staykov, A.; Yamauchi, M.; et al. High-pressure zinc oxide phase as visible-light-active photocatalyst with narrow band gap. J. Mater. Chem. A 2017, 5, 20298-20303. [CrossRef]

71. Hidalgo-Jimenez, J.; Wang, Q.; Edalati, K.; Cubero-Sesin, J.M.; Razavi-Khosroshahi, H.; Ikoma, Y.; Gutierrez-Fallas, D.; Dittel-Meza, F.A.; Rodriguez-Rufino, J.C.; Fuji, M.; et al. Phase transformations, vacancy formation and variations of optical and photocatalytic properties in $\mathrm{TiO}_{2}-\mathrm{ZnO}$ composites by high-pressure torsion. Int. J. Plast. 2020, 124, 170-185. [CrossRef]

72. Ozgur, U.; Alivov, Y.I.; Liu, C.; Teke, A.; Reshchikov, M.A.; Doganl, S.; Avrutin, V.; Cho, J.S.; Morkoc, H. A comprehensive review of $\mathrm{ZnO}$ materials and devices. J. Appl. Phys. 2005, 98, 041301. [CrossRef]

73. Kamble, A.S.; Sinha, B.B.; Chung, K.; Gil, M.G.; Burungale, V.; Park, C.J.; Kim, J.H.; Patil, P.S. Effect of hydroxide anion generating agents on growth and properties of $\mathrm{ZnO}$ nanorod arrays. Electrochim. Acta 2014, 149, 386-393. [CrossRef]

74. Wang, Z.L. Nanostructures of zinc oxide. Mater. Today 2004, 7, 26-33. [CrossRef]

75. Mora-Fonz, D.; Lazauskas, T.; Farrow, M.R.; Catlow, R.A.; Woodley, S.M.; Sokol, A.A. Why are polar surfaces of ZnO stable? Chem. Mater. 2017, 29, 5306-5320. [CrossRef]

76. Rana, A.U.; Lee, J.Y.; Shahid, A.; Kim, H.-S. Growth method-dependent and defect density-oriented structural, optical, conductive, and physical properties of solution-grown $\mathrm{ZnO}$ nanostructures. Nanomaterials 2017, 7, 266. [CrossRef]

77. Araujo, E.A., Jr.; Nobre, F.X.; da Silva Sousa, G.; Cavalcante, L.S.; Santos, M.R.; Souza, F.L.; de Matos, J.M. Synthesis, growth mechanism, optical properties and catalytic activity of $\mathrm{ZnO}$ microcrystals obtained via hydrothermal processing. RSC Adv. 2017, 7, 24263. [CrossRef]

78. Napi, M.L.; Sultan, S.M.; Ismail, R.; How, K.W.; Ahmad, M.K. Electrochemical-based biosensors on different zinc oxide nanostructures: A review. Materials 2019, 12, 2985. [CrossRef]

79. Karnati, P.; Haque, A.; Taufique, M.F.N.; Ghosh, K. A Systematic study on the structural and optical properties of vertically aligned zinc oxide nanorods grown by high pressure assisted pulsed laser deposition technique. Nanomaterials 2018, 8, 62. [CrossRef]

80. Ching, K.L.; Li, G.; Ho, Y.L.; Kwok, H.S. The role of polarity and surface energy in the growth mechanism of $\mathrm{ZnO}$ from nanorods to nanotubes. CrystEngComm 2016, 18, 779-786. [CrossRef]

81. Leelavathi, A.; Madras, G.; Ravishankar, N. Origin of enhanced photocatalytic activity and photoconduction in high aspect ratio ZnO nanorods. Phys. Chem. Chem. Phys. 2013, 15, 10795-10802. [CrossRef] 
82. Samadi, M.; Zirak, M.; Naseri, A.; Kheirabadi, M.; Ebrahimi, M.; Moshfegh, A.Z. Design and tailoring of one-dimensional $\mathrm{ZnO}$ nanomaterials for photocatalytic degradation of organic dyes: A review. Res. Chem. Intermed. 2019, 45, 2197-2254. [CrossRef]

83. Chaudhary, S.; Umar, A.; Bhasin, K.K.; Baskoutas, S. Chemical sensing applications of ZnO nanomaterials. Materials 2018, 11, 287. [CrossRef] [PubMed]

84. Ishioka, J.; Kogure, K.; Ofuji, K.; Kawaguchi, K.; Jeem, M.; Kato, T.; Shibayama, T.; Watanabe, S. In situ direct observation of photocorrosion in $\mathrm{ZnO}$ crystals in ionic liquid using a laser-equipped high-voltage electron microscope. AIP Adv. 2017, 7, 035220. [CrossRef]

85. Han, J.; Qiu, W.; Gao, W. Potential dissolution and photo-dissolution of ZnO thin films. J. Hazard. Mater. 2010, 178, 115-122. [CrossRef] [PubMed]

86. Zhang, L.; Jeem, M.; Okamoto, K.; Watanabe, S. Photochemistry and the role of light during the submerged photosynthesis of zinc oxide nanorods. Sci. Rep. 2018, 8, 177. [CrossRef] [PubMed]

87. Zhang, L.; Cheng, H.; Zong, R.; Zhu, Y. Photocorrosion suppression of ZnO nanoparticles via hybridization with graphite-like carbon and enhanced photocatalytic activity. J. Phys. Chem. C 2009, 113, 2368-2374. [CrossRef]

88. Han, C.; Yang, M.Q.; Weng, B.; Xu, X.J. Improving the photocatalytic activity and anti-photocorrosion of semiconductor $\mathrm{ZnO}$ by coupling with versatile carbon. Phys. Chem. Chem. Phys. 2014, 16, 16891-16903. [CrossRef]

89. Peng, Y.; Ji, J.; Chen, D. Ultrasound assisted synthesis of ZnO/reduced graphene oxide composites with enhanced photocatalytic activity and anti-photocorrosion. Appl. Surf. Sci. 2015, 356, 762-768. [CrossRef]

90. Zhang, Y.; Mandal, R.; Ratchford, D.C.; Anthony, R.; Yeom, J. Si nanocrystals/ZnO nanowires hybrid structures as immobilized photocatalysts for photodegradation. Nanomaterials 2020, 10, 491. [CrossRef]

91. Rodwihok, C.; Wongratanaphisan, D.; Ngo, Y.L.; Khandelwal, M.; Hur, S.H.; Chung, J.S. Effect of GO additive in $\mathrm{ZnO} / \mathrm{rGO}$ nanocomposites with enhanced photosensitivity and photocatalytic activity. Nanomaterials 2019, 9, 1441. [CrossRef]

92. Taylor, C.M.; Ramirez-Canon, A.; Wenk, J.; Mattia, D. Enhancing the photo-corrosion resistance of ZnO nanowire photocatalysts. J. Hazard. Mater. 2019, 378, 120799. [CrossRef] [PubMed]

93. Zhang, Q.; Xu, M.; You, B.; Zhang, Q.; Yuan, H.; Ostrikov, K. Oxygen vacancy-mediated ZnO nanoparticle photocatalyst for degradation of methylene blue. Appl. Sci. 2018, 8, 353. [CrossRef]

94. Ansari, S.A.; Khan, M.M.; Kalathil, S.; Nisar, A.; Lee, J.; Cho, M.H. Oxygen vacancy induced band gap narrowing of $\mathrm{ZnO}$ nanostructures by an electrochemically active biofilm. Nanoscale 2013, 5, 9238-9246. [CrossRef] [PubMed]

95. Tang, Y.; Zhou, H.; Zhang, K.; Ding, J.; Fan, T.; Zhang, D. Visible-light-active ZnO via oxygen vacancy manipulation for efficient formaldehyde photodegradation. Chem. Eng. J. 2015, 262, 260-267. [CrossRef]

96. Dash, P.; Manna, A.; Mishra, N.C.; Varma, S. Synthesis and characterization of aligned ZnO nanorods for visible light photocatalysis. Physica E 2019, 107, 38-46. [CrossRef]

97. Gupta, J.; Bahadur, D. Defect-mediated reactive oxygen species generation in Mg-substituted $\mathrm{ZnO}$ nanoparticles: Efficient nanomaterials for bacterial inhibition and cancer therapy. ACS Omega 2018, 3, 2956-2965. [CrossRef]

98. Mia, M.N.H.; Pervez, M.F.; Hossain, M.K.; Rahman, M.R.; Uddin, M.J.; Al Mashud, M.A.; Ghosh, H.K.; Hoq, M. Influence of $\mathrm{Mg}$ content on tailoring optical bandgap of Mg-doped $\mathrm{ZnO}$ thin film prepared by sol-gel method. Results Phys. 2017, 7, 2683-2691. [CrossRef]

99. Kasi, G.; Seo, J. Influence of Mg doping on the structural, morphological, optical, thermal, and visible-light responsive antibacterial properties of $\mathrm{ZnO}$ nanoparticles synthesized via co-precipitation. Mater. Sci. Eng. C 2019, 98, 717-725. [CrossRef]

100. Ma, Z.; Ren, F.; Ming, X.; Long, Y.; Volinsky, A.A. Cu-doped ZnO electronic structure and optical properties studied by first-principles calculations and experiments. Materials 2019, 12, 196. [CrossRef]

101. Modwi, A.; Ghanem, M.A.; Al-Mayouf, A.M.; Houas, M. Lowering energy band gap and enhancing photocatalytic properties of $\mathrm{Cu} / \mathrm{ZnO}$ composite decorated by transition metals. J. Mol. Struct. 2018, 1173, 1-6. [CrossRef]

102. Gupta, J.; Bahadur, D. Visible light sensitive mesoporous $\mathrm{Cu}$-substituted $\mathrm{ZnO}$ nano assembly for enhanced photocatalysis, bacterial inhibition, and noninvasive tumor regression, ACS Sustain. Chem. Eng. 2017, 5, 8702-8709. [CrossRef] 
103. Bhuyan, T.; Sharma, R.; Anand, S. A comparative study of pure and copper (Cu)-doped ZnO nanorods for antibacterial and photocatalytic applications with their mechanism of action. J. Nanopart. Res. 2015, 17, 288. [CrossRef]

104. Rajivgandhi, G.N.; Ramachandran, G.; Alharbi, N.S.; Kadaikunnan, S.; Khaleed, J.M.; Manokaran, N.; Li, W.J. Substantial effect of $\mathrm{Cr}$ doping on the antimicrobial activity of $\mathrm{ZnO}$ nanoparticles prepared by ultrasonication process. Mater. Sci. Eng. B 2021, 263, 114817. [CrossRef]

105. Jacob, N.M.; Madras, G.; Kottam, N.; Thomas, T. Multivalent Cu-doped ZnO nanoparticles with full solar spectrum absorbance and enhanced photoactivity. Ind. Eng. Chem. Res. 2014, 53, 5895-5904. [CrossRef]

106. Tsuzuki, T.; He, R.; Dodd, A.; Saunders, M. Challenges in determining the location of dopants, to study the influence of metal doping on the photocatalytic activities of $\mathrm{ZnO}$ nanopowders. Nanomaterials 2019, 9, 481. [CrossRef] [PubMed]

107. Ma, Q.; Lv, X.; Wang, Y.; Chen, J. Optical and photocatalytic properties of Mn doped flower-like ZnO hierarchical structures. Opt. Mater. 2016, 60, 86-93. [CrossRef]

108. Li, W.; Wang, G.; Chen, C.; Liao, J.; Li, Z. Enhanced visible light photocatalytic activity of ZnO nanowires doped with $\mathrm{Mn}^{2+}$ and $\mathrm{Co}^{2+}$ ions. Nanomaterials 2017, 7, 20. [CrossRef]

109. Achouri, F.; Corbel, S.; Balan, L.; Mozet, K.; Girot, E.; Medjahdi, G.; Said, M.B.; Ghrabi, A.; Schneider, R. Porous Mn-doped $\mathrm{ZnO}$ nanoparticles for enhanced solar and visible light photocatalysis. Mater. Des. 2016, 101, 309-316. [CrossRef]

110. Han, X.; Wahl, S.; Russo, P.A.; Pinna, N. Cobalt-assisted morphology and assembly control of Co-doped ZnO nanoparticles. Nanomaterials 2018, 8, 249. [CrossRef]

111. Yin, Q.; Qiao, R.; Li, Z.; Zhang, X.L.; Zhu, L. Hierarchical nanostructures of nickel-doped zinc oxide: Morphology controlled synthesis and enhanced visible-light photocatalytic activity. J. Alloy Compd. 2015, 618, 318-325. [CrossRef]

112. Singh, P.; Kumar, R.; Singh, R.K. Progress on transition metal-doped ZnO nanoparticles and its application. Ind. Eng. Chem. Res. 2019, 58, 17130-17163. [CrossRef]

113. Bora, T.; Zoepfl, D.; Dutta, J. Importance of plasmonic heating on visible light driven photocatalysis of gold nanoparticle decorated zinc oxide nanorods. Sci. Rep. 2016, 6, 26913. [CrossRef] [PubMed]

114. Sarma, B.; Sarma, B.K. Fabrication of Ag/ZnO heterostructure and the role of surface coverage of $\mathrm{ZnO}$ microrods by Ag nanoparticles on the photophysical and photocatalytic properties of the metal-semiconductor system. Appl. Surf. Sci. 2017, 410, 557-565. [CrossRef]

115. Liu, Q.; Liu, E.; Li, J.; Qiu, Y.; Chen, R. Rapid ultrasonic-microwave assisted synthesis of spindle-like Ag/ZnO nanostructures and their enhanced visible-light photocatalytic and antibacterial activities. Catal. Today 2020, 339, 391-402. [CrossRef]

116. Lyadov, N.M.; Gumarov, A.I.; Kashapov, R.N.; Noskov, A.I.; Valeev, V.F.; Nuzhdin, V.I.; Bazarov, V.V.; Khaibullin, R.I.; Faizrakhmanov, I.A. Structure and optical properties of $\mathrm{ZnO}$ with silver nanoparticles. Semiconductors 2016, 50, 43-49. [CrossRef]

117. Liu, H.; Hu, Y.; Zhang, Z.; Liu, Z.; Jia, H.; Xu, B. Synthesis of spherical Ag/ZnO heterostructural composites with excellent photocatalytic activity under visible light and UV irradiation. Appl. Surf. Sci. 2015, 355, 644-652. [CrossRef]

118. Raji, R.; Sibi, K.S.; Gopchandran, K.G. ZnO: Ag nanorods as efficient photocatalysts: Sunlight driven photocatalytic degradation of sulforhodamine B. Appl. Surf. Sci. 2018, 427 Pt B, 863-875. [CrossRef]

119. Chamorro, W.; Ghanbaja, J.; Battie, Y.; Naciri, A.E.; Soldera, F.; Mücklich, F.; Horwat, D. Local structure-driven localized surface plasmon absorption and enhanced photoluminescence in $\mathrm{ZnO}-\mathrm{Au}$ thin films. J. Phys. Chem. C 2016, 120, 29405-29413. [CrossRef]

120. Zhang, J.; Tse, K.; Wong, M.; Zhang, Y.; Zhu, J. A brief review of co-doping. Front. Phys. 2016, 11, 117405. [CrossRef]

121. Yan, F.; Wang, Y.; Zhang, J.; Lin, Z. Schottky or Ohmic metal-semiconductor contact: Influence on photocatalytic efficiency of $\mathrm{Ag} / \mathrm{ZnO}$ and $\mathrm{Pt} / \mathrm{ZnO}$ model systems. ChemSusChem 2014, 7, 101-104. [CrossRef]

122. Clavero, C. Plasmon-induced hot-electron generation at nanoparticle/metal-oxide interfaces for photovoltaic and photocatalytic devices. Nat. Photonics 2014, 8, 95-103. [CrossRef]

123. Furube, A.; Hashimoto, S. Insight into plasmonic hot-electron transfer and plasmon molecular drive: New dimensions in energy conversion and nanofabrication. NPG Asia Mater. 2017, 9, e454. [CrossRef] 
124. Krajczewski, J.; Kolataj, K.; Kudelski, A. Plasmonic nanoparticles in chemical analysis. RSC Adv. 2017, 7, 17559-17576. [CrossRef]

125. Wang, C.S.; Lin, H.Y.; Lin, J.M.; Chen, Y.F. Surface-plasmon-enhanced ultraviolet random lasing from ZnO nanowires assisted by Pt nanoparticles. Appl. Phys. Express 2012, 6, 062033. [CrossRef]

126. Pei, J.; Jiang, D.; Zhao, M.; Duan, Q.; Liu, R.; Sun, L.; Guo, Z.; Hou, J.; Qin, J.; Li, B.; et al. Controlled enhancement range of the responsivity in $\mathrm{ZnO}$ ultraviolet photodetectors by Pt nanoparticles. Appl. Surf. Sci. 2016, 389, 1056-1061. [CrossRef]

127. Fageria, P.; Gangopadhyay, S.; Pande, S. Synthesis of $\mathrm{ZnO} / \mathrm{Au}$ and $\mathrm{ZnO} / \mathrm{Ag}$ nanoparticles and their photocatalytic application using UV and visible light. RSC Adv. 2014, 4, 24962-24972. [CrossRef]

128. Ziashahabi, A.; Prato, M.; Dang, Z.; Poursalehi, R.; Naseri, N. The effect of silver oxidation on the photocatalytic activity of $\mathrm{Ag} / \mathrm{ZnO}$ hybrid plasmonic/metal-oxide nanostructures under visible light and in the dark. Sci. Rep. 2019, 9, 11839. [CrossRef]

129. Zhang, L.; Zhu, X.; Wang, Z.; Yun, S.; Guo, T.; Zhang, J.; Hu, T.; Jiang, J.; Chen, J. Synthesis of ZnO doped high valence $S$ element and study of photogenerated charges properties. RSC Adv. 2019, 9, 4422. [CrossRef]

130. Zhang, X.; Qin, J.; Hao, R.; Wang, L.; Shen, X.; Yu, R.; Limpanart, S.; Ma, M.; Liu, R. Carbon-doped ZnO nanostructures: Facile synthesis and visible light photocatalytic applications. J. Phys. Chem. C 2015, 119, 20544-20554. [CrossRef]

131. Lavand, A.B.; Malghe, Y.S. Synthesis, characterization, and visible light photocatalytic activity of nanosized carbon doped zinc oxide. Int. J. Photochem. 2015, 2015, 790153. [CrossRef]

132. Gionco, C.; Fabbri, D.; Calza, P.; Paganini, M.C. Photocatalytic tests of N-doped zinc oxide: A New interesting photocatalyst. J. Nanometer. 2016, 2016, 4129864. [CrossRef]

133. Kumari, R.; Sahai, A.; Goswami, N. Effect of nitrogen doping on structural and optical properties of ZnO nanoparticles. Prog. Nat. Sci-Mater. 2015, 25, 300-309. [CrossRef]

134. Lavand, A.B.; Malghe, Y.S. Synthesis, characterization and visible light photocatalytic activity of nitrogen-doped zinc oxide nanospheres. J. Asian Ceram. Soc. 2015, 3, 305-310. [CrossRef]

135. Gupta, R.; Eswar, N.K.; Modak, J.M.; Madras, G. Visible light driven efficient N and Cu co-doped ZnO for photoinactivation of Escherichia coli. RSC Adv. 2016, 6, 85675-85687. [CrossRef]

136. Wang, Y.; Cheng, J.; Yu, S.; Alcocer, E.J.; Shahid, M.; Wang, Z.; Pan, W. Synergistic effect of N-decorated and $\mathrm{Mn}^{2+}$ doped $\mathrm{ZnO}$ nanofibers with enhanced photocatalytic activity. Sci. Rep. 2016, 6, 32711. [CrossRef] [PubMed]

137. Georgakilas, V.; Perman, J.A.; Tucek, J.; Zboril, R. Broad family of carbon nanoallotropes: Classification, chemistry, and applications of fullerenes, carbon dots, nanotubes, graphene, nanodiamonds, and combined superstructures. Chem. Rev. 2015, 115, 4744-4822. [CrossRef]

138. Nair, R.R.; Blake, P.; Grigorenko, A.N.; Novoselov, K.S.; Booth, T.J.; Stauber, T.; Peres, N.M.; Geim, A.K. Fines structure constant defines visual transparency of graphene. Science 2008, 320, 1308. [CrossRef]

139. Hu, L.; Hecht, D.S.; Grüner, G. Carbon nanotube thin films: Fabrication, properties, and applications. Chem. Rev. 2010, 110, 5790-5844. [CrossRef]

140. Kim, H.; Wang, M.; Lee, S.K.; Kang, J.; Nam, J.D.; Ci, L.; Suhr, J. Tensile properties of millimeter-long multi-walled carbon nanotubes. Sci. Rep. 2017, 7, 9512. [CrossRef]

141. Kumar, P.; Huo, P.; Zhang, R.; Liu, B. Antibacterial properties of graphene-based nanomaterials. Nanomaterials 2019, 9, 737. [CrossRef]

142. Karahan, H.E.; Wiraja, C.; Xu, C.; Wei, J.; Wang, Y.; Wang, L.; Liu, F.; Chen, Y. Graphene materials in antimicrobial nanomedicine: Current status and future perspectives. Adv. Healthc. Mater. 2018, 7, 1701406. [CrossRef] [PubMed]

143. Al-Jumaili, A.; Alancherry, S.; Bazaka, K.; Jacob, M.V. Review on the antimicrobial properties of carbon nanostructures. Materials 2017, 10, 1066. [CrossRef] [PubMed]

144. He, L.; Tjong, S.C. Nanostructured transparent conductive films: Fabrication, characterization and applications. Mater. Sci. Eng. R Rep. 2016, 109, 1-101. [CrossRef]

145. He, L.; Tjong, S.C. Aqueous graphene oxide-dispersed carbon nanotubes as inks for the scalable production of all-carbon transparent conductive films. J. Mater. Chem. C 2016, 4, 7043-7051. [CrossRef]

146. He, L.; Liao, C.; Tjong, S.C. Scalable fabrication of high-performance transparent conductors using graphene oxide-stabilized single-walled carbon nanotube inks. Nanomaterials 2018, 8, 224. [CrossRef] 
147. Ma, Y.; Zhi, L. Graphene-based transparent conductive films: Material systems, preparation and applications. Small Methods 2019, 3, 1800199. [CrossRef]

148. He, L.; Tjong, S.C. Silver-decorated reduced graphene oxides as novel building blocks for transparent conductive films. RSC Adv. 2017, 7, 2058-2065. [CrossRef]

149. He, L.; Tjong, S.C. Low percolation threshold of graphene/polymer composites prepared by solvothermal reduction of graphene oxide in the polymer solution. Nanoscale Res. Lett. 2013, 8, 132. [CrossRef]

150. Tjong, S.C. Polymer nanocomposite bipolar plates reinforced with carbon nanotubes and graphite nanosheets. Energy Environ. Sci. 2011, 4, 605-626. [CrossRef]

151. Albero, J.; Mateo, D.; Garcia, H. Graphene-based materials as efficient photocatalysts for water splitting. Molecules 2019, 24, 906. [CrossRef]

152. Khazi-Syed, A.; Hasan, M.T.; Campbell, E.; Gonzalez-Rodriguez, R.; Naumov, A.V. Single-walled carbon nanotube-assisted antibiotic delivery and imaging in $\mathrm{S}$. epidermidis strains addressing antibiotic resistance. Nanomaterials 2019, 9, 1685. [CrossRef] [PubMed]

153. Bellamkonda, S.; Thangavel, S.; Hafeez, H.Y.; Neppolian, B.; Ranga Rao, G. Highly active and stable multi-walled carbon nanotubes-graphene- $\mathrm{TiO}_{2}$ nanohybrid: An efficient non-noble metal photocatalyst for water splitting. Catal. Today 2019, 321-322, 120-127. [CrossRef]

154. Rauwel, P.; Galeckas, A.; Ducroquet, F.; Rauwel, E. Selective photocurrent generation in $\mathrm{HfO}_{2}$ and carbon nanotube hybrid nanocomposites under ultra-violet and visible photoexcitations. Mater. Lett. 2019, 246, 45-48. [CrossRef]

155. Bobrinetskiy, A.I.; Knezevic, N.Z. Graphene-based biosensors for on-site detection of contaminants in food. Anal. Methods 2018, 10, 5061-5070. [CrossRef]

156. Peña-Bahamonde, J.; Nguyen, H.N.; Fanouraki, S.K.; Rodriques, D.F. Recent advances in graphene-based biosensor technology with applications in life sciences. J. Nanobiotechnol. 2018, 16, 75. [CrossRef]

157. Campbell, E.; Hasan, M.T.; Pho, C.; Callaghan, K.; Naumov, A.V. Graphene oxide as a multifunctional platform for intracellular delivery, imaging, and cancer sensing. Sci. Rep. 2019, 9, 416. [CrossRef] [PubMed]

158. Maiti, D.; Tong, X.; Mou, X.; Yang, K. Carbon-based nanomaterials for biomedical applications: A recent study. Front. Pharmacol. 2019, 9, 1401. [CrossRef]

159. Plachá, D.; Jampilek, J. Graphenic materials for biomedical applications. Nanomaterials 2019, 9, 1758. [CrossRef]

160. Mohamed, R.M.; Shawky, A. CNT supported Mn-doped ZnO nanoparticles: Simple synthesis and improved photocatalytic activity for degradation of malachite green dye under visible light. Appl. Nanosci. 2018, 8, 1179-1188. [CrossRef]

161. Tie, W.; Bhattacharyya, S.S.; Wang, Y.; He, W.; Lee, S.H. Facile in-situ synthesis of a zinc oxide crystals/few-layered graphene flake composite for enhanced photocatalytic performance. J. Photochem. Photobiol. A 2017, 348, 89-95. [CrossRef]

162. Wang, F.; Zhou, Y.; Pan, X.; Lu, B.; Huang, J.; Ye, Z. Enhanced photocatalytic properties of ZnO nanorods by electrostatic self-assembly with reduced graphene oxide. Phys. Chem. Chem. Phys. 2018, 20, 6959-6969. [CrossRef] [PubMed]

163. Polat, E.O.; Balci, O.; Kakenov, N.; Uzlu, H.B.; Kocabas, C.; Dahiya, R. Synthesis of large area graphene for high performance in flexible optoelectronic devices. Sci. Rep. 2015, 5, 16744. [CrossRef] [PubMed]

164. Moreno-Bárcenas, A.; Perez-Robles, J.F.; Vorobiev, Y.V.; Ornelas-Soto, N.; Mexicano, A.; García, A.G. Graphene synthesis using a CVD reactor and a discontinuous feed of gas precursor at atmospheric pressure. J. Nanomater. 2018, 2018, 3457263. [CrossRef]

165. Chen, M.; Haddon, R.C.; Yan, R.; Bekyarova, E. Advances in transferring chemical vapor deposition graphene: A review. Mater. Horiz. 2017, 4, 1054-1063. [CrossRef]

166. Knapp, M.; Hoffmann, R.; Cimalla, V.; Ambacher, O. Wettability investigations and wet transfer enhancement of large-area CVD-graphene on aluminum nitride. Nanomaterials 2017, 7, 226. [CrossRef]

167. Guerrero-Contreras, J.; Caballero-Briones, F. Graphene oxide powders with different oxidation degree, prepared by synthesis variations of the Hummers method. Mater. Chem. Phys. 2015, 153, 209-220. [CrossRef]

168. Dreyer, D.R.; Park, S.; Bielawski, C.W.; Ruoff, R.S. The chemistry of graphene oxide. Chem. Soc. Rev. 2010, 39, 228-240. [CrossRef]

169. Park, S.; An, J.; Potts, J.R.; Velamakanni, A.; Murali, S.; Ruoff, R.S. Hydrazine-reduction of graphite- and graphene oxide. Carbon 2011, 49, 3019-3023. [CrossRef] 
170. Dave, K.; Park, K.H.; Dhayal, M. Two-step process for programmable removal of oxygen functionalities of graphene oxide: Functional, structural and electrical characteristics. RSC. Adv. 2015, 5, 95657-95665. [CrossRef]

171. Hayes, W.I.; Joseph, P.; Mughal, M.Z.; Papakonstantinou, P. Production of reduced graphene oxide via hydrothermal reduction in an aqueous sulfuric acid suspension and its electrochemical behavior. J. Solid State Electrochem. 2015, 19, 361-380. [CrossRef]

172. Pan, X.; Yang, M.Q.; Xu, Y.J. Morphology control, defect engineering and photoactivity tuning of ZnO crystals by graphene oxide-A unique 2D macromolecular surfactant. Phys. Chem. Chem. Phys. 2014, 16, 5589-5599. [CrossRef] [PubMed]

173. Wu, D.; An, T.; Li, G.; Wang, W.; Cai, Y.; Yip, H.Y.; Zhao, H.; Wong, P.K. Mechanistic study of the visible-light-driven photocatalytic inactivation of bacteria by graphene oxide-zinc oxide composite. Appl. Surf. Sci. 2015, 358 Pt A, 137-145. [CrossRef]

174. Osorio, A.G.; Silveira, I.C.; Bueno, V.L.; Bergmann, C.P. $\mathrm{H}_{2} \mathrm{SO}_{4} / \mathrm{HNO}_{3} / \mathrm{HCl}$-Functionalization and its effect on dispersion of carbon nanotubes in aqueous media. Appl. Surf. Sci. 2008, 255, 2485-2489. [CrossRef]

175. Chaudhary, D.; Singh, S.; Vankar, V.D.; Khare, N. ZnO nanoparticles decorated multi-walled carbon nanotubes for enhanced photocatalytic and photoelectrochemical water splitting. J. Photochem. Photobiol. A 2018, 351, 154-161. [CrossRef]

176. Ganose, A.M.; Scanlon, D.O. Band gap and work function tailoring of $\mathrm{SnO}_{2}$ for improved transparent conducting ability in photovoltaics. J. Mater. Chem. C. 2016, 4, 1467-1475. [CrossRef]

177. Hamrouni, A.; Moussa, N.; Parrino, F.; Di Paola, A.; Houas, A.; Parmisano, L. Sol-gel synthesis and photocatalytic activity of $\mathrm{ZnO}-\mathrm{SnO}_{2}$ nanocomposites. J. Mol. Catal. A Chem. 2014, 390. [CrossRef]

178. Xie, W.; Li, R.; Xu, Q. Enhanced photocatalytic activity of Se-doped $\mathrm{TiO}_{2}$ under visible light irradiation. Sci. Rep. 2018, 8, 8752. [CrossRef] [PubMed]

179. Kang, X.; Liu, S.; Dai, Z.; He, Y.; Song, X.; Tan, Z. Titanium dioxide: From engineering to applications. Catalysts 2019, 9, 191. [CrossRef]

180. Zhang, F.; Wang, X.; Liu, H.; Liu, C.; Wan, Y.; Long, Y.; Cai, Z. Recent advances and applications of semiconductor photocatalytic technology. Appl. Sci. 2019, 9, 2489. [CrossRef]

181. Maya-Trevino, M.L.; Guzman-Mar, J.L.; Hinojosa-Reyes, L.; Ramos-Delgado, N.A.; Maldonado, M.I.; Hernandez-Ramirez, A. Activity of the $\mathrm{ZnO}-\mathrm{Fe}_{2} \mathrm{O}_{3}$ catalyst on the degradation of Dicamba and 2,4-D herbicides using simulated solar light. Ceram. Int. 2014, 40, 8701-8708. [CrossRef]

182. Guo, L.; Wang, Y.; He, T. Photocatalytic reduction of $\mathrm{CO}_{2}$ over heterostructure semiconductors into value added chemicals. Chem. Rec. 2016, 16, 1918-1933. [CrossRef] [PubMed]

183. Moniz, S.J.; Shevlin, S.A.; Martin, D.J.; Guo, Z.X.; Tang, J. Visible-light driven heterojunction photocatalysts for water splitting-A critical review. Energy Environ. Sci. 2015, 8, 731-759. [CrossRef]

184. Wang, Y.; Wang, Q.; Zhan, X.; Wang, F.; Safdar, M.; He, J. Visible light driven type II heterostructures and their enhanced photocatalysis properties: A review. Nanoscale 2013, 5, 8326-8339. [CrossRef] [PubMed]

185. Sakib, A.A.; Masum, S.M.; Hinkis, J.; Islam, R.; Molla, M.A. Synthesis of CuO/ZnO nanocomposites and their application in photodegradation of toxic textile dye. J. Compos. Sci. 2019, 3, 91. [CrossRef]

186. Isac, L.; Cazan, C.; Enesca, A.; Andronic, L. Copper sulfide based heterojunctions as photocatalysts for dyes photodegradation. Front. Chem. 2019, 7, 694. [CrossRef] [PubMed]

187. Kołodziejczak-Radzimska, A.; Jesionowski, T. Zinc oxide-from synthesis to application: A review. Materials 2014, 7, 2833-2881. [CrossRef]

188. Hanif, M.A.; Lee, I.; Akter, J.; Islam, M.A.; Zahid, A.A.; Sapkota, K.P.; Hahn, J.R. Enhanced Photocatalytic and antibacterial performance of $\mathrm{ZnO}$ nanoparticles prepared by an efficient thermolysis method. Catalysts 2019, 9, 608. [CrossRef]

189. Baptista, A.; Silva, F.; Porteiro, J.; Míguez, J.; Pinto, G. Sputtering physical vapour deposition (PVD) coatings: A critical review on process improvement and market trend demands. Coatings 2018, 8, 402. [CrossRef]

190. Laurenti, M.; Cuda, V. Porous zinc oxide thin Films: Synthesis approaches and applications. Coatings 2018, 8, 67. [CrossRef]

191. Wen, X.; Zhang, Q.; Shao, Z. Magnetron sputtering for ZnO:Ga scintillation film production and its application research status in nuclear detection. Crystals 2019, 9, 263. [CrossRef]

192. Kim, M.; Osone, S.; Kim, T.; Higashi, H.; Seto, T. Synthesis of nanoparticles by laser ablation: A review. Kona Powder Part J. 2017, 34, 80-90. [CrossRef] 
193. Wisz, G.; Virt, I.; Sagan, P.; Potera, P.; Yavorskyi, R. Structural, optical and electrical properties of zinc oxide layers produced by pulsed laser deposition method. Nanoscale Res. Lett. 2017, 12, 253. [CrossRef] [PubMed]

194. Luo, C.Q.; Ling, F.C.; Rahman, M.A.; Phillips, M.; Ton-That, C.; Liao, C.; Shih, K.; Lin, J.; Tam, H.W.; Djurisic, A.B.; et al. Surface polarity control in ZnO films deposited by pulsed laser deposition. Appl. Surf. Sci. 2019, 483, 1129-1135. [CrossRef]

195. Kaassamani, S.; Kassem, W.; Tabbal, M. X-ray diffraction lineshape analysis of pulsed laser deposited ZnO nano-structured thin films. Appl. Surf. Sci. 2019, 473, 298-302. [CrossRef]

196. Sportelli, M.C.; Izzi, M.; Volpe, A.; Clemente, M.; Picca, R.A.; Ancona, A.; Lugarà, P.M.; Palazzo, G.; Cioffi, N. The pros and cons of the use of laser ablation synthesis for the production of silver nano-antimicrobials. Antibiotics 2018, 7, 67. [CrossRef]

197. Ostrowski, R.; Barcikowski, S.; Marczak, J.; Ostendorf, A.; Strzelec, M.; Walter, J. Health risks caused by particulate emission during laser cleaning. In Lasers in the Conservation of Artworks, Springer Proceedings in Physics, Madrid, Spain, 17-21 September 2007; Nimmrichter, J., Kautek, W., Schreiner, M., Eds.; Springer: Berlin/Heidelberg, Germany, 2007; Volume 116.

198. Rauwel, E.; Willinger, M.G.; Ducroquet, F.; Rauwel, P.; Matko, I.; Kiselev, D.; Pinna, N. Carboxylic acids as oxygen sources for the atomic layer deposition of high-k metal oxides. J. Phys. Chem. C 2008, 112, 12754-12759. [CrossRef]

199. Lu, Y.; Hsiech, C.; Su, G. The role of ALD-ZnO seed layers in the growth of ZnO nanorods for hydrogen sensing. Micromachines 2019, 10, 491. [CrossRef]

200. Laube, J.; Nübling, D.; Beh, H.; Gutsch, S.; Hiller, D.; Zacharias, M. Resistivity of atomic layer deposition grown ZnO: The influence of deposition temperature and post-annealing. Thin Solid Films 2016, 603, 377-381. [CrossRef]

201. Lee, B.J.; Jo, S.I.; Jeong, G.H. Synthesis of $\mathrm{ZnO}$ nanomaterials using low-cost compressed air as microwave plasma gas at atmospheric pressure. Nanomaterials 2019, 9, 942. [CrossRef]

202. Yang, P.; Yan, H.; Mao, S.; Russo, R.; Johnson, T.; Saykally, R.; Morris, N.; Pham, J.; He, R.; Cho, H.J. Controlled growth of $\mathrm{ZnO}$ nanowires and their optical properties. Adv. Funct. Mater. 2002, 12, 323-331. [CrossRef]

203. Wan, H.; Ruda, H. A study of the growth mechanism of CVD-grown ZnO nanowires. J. Mater. Sci. Mater. Electron. 2010, 21, 1014-1019. [CrossRef]

204. Tang, C.; Spencer, M.J.; Barnard, A.S. Activity of ZnO polar surfaces: An insight from surface energies. Phys. Chem. Chem. Phys. 2014, 16, 22139. [CrossRef] [PubMed]

205. Gao, P.X.; Ding, Y.; Wang, Z.L. Crystallographic orientation-aligned ZnO nanorods grown by a tin catalyst. Nano Lett. 2003, 3, 1315-1320. [CrossRef]

206. Zhao, X.; Shaymurat, T.; Pei, T.; Bai, L.; Cai, B.; Tong, Y.; Tang, Q.; Liu, Y. Low-temperature, catalyst-free vapor-solid growth of ultralong ZnO nanowires. Mater. Chem. Phys. 2012, 136, 455-459. [CrossRef]

207. Hedrich, C.; Haugg, S.; Pacarizi, L.; Furlan, K.P.; Blick, R.H.; Zierold, R. Low-temperature vapor-solid growth of $\mathrm{ZnO}$ nanowhiskers for electron field emission. Coatings 2019, 9, 698. [CrossRef]

208. Ding, Y.; Gao, P.X.; Wang, Z.L. Catalyst-nanostructure interfacial lattice mismatch in determining the shape of VLS grown nanowires and nanobelts: A case of Sn/ZnO. J. Am. Chem. Soc. 2004, 126, 2066-2072. [CrossRef]

209. Kong, X.Y.; Wang, Z.L. Spontaneous polarization-induced nanohelixes, nanosprings, and nanorings of piezoelectric nanobelts. Nano Lett. 2003, 3, 1625-1631. [CrossRef]

210. Uekawa, N.; Yamashita, R.; Wu, Y.J.; Kakegawa, K. Effect of alkali metal hydroxide on formation processes of zinc oxide crystallites from aqueous solutions containing $\mathrm{Zn}(\mathrm{OH})_{4}{ }^{2-}$ ions. Phys. Chem. Chem. Phys. 2004, 6 , 442-446. [CrossRef]

211. He, G.; Huang, B.; Lin, Z.; Yang, W.; He, Q.; Li, L. Morphology transition of ZnO nanorod arrays synthesized by a two-step aqueous solution method. Crystals 2018, 8, 152. [CrossRef]

212. Akhtar, M.J.; Ahamed, M.; Kumar, S.; Khan, M.M.; Ahmad, J.; Alrokayan, S.A. Zinc oxide nanoparticles selectively induce apoptosis in human cancer cells through reactive oxygen species. Int. J. Nanomed. 2012, 7, 845-857. [CrossRef]

213. Cao, D.; Gong, S.; Shu, X.; Zhu, D.; Liang, S. Preparation of ZnO nanoparticles with high dispersibility based on oriented attachment (OA) process. Nanoscale Res. Lett. 2019, 14, 210. [CrossRef] [PubMed]

214. Ali, A.; Ambreen, S.; Javed, R.; Tabassum, S.; Haq, I.U.; Zia, M. ZnO nanostructure fabrication in different solvents transforms physio-chemical, biological and photodegradable properties. Mater. Sci. Eng. C 2017, 74, 137-145. [CrossRef] [PubMed] 
215. Pourrahimi, A.M.; Liu, D.; Pallon, L.K.; Andersson, R.L.; Abad, A.M.; Lagaron, J.M.; Hedenqvist, M.S.; Strom, V.; Gedde, U.W.; Olsson, R.T. Water-based synthesis and cleaning methods for high purity ZnO nanoparticles-Comparing acetate, chloride, sulphate and nitrate zinc salt precursors. RSC Adv. 2014, 4, 35568-35577. [CrossRef]

216. Nithya, K.; Kalyanasundharam, S. Effect of chemically synthesis compared to biosynthesized ZnO nanoparticles using aqueous extract of $C$. halicacabum and their antibacterial activity. OpenNano 2019, 4, 100024. [CrossRef]

217. Kumar, B.; Smita, K.; Cumbal, L.; Debut, A. Green approach for fabrication and applications of zinc oxide nanoparticles. Bioinorg. Chem. Appl. 2014, 2014, 523869. [CrossRef]

218. Nava, O.J.; Soto-Robles, C.A.; Gómez-Gutiérrez, C.M.; Vilchis-Nestor, A.R.; Castro-Beltrán, A.; Olivas, A.; Luque, P.A. Fruit peel extract mediated green synthesis of zinc oxide nanoparticles. J. Mol. Struct. 2017, 1147, 1-6. [CrossRef]

219. Thi, T.U.; Nguyen, T.T.; Thi, Y.D.; Thi, K.H.; Phan, B.T.; Pham, K.N. Green synthesis of ZnO nanoparticles using orange fruit peel extract for antibacterial activities. RSC Adv. 2020, 10, 23899. [CrossRef]

220. Rupa, E.J.; Kaliraj, L.; Abid, S.; Yang, D.C.; Jung, S.K. Synthesis of a zinc oxide nanoflower photocatalyst from sea buckthorn fruit for degradation of industrial dyes in wastewater treatment. Nanomaterials 2019, 9, 1692. [CrossRef]

221. Liu, Z.; Ya, J.; Lei, E. Effects of substrates and seed layers on solution growing ZnO nanorods. J. Solid State Electrochem. 2010, 14, 957-963. [CrossRef]

222. Tlemcani, T.S.; Justeau, C.; Nadaud, K.; Poulin-Vittrant, G.; Alquier, D. Deposition time and annealing effects of $\mathrm{ZnO}$ seed layer on enhancing vertical alignment of piezoelectric $\mathrm{ZnO}$ nanowires. Chemosensors 2019, 7, 7. [CrossRef]

223. Karim, S.S.; Takamura, Y.; Tue, P.T.; Tung, N.T.; Kazmi, J.; Dee, C.F.; Majlis, B.Y.; Mohamed, M.A. Developing conductive highly ordered zinc oxide nanorods by acetylacetonate-assisted growth. Materials 2020, 13, 1136. [CrossRef] [PubMed]

224. Matei, A.; Dumitrescu, L.; Cernica, I.; Tucureanu, V.; Mihalache, I.; Bita, B.; Danila, M.; Manciulea, I. Study of the influence of capping agents on the structural and optical properties of $\mathrm{ZnO}$ nanostructures. J. Optoelectron. Adv. M 2015, 17, 952-957.

225. Ramimoghadam, D.; Hussein, M.Z.; Taufiq-Yap, Y.H. The effect of sodium dodecyl sulfate (SDS) and cetyltrimethylammonium bromide (CTAB) on the properties of $\mathrm{ZnO}$ synthesized by hydrothermal method. Int. J. Mol. Sci. 2012, 13, 13275-13293. [CrossRef] [PubMed]

226. Thilagavathi, T.; Geetha, D. Nano ZnO structures synthesized in presence of anionic and cationic surfactant under hydrothermal process. Appl. Nanosci. 2014, 4, 127-132. [CrossRef]

227. Zhang, Y.; Newton, B.; Lewis, E.; Fu, P.P.; Kafoury, R.; Ray, P.C.; Yu, H. Cytotoxicity of organic surface coating agents used for nanoparticles synthesis and stability. Toxicol Vitr. 2015, 29, 762-768. [CrossRef]

228. Fukui, H.; Iwahashi, H.; Nishio, K.; Hagihara, Y.; Yoshida, Y.; Horie, M. Ascorbic acid prevents zinc oxide nanoparticle-Induced intracellular oxidative stress and inflammatory responses. Toxicol. Ind. Health 2017, 33, 687-695. [CrossRef]

229. Hossain, A.; Abdalla, Y.; Ali, M.A.; Masum, M.M.; Li, B.; Sun, G.; Meng, Y.; Wang, Y.; An, Q. Lemon-fruit-based green synthesis of zinc oxide nanoparticles and titanium dioxide nanoparticles against soft rot bacterial pathogen Dickeya dadantii. Biomolecules 2019, 9, 863. [CrossRef]

230. Dong, J.; Wu, J.; Hao, H.; Xing, J.; Liu, H.; Gao, H. Synthesis of ZnO nanocrystals and application in inverted polymer solar cells. Nanoscale Res. Lett. 2017, 12, 529. [CrossRef]

231. Qiu, J.; Weng, B.; Zhao, L.; Chang, C.; Shi, Z.; Li, X.; Kim, H.K.; Hwang, Y.H. Synthesis and characterization of flower-like bundles of $\mathrm{ZnO}$ nanosheets by a surfactant-free hydrothermal process. J. Nanomater. 2014, 2014, 281461. [CrossRef]

232. Napi, M.L.; Sultan, S.M.; Ismail, R.; Ahmad, M.K.; Chai, G.M. Optimization of a hydrothermal growth process for low resistance 1D fluorine-doped zinc oxide nanostructures. J. Nanomater. 2019, 2019, 4574507. [CrossRef]

233. Zhou, Q.; Wen, J.Z.; Zhao, P.; Anderson, W.A. Synthesis of vertically-aligned zinc oxide nanowires and their application as a photocatalyst. Nanomaterials 2017, 7, 9. [CrossRef] [PubMed] 
234. Zare, M.; Namratha, K.; Byrappa, K.; Surendra, D.M.; Yallappa, S.; Hungund, B. Surfactant assisted solvothermal synthesis of $\mathrm{ZnO}$ nanoparticles and study of their antimicrobial and antioxidant properties. J. Mater. Sci. Technol. 2018, 34, 1035-1043. [CrossRef]

235. Agnihotri, S.; Bajaj, G.; Mukherji, S.; Mukherji, S. Arginine-assisted immobilization of silver nanoparticles on $\mathrm{ZnO}$ nanorods: An enhanced and reusable antibacterial substrate without human cell cytotoxicity. Nanoscale 2015, 7, 7415-7429. [CrossRef] [PubMed]

236. Garino, N.; Limongi, T.; Dumontel, B.; Canta, M.; Racca, L.; Laurenti, M.; Castellino, M.; Casu, A.; Falqui, A.; Cauda, V. A microwave-assisted synthesis of zinc oxide nanocrystals finely tuned for biological applications. Nanomaterials 2019, 9, 212. [CrossRef]

237. Wojnarowicz, J.; Chudoba, T.; Gierlotka, S.; Lojkowski, W. Effect of microwave radiation power on the size of aggregates of ZnO NPs prepared using microwave solvothermal synthesis. Nanomaterials 2018, 8, 343. [CrossRef]

238. Sounart, T.L.; Liu, J.; Voight, J.A.; Hoe, M.; Spoerke, E.D.; McKenzie, B. Secondary nucleation and growth of ZnO. J. Am. Chem. Soc. 2007, 129, 15786-15793. [CrossRef]

239. Pung, S.Y.; Lee, W.P.; Aziz, A. Kinetic study of organic dye degradation using ZnO particles with different morphologies as a photocatalyst. Int. J. Inorg. Chem. 2012, 2012, 608183. [CrossRef]

240. Zhong, L.; Yun, K. Graphene oxide-modified ZnO particles: Synthesis, characterization, and antibacterial properties. Int. J. Nanomed. 2015, 10, 79-92. [CrossRef]

241. Tuan, P.V.; Phuong, T.T.; Tan, V.T.; Nguyen, S.X.; Khiem, N. In-situ hydrothermal fabrication and photocatalytic behavior of $\mathrm{ZnO} /$ reduced graphene oxide nanocomposites with varying graphene oxide concentrations. Mater. Sci. Semicond. Process. 2020, 115, 105114. [CrossRef]

242. Wang, Y.W.; Cao, A.; Jiang, Y.; Zhang, X.; Liu, J.H.; Liu, Y.; Wang, H. Superior antibacterial activity of zinc oxide/graphene oxide composites originating from high zinc concentration localized around bacteria. ACS Appl. Mater. Interfaces 2014, 6, 2791-2798. [CrossRef]

243. Rajveer, R.S.; Sharma, V.; Ronin, R.S.; Gupta, D.K.; Srivastava, S.; Agrawal, K.; Vijay, Y.K. Synthesis, characterization and enhanced antimicrobial activity of reduced graphene oxide-zinc oxide nanocomposite. Mater. Res. Express 2017, 4, 025401. [CrossRef]

244. Zhang, P.; Li, Z.; Zhang, S.; Shao, G. Recent advances in effective reduction of graphene oxide for highly improved performance toward electrochemical energy storage. Energy Environ Mater. 2018, 5, 1-12. [CrossRef]

245. Hsueh, Y.-H.; Hsieh, C.-T.; Chiu, S.-T.; Tsai, P.-H.; Liu, C.-Y.; Ke, W.-J. Antibacterial property of composites of reduced graphene oxide with nano-silver and zinc oxide nanoparticles synthesized using a microwave-assisted approach. Int. J. Mol. Sci. 2019, 20, 5394. [CrossRef] [PubMed]

246. Prema, D.; Prakash, J.; Vignesh, S.; Veluchamy, P.; Ramachandran, C.; Samal, D.B.; Oh, D.H.; Sahabudeen, S.; Venkatasubbu, G.D. Mechanism of inhibition of graphene oxide/zinc oxide nanocomposite against wound infection causing pathogens. Appl. Nanosci. 2020, 10, 827-849. [CrossRef]

247. Khan, M.F.; Ansari, A.H.; Hameedullah, M.; Ahmad, E.; Husain, F.M.; Zia, Q.; Baig, U.; Zaheer, M.; Alam, M.M.; Khan, A.M.; et al. Sol-gel synthesis of thorn-like ZnO nanoparticles endorsing mechanical stirring effect and their antimicrobial activities: Potential role as nano-antibiotics. Sci. Rep. 2016, 6, 27689. [CrossRef] [PubMed]

248. Danks, A.E.; Hall, S.R.; Schnepp, Z. The evolution of 'sol-gel' chemistry as a technique for materials synthesis. Mater. Horiz. 2016, 3, 91-112. [CrossRef]

249. Iannaccone, G.; Bernardi, A.; Suriano, R.; Bianchi, C.L.; Levi, M.; Turri, S.; Griffini, G. The role of sol-gel chemistry in the low temperature formation of $\mathrm{ZnO}$ buffer layers for polymer solar cells with improved performance. RSC Adv. 2016, 6, 46915-46924. [CrossRef]

250. Deshmukh, R.; Niederberger, M. Mechanistic aspects in the formation, growth and surface functionalization of metal oxide nanoparticles in organic solvents. Chem. Eur. J. 2017, 23, 8542-8570. [CrossRef]

251. Davis, K.; Yarbrough, R.; Froeschle, M.; White, J.; Rathnayake, H. Band gap engineered zinc oxide nanostructures via a sol-gel synthesis of solvent driven shape controlled crystal growth. RSC Adv. 2019, 9, 14638. [CrossRef]

252. Haque, M.J.; Bellah, M.M.; Hassan, M.R.; Rahman, S. Synthesis of ZnO nanoparticles by two different methods \& comparison of their structural, antibacterial, photocatalytic and optical properties. Nano Express 2020, 1, 010007. [CrossRef] 
253. Rodrigues, E.S.; Silva, M.S.; Azevedo, W.M.; Feitosa, S.S.; Stingl, A.; Farias, P.M. ZnO nanoparticles with tunable bandgap obtained by modified Pechini method. Appl. Phys. A 2019, 125, 504. [CrossRef]

254. Hingorani, S.; Pillai, V.; Kumar, P.; Multani, M.S.; Shah, D.O. Microemulsion mediated synthesis of zinc-oxide nanoparticles for varistor studies. Mater. Res. Bull. 1993, 28, 1303-1310. [CrossRef]

255. Pineda-Reyes, A.M.; Olvera, M. Synthesis of $\mathrm{ZnO}$ nanoparticles from water-in-oil (w/o) microemulsions. Mater. Chem. Phys. 2018, 203, 141-147. [CrossRef]

256. Bumajdad, A.; Madkour, M. In situ growth of $\mathrm{ZnO}$ nanoparticles in precursor-insensitive water-in-oil microemulsion as soft nanoreactors. Nanoscale Res. Lett. 2015, 10, 19. [CrossRef]

257. Loh, J.H.; Samanta, A.K.; Heng, P.W. Overview of milling techniques for improving the solubility of poorly water-soluble drugs. Asian J. Pharm. 2015, 10, 255-274. [CrossRef]

258. Manzoor, U.; Siddique, S.; Ahmed, R.; Noreen, Z.; Bokhari, H.; Ahmad, I. Antibacterial, structural and optical characterization of mechano-chemically prepared ZnO nanoparticles. PLoS ONE 2016, 11, e0154704. [CrossRef]

259. Soldano, G.J.; Zanotto, F.M.; Mariscal, M.M. Mechanochemical stability of sub-nm ZnO chains. Phys. Chem. Chem. Phys. 2016, 18, 7688-7694. [CrossRef]

260. Arsalani, N.; Bazazi, S.; Abuali, M.; Jodeyri, S. A new method for preparing ZnO/CNT nanocomposites with enhanced photocatalytic degradation of malachite green under visible light. J. Photochem. Photobiol. A 2020, 389, 112207. [CrossRef]

261. Mohd Yusof, H.; Mohamad, R.; Zaidan, U.H.; Rahman, N.A. Microbial synthesis of zinc oxide nanoparticles and their potential application as an antimicrobial agent and a feed supplement in animal industry: A review. J. Animal Sci. Biotechnol. 2019, 10, 57. [CrossRef]

262. Tiwari, V.; Mishra, N.; Gadani, K.; Solanki, P.S.; Shah, N.A.; Tiwari, M. Mechanism of anti-bacterial activity of zinc oxide nanoparticle against carbapenem-resistant Acinetobacter baumannii. Front. Microbiol. 2018, 9, 1218. [CrossRef]

263. Gold, K.; Slay, B.; Knackstedt, M.; Gaharwar, A.K. Antimicrobial activity of metal and metal-oxide based nanoparticles. Adv. Ther. 2018, 1, 1700033. [CrossRef]

264. Ahmed, B.; Solanki, B.; Zaidi, A.; Khan, M.S.; Musarrat, J. Bacterial toxicity of biomimetic green zinc oxide nanoantibiotic: Insights into ZnONP uptake and nanocolloid-bacteria interface. Toxicol. Res. 2019, 8, $246-261$. [CrossRef] [PubMed]

265. Omar, F.M.; Aziz, H.A.; Stoll, S. Stability of $\mathrm{ZnO}$ nanoparticles in solution. Influence of $\mathrm{pH}$, dissolution, aggregation and disaggregation effects. J. Colloid Sci. Biotechnol. 2014, 3, 1-10. [CrossRef]

266. Tripathy, A.; Sen, P.; Su, B.; Briscoe, W.H. Natural and bioinspired nanostructured bactericidal surfaces. Adv. Colloid Interface Sci. 2017, 248, 85-104. [CrossRef]

267. Caudill, E.R.; Hernandez, R.T.; Johnson, K.P.; O’Rourke, J.T.; Zhu, L.; Haynes, C.L.; Feng, V.; Pedersen, J.A. Wall teichoic acids govern cationic gold nanoparticle interaction with Gram-positive bacterial cell walls. Chem. Sci. 2020, 11, 4106-4118. [CrossRef]

268. Bertani, B.; Ruiz, N. Function and biogenesis of lipopolysaccharides. EcoSal Plus 2018, 8. [CrossRef]

269. Botos, I.; Noinaj, N.; Buchanan, S.K. Insertion of proteins and lipopolysaccharide into the bacterial outer membrane. Philos. Trans. R. Soc. B 2017, 372, 20160224. [CrossRef]

270. Pace, N.J.; Weerapana, E. Zinc-binding cysteines: Diverse functions and structural Motifs. Biomolecules 2014, 4, 419-434. [CrossRef]

271. Ishida, T. Antibacterial mechanism of bacteriolyses of bacterial cell walls by zinc (II) ion induced activations of PGN autolysins, and DNA damages. J. Genes Proteins 2017, 1, 1.

272. Kadiyala, U.; Turali-Emre, E.S.; Bahng, J.H.; Kotov, N.A.; VanEpps, J.S. Unexpected insights into antibacterial activity of zinc oxide nanoparticles against methicillin resistant Staphylococcus aureus (MRSA). Nanoscale 2018, 10, 4927-4939. [CrossRef]

273. Dutta, R.K.; Nenavathu, B.P.; Gangishetty, M.K.; Reddy, A.V. Studies on antibacterial activity of ZnO nanoparticles by ROS induced lipid peroxidation. Colloids Surf B Biointerfaces 2012, 94, 143-150. [CrossRef] [PubMed]

274. Stark, G. Functional consequences of oxidative membrane damage. J. Membrane Biol. 2005, 205, 1-16. [CrossRef] [PubMed]

275. Arakha, M.; Salem, M.; Mallick, B.C.; Jha, S. The effects of interfacial potential on antimicrobial propensity of ZnO nanoparticle. Sci. Rep. 2015, 5, 9578. [CrossRef] [PubMed] 
276. Singh, R.; Cheng, S.; Singh, S. Oxidative stress-mediated genotoxic effect of zinc oxide nanoparticles on Deinococcus radiodurans. 3 Biotech 2020, 10, 66. [CrossRef] [PubMed]

277. Hirota, K.; Sugimoto, M.; Kato, M.; Tsukagoshi, K.; Tanigawa, T.; Sugimoto, H. Preparation of zinc oxide ceramics with a sustainable antibacterial activity under dark conditions. Ceram. Int. 2010, 36, 497-506. [CrossRef]

278. Leung, Y.; Xu, X.; Ma, A.; Liu, F.; Ng, A.M.; Shen, Z.; Gethings, L.A.; Guo, M.Y.; Djurisic, A.B.; Lee, P.K.H.; et al. Toxicity of $\mathrm{ZnO}$ and $\mathrm{TiO}_{2}$ to Escherichia coli cells. Sci. Rep. 2016, 6, 35243. [CrossRef]

279. Jiang, Y.; Zhang, L.; Wen, D.; Ding, Y. Role of physical and chemical interactions in the antibacterial behavior of ZnO nanoparticles against E. coli. Mater. Sci. Eng. C 2016, 69, 1361-1366. [CrossRef]

280. Raghupathi, K.R.; Koodali, R.T.; Manna, A.C. Size-dependent bacterial growth inhibition and mechanism of antibacterial activity of zinc oxide nanoparticles. Langmuir 2011, 27, 4020-4028. [CrossRef]

281. Abbasi, B.H.; Shah, M.; Hashmi, S.S.; Nazir, M.; Naz, S.; Ahmad, W.; Khan, I.U.; Hano, C. Green bio-assisted synthesis, characterization and biological evaluation of biocompatible ZnO NPs synthesized from different tissues of milk thistle (Silybum marianum). Nanomaterials 2019, 9, 1171. [CrossRef]

282. Zare, M.; Namratha, K.; Alghamdi, S.; Mohammad, Y.H.; Hezam, A.; Zare, M.; Drmosh, Q.A.; Byrappa, K.; Chandrashekar, B.N.; Ramakrishna, S.; et al. Novel green biomimetic approach for synthesis of ZnO-Ag nanocomposite; antimicrobial activity against food-borne pathogen, biocompatibility and solar photocatalysis. Sci. Rep. 2019, 9, 8303. [CrossRef]

283. Verma, R.; Chauhan, A.; Shandilya, M.; Li, X.; Kumar, R.; Kulshrestha, S. Antimicrobial potential of ag-doped $\mathrm{ZnO}$ nanostructure synthesized by the green method using moringa oleifera extract. J. Environ. Chem. Eng. 2020, 8, 103730. [CrossRef]

284. Zhang, H.; Chen, B.; Jiang, H.; Wang, C.; Wang, H.; Wang, X. A strategy for ZnO nanorod mediated multi-mode cancer treatment. Biomaterials 2011, 32, 1906-1914. [CrossRef] [PubMed]

285. Chang, J.S.; Strunk, J.; Chong, M.N.; Poh, P.E.; Ocon, J.D. Multi-dimensional zinc oxide (ZnO) nanoarchitectures as efficient photocatalysts: What is the fundamental factor that determines photoactivity in ZnO? J. Hazard. Mater. 2020, 381, 120958. [CrossRef] [PubMed]

286. Hong, H.; Shi, J.; Yang, Y.; Zhang, Y.; Engle, J.W.; Nickles, R.J.; Wang, X.; Cai, W. Cancer-targeted optical imaging with fluorescent zinc oxide nanowires. Nano Lett. 2011, 11, 3744-3750. [CrossRef] [PubMed]

287. Sadhukhan, P.; Kundu, M.; Rana, S.; Kumar, R.; Das, J.; Sil, P.C. Microwave induced synthesis of ZnO nanorods and their efficacy as a drug carrier with profound anticancer and antibacterial properties. Toxicol. Rep. 2019, 6, 176-185. [CrossRef] [PubMed]

288. Jeong, E.; Kim, C.I.; Byun, J.; Lee, J.; Kim, H.E.; Kim, E.J.; Choi, K.J.; Hong, S.W. Quantitative evaluation of the antibacterial factors of $\mathrm{ZnO}$ nanorod arrays under dark conditions: Physical and chemical effects on Escherichia coli inactivation. Sci. Total Environ. 2020, 712, 136574. [CrossRef]

289. Li, G.R.; Hu, T.; Pan, G.L.; Yan, T.Y.; Gao, X.P.; Zhu, H.Y. Morphology-function relationship of ZnO: Polar planes, oxygen vacancies, and activity. J. Phys. Chem. C 2008, 112, 11859-11864. [CrossRef]

290. Tu, Y.; Chen, S.; Li, X.; Gorbaciova, J.; Gillin, W.P.; Krause, S.; Briscoe, J. Control of oxygen vacancies in ZnO nanorods by annealing and their influence on ZnO/PEDOT:PSS diode behavior. J. Mater. Chem. C 2018, 6, 1815-1821. [CrossRef]

291. Tam, K.H.; Cheung, C.K.; Leung, Y.H.; Djurisic, A.B.; Ling, C.C.; Beling, C.D.; Fung, S.; Kwok, W.M.; Chan, W.K.; Philips, D.L.; et al. Defects in ZnO nanorods prepared by a hydrothermal method. J. Phys. Chem. B 2006, 110, 20865-20871. [CrossRef]

292. Cunningham, M.W. Pathogenesis of group A streptococcal infections. Clin. Microbiol. Rev. 2000, 13, 470-511. [CrossRef]

293. Hennigham, A.; Dohrmann, S.; Nizet, V.; Cole, J.N. Mechanisms of group A Streptococcus resistance to reactive oxygen species. FEMS Microbiol. Rev. 2015, 39, 488-508. [CrossRef]

294. Akhavan, O.; Ghaderi, E.; Esfandiar, A. Wrapping bacteria by graphene nanosheets for isolation from environment, reactivation by sonication and inactivation by near-infrared irradiation. J. Phys. Chem. B 2011, 115, 6279-6288. [CrossRef] [PubMed]

295. Wang, D.; Zhao, L.; Ma, H.; Zhang, H.; Guo, L.H. Quantitative analysis of reactive oxygen species photogenerated on metal oxide nanoparticles and their bacteria toxicity: The role of superoxide radicals. Environ. Sci. Technol. 2017, 51, 10137-10145. [CrossRef] [PubMed] 
296. Guo, B.L.; Han, P.; Guo, L.C.; Cao, Y.Q.; Li, A.D.; Kong, J.Z.; Zhai, H.F.; Wu, D. The antibacterial activity of Ta-doped ZnO nanoparticles. Nanoscale Res. Lett. 2015, 10, 336. [CrossRef] [PubMed]

297. Vijayalakshmi, K.; Sivaraj, D. Enhanced antibacterial activity of Cr doped ZnO nanorods synthesized using microwave processing. RSC Adv. 2015, 5, 68461-68469. [CrossRef]

298. Qi, K.; Xing, X.; Zada, A.; Li, M.; Wang, Q.; Liu, S.Y.; Lin, H.; Wang, G. Transition metal doped ZnO nanoparticles with enhanced photocatalytic and antibacterial performances: Experimental and DFT studies. Ceram. Int. 2020, 46, 1494-1502. [CrossRef]

299. Kumar, R.; Anandan, S.; Hembram, K.; Rao, T.N. Efficient ZnO-based visible-light-driven photocatalyst for antibacterial applications. ACS Appl. Mater. Interfaces 2014, 6, 13138-13148. [CrossRef]

300. Zhang, X.; Qin, J.; Xue, Y.; Yu, P.; Zhang, B.; Wang, L.; Liu, R. Effect of aspect ratio and surface defects on the photocatalytic activity of $\mathrm{ZnO}$ nanorods. Sci. Rep. 2014, 4, 4596. [CrossRef]

301. Fang, J.; Fan, H.; Ma, Y.; Wang, J.; Chang, Q. Surface defects control for ZnO nanorods synthesized by quenching and their anti-recombination in photocatalysis. Appl. Surf. Sci. 2015, 332, 47-54. [CrossRef]

302. Prasanna, V.K.; Vijayaraghavan, R. Chemical manipulation of oxygen vacancy and antibacterial activity in ZnO. Mater. Sci. Eng. C 2017, 77, 1027-1034. [CrossRef]

303. Sajjad, M.; Ullah, I.; Khan, M.I.; Khan, J.; Khan, M.Y.; Qureshi, M.T. Structural and optical properties of pure and copper doped zinc oxide nanoparticles. Results Phys. 2018, 9, 1301-1309. [CrossRef]

304. Gupta, J.; Mohapatra, J.; Bahadur, D. Visible light driven mesoporous Ag-embedded ZnO nanocomposites: Reactive oxygen species enhanced photocatalysis, bacterial inhibition and photodynamic therapy. Dalton Trans. 2017, 46, 685-696. [CrossRef] [PubMed]

305. He, W.; Kim, H.K.; Wamer, W.G.; Melka, D.; Callahan, J.H.; Yin, J.J. Photogenerated charge carriers and reactive oxygen species in $\mathrm{ZnO} / \mathrm{Au}$ hybrid nanostructures with enhanced photocatalytic and antibacterial activity. J. Am. Chem. Soc. 2014, 136, 750-757. [CrossRef] [PubMed]

306. Das, S.; Sinha, S.; Das, B.; Jayabalan, R.; Suar, M.; Mishra, A.; Tamhankar, A.J.; Lundborg, C.S.; Tripathy, S.K. Disinfection of multidrug resistant Escherichia coli by solar-photocatalysis using Fe-doped ZnO nanoparticles. Sci. Rep. 2017, 7, 104. [CrossRef] [PubMed]

307. Grotel, J.; Pikula, T.; Siedliska, K.; Ruchomski, L.; Panek, R.; Wiertel, M.; Jartych, E. Structure and hyperfine interactions of Fe-doped $\mathrm{ZnO}$ powder prepared by co-precipitation method. Acta Phys. Pol. A 2018, 134, 1048-1052. [CrossRef]

308. Cherifi, Y.; Chaouchi, A.; Lorgoilloux, Y.; Rguiti, M.; Kadri, A.; Courtois, C. Electrical, dielectric and photocatalytic properties of Fe-doped $\mathrm{ZnO}$ nanomaterials synthesized by sol gel method. Process. Appl. Ceram. 2016, 10, 125-135. [CrossRef]

309. Kadi, M.W.; McKinney, D.; Mohamed, R.M.; Mkhalid, I.A.; Sigmund, W. Fluorine doped zinc oxide nanowires: Enhanced photocatalysts degrade malachite green dye under visible light conditions. Ceram. Int. 2016, 42, 4672-4678. [CrossRef]

310. Podporska-Carroll, J.; Myles, A.; Quilty, B.; McCormack, D.E.; Fagan, R.; Hinder, S.J.; Dionysiou, D.D.; Pillai, S.C. Antibacterial properties of F-doped ZnO visible light photocatalyst. J. Hazard. Mater. 2017, $324 \mathrm{Pt}$ A, 39-47. [CrossRef]

311. Pal, S.; Maiti, S.; Maiti, U.N.; Chattopadhyay, K.K. Low temperature solution processed ZnO/CuO heterojunction photocatalyst for visible light induced photo-degradation of organic pollutants. CrystEngComm 2015, 17, 1464-1476. [CrossRef]

312. Mageshwari, K.; Nataraj, D.; Pal, T.; Sathyamoorthy, R.; Park, J. Improved photocatalytic activity of ZnO coupled $\mathrm{CuO}$ nanocomposites synthesized by reflux condensation method. J. Alloys Compd. 2015, 625, 362-370. [CrossRef]

313. Liu, Z.; Bai, H.; Sun, D.D. Hierarchical CuO/ZnO membranes for environmental applications under the irradiation of visible light. Int. J. Photoenergy 2012, 2012, 804840. [CrossRef]

314. Sapkota, K.P.; Lee, I.; Hanif, M.A.; Islam, M.A.; Hahn, J.R. Solar-light-driven efficient ZnO-single-walled carbon nanotube photocatalyst for the degradation of a persistent water pollutant organic dye. Catalysts 2019, 9, 498. [CrossRef]

315. Castilho, C.J.; Li, D.; Liu, M.; Liu, Y.; Gao, H.; Hurt, R.H. Mosquito bite prevention through graphene barrier layers. Proc. Natl. Acad. Sci. USA 2019, 116, 18304-18309. [CrossRef] [PubMed]

316. Kenry, K.; Lim, Y.B.; Nai, M.H.; Cao, J.; Loh, K.P.; Lim, C.T. Graphene oxide inhibits malaria parasite invasion and delays parasitic growth in vitro. Nanoscale 2017, 9, 14065-14073. [CrossRef] [PubMed] 
317. Paul, B.; Panigrahi, A.K.; Singh, V.; Singh, S.G. A multi-walled carbon nanotube-zinc oxide nanofiber based flexible chemiresistive biosensor for malaria biomarker detection. Analyst 2017, 142, 2128-2135. [CrossRef]

318. Howard, R.J.; Uni, S.; Aikawa, M.; Aley, S.B.; Leech, J.H.; Lew, A.M.; Wellems, T.E.; Rener, J.; Taylor, D.W. Secretion of a malarial histidine-rich protein (Pf HRP II) from Plasmodium falciparum-infected erythrocytes. J. Cell Biol. 1986, 103, 1269-1277. [CrossRef]

319. Zhao, C.; Tan, S.X.; Xiao, X.; Qiu, X.S.; Pan, J.Q.; Tang, Z.X. Effects of dietary zinc oxide nanoparticles on growth performance and antioxidative status in broilers. Biol. Trace Elem. Res. 2014, 160, 361-367. [CrossRef]

320. Wadhwa, R.; Aggarwal, T.; Thapliyal, N.; Kumar, A.; Yadav, P.; Kumari, V.; Reddy, B.S.; Chandra, P.; Maurya, P.K. Red blood cells as an efficient in vitro model for evaluating the efficacy of metallic nanoparticles. 3 Biotech 2019, 9, 279. [CrossRef]

321. ASTM E2524-08 (2013): Standard Test Method for Analysis of Hemolytic Properties of Nanoparticles; American Society for Testing and Materials: West Conshohocken, PA, USA, 2013.

322. ASTM F756: Standard Practice for Assessment of Hemolytic Properties of Materials; American Society for Testing and Materials: West Conshohocken, PA, USA, 2017.

323. Babu, E.P.; Subastri, A.; Suyavaran, A.; Premkumar, K.; Sujatha, V.; Aristatile, B.; Alshammari, G.M.; Dharuman, V.; Thirunavukkarasu, C. Size dependent uptake and hemolytic effect of zinc oxide nanoparticles on erythrocytes and biomedical potential of ZnO-ferulic acid conjugates. Sci. Rep. 2017, 7, 4203. [CrossRef]

324. Kumar, N.; Pruthi, V. Potential applications of ferulic acid from natural sources. Biotechnol. Rep. 2014, 4, 86-93. [CrossRef]

325. Khan, M.; Naqvi, A.H.; Ahmad, M. Comparative study of the cytotoxic and genotoxic potentials of zinc oxide and titanium dioxide nanoparticles. Toxicol. Rep. 2015, 2, 765-774. [CrossRef] [PubMed]

326. Mahanta, S.; Prathap, S.; Ban, D.K.; Paul, S. Protein functionalization of ZnO nanostructure exhibits selective and enhanced toxicity to breast cancer cells through oxidative stress-based cell death mechanism. J. Photochem. Photobiol. B 2017, 173, 376-388. [CrossRef] [PubMed]

327. Bian, Y.; Kim, K.; Ngo, T.; Kim, I.; Bae, O.N.; Lim, K.M.; Chung, J.H. Silver nanoparticles promote procoagulant activity of red blood cells: A potential risk of thrombosis in susceptible population. Part. Fibre Toxicol. 2019, 16, 9. [CrossRef] [PubMed]

328. Mahalakshmi, S.; Hema, N.; Vijaya, P.P. In vitro biocompatibility and antimicrobial activities of zinc oxide nanoparticles ( $\mathrm{ZnO} \mathrm{NPs}$ ) prepared by chemical and green synthetic route-A comparative study. Bionanoscience 2020, 10, 112-121. [CrossRef]

329. Jan, H.; Shah, M.; Usman, H.; Khan, M.A.; Zia, M.; Hano, C.; Abbasi, B.H. Biogenic synthesis and characterization of antimicrobial and antiparasitic zinc oxide $(\mathrm{ZnO})$ nanoparticles using aqueous extracts of the Himalayan Columbine (Aquilegia pubiflora). Front. Mater. 2020, 7, 249. [CrossRef]

330. Rajapriya, M.; Sharmili, S.A.; Baskar, R.; Balaji, R.; Alharbi, N.S.; Kadaikunnan, S.; Khaled, J.M.; Alanzi, K.F.; Vaseeharan, B. Correction to: Synthesis and characterization of zinc oxide nanoparticles using Cynara scolymus leaves: Enhanced hemolytic, antimicrobial, antiproliferative, and photocatalytic activity. J. Clust. Sci. 2020, 31, 791-981. [CrossRef]

331. Vinotha, V.; Iswarya, A.; Thaya, R.; Govindarajan, M.; Alharbi, N.S.; Kadaikunnan, S.; Khaled, J.M.; Al-Anbr, M.N.; Vaseeharan, B. Synthesis of ZnO nanoparticles using insulin-rich leaf extract: Anti-diabetic, antibiofilm and anti-oxidant properties. J. Photochem. Photobiol. B 2019, 197, 111541. [CrossRef]

332. Rauf, M.A.; Oves, M.; Rehman, F.U.; Khan, A.R.; Husain, N. Bougainvillea flower extract mediated zinc oxide's nanomaterials for antimicrobial and anticancer activity. Biomed. Pharmacother. 2019, 116, 108983. [CrossRef]

333. Hirayama, D.; Iida, T.; Nakase, H. The phagocytic function of macrophage-enforcing innate immunity and tissue homeostasis. Int. J. Mol. Sci. 2018, 19, 92. [CrossRef]

334. Chang, H.; Ho, C.C.; Yang, C.S.; Chang, W.H.; Tsai, M.H.; Tsai, H.T.; Lin, P. Involvement of MyD88 in zinc oxide nanoparticle-induced lung inflammation. Exp. Toxicol. Pathol. 2013, 65, 887-896. [CrossRef]

335. Alghsham, R.S.; Satpathy, S.R.; Bodduluri, S.R.; Hegde, B.; Jala, V.R.; Twal, W.; Burlison, J.A.; Sunkara, M.; Haribabu, B. Zinc oxide nanowires exposure induces a distinct inflammatory response via CCL11-mediated eosinophil recruitment. Front. Immunol. 2019, 10, 2604. [CrossRef] [PubMed]

336. Shen, C.; James, S.A.; de Jonge, M.D.; Turney, T.W.; Wright, P.F.; Feltis, B.N. Relating cytotoxicity, zinc ions, and reactive oxygen in $\mathrm{ZnO}$ nanoparticle-Exposed human immune cells. Toxicol. Sci. 2013, 136, 120-130. [CrossRef] [PubMed] 
337. Song, W.; Zhang, J.; Guo, J.; Zhang, J.; Ding, F.; Li, L.; Sun, Z. Role of the dissolved zinc ion and reactive oxygen species in cytotoxicity of ZnO nanoparticles. Toxicol. Lett. 2010, 199, 389-397. [CrossRef] [PubMed]

338. Johnson, B.M.; Fraietta, J.A.; Gracias, D.T.; Hope, J.L.; Stairiker, C.J.; Patel, P.R.; Mueller, Y.M.; McHugh, M.D.; Jablonowski, L.J.; Wheatley, M.A.; et al. Acute exposure to $\mathrm{ZnO}$ nanoparticles induces autophagic immune cell death. Nanotoxicology 2015, 9, 737-748. [CrossRef]

339. Roy, R.; Singh, S.K.; Chauhan, L.K.; Das, M.; Tripathi, A.; Dwivedi, P.D. Zinc oxide nanoparticles induce apoptosis by enhancement of autophagy via PI3K/Akt/mTOR inhibition. Toxicol. Lett. 2014, 227, $29-40$. [CrossRef]

340. Yan, G.; Guo, Y.; Guo, J.; Wang, W.; Wang, C.; Wang, X. N-Acetylcysteine attenuates lipopolysaccharide-Induced osteolysis by restoring bone remodeling balance via reduction of reactive oxygen species formation during osteoclastogenesis. Inflammation 2020, 43, 1279-1292. [CrossRef]

341. Luo, M.; Shen, C.; Feltis, B.N.; Martin, L.L.; Hughes, A.E.; Wright, P.F.; Turney, T.W. Reducing ZnO nanoparticle cytotoxicity by surface modification. Nanoscale 2014, 6, 5791-5798. [CrossRef]

342. Nagajyothi, P.C.; Cha, S.J.; Yang, I.J.; Sreekanth, T.V.; Kim, K.J.; Shin, H.M. Antioxidant and anti-inflammatory activities of zinc oxide nanoparticles synthesized using Polygala tenuifolia root extract. J. Photochem. Photobiol. B Biol. 2015, 146, 10-17. [CrossRef]

343. Thatoi, P.; Kerry, R.G.; Gouda, S.; Das, G.; Pramanik, K.; Thatoi, H.; Patra, J.K. Photo-mediated green synthesis of silver and zinc oxide nanoparticles using aqueous extracts of two mangrove plant species, Heritiera fomes and Sonneratia apetala and investigation of their biomedical applications. J. Photochem. Photobiol. B Biol. 2016, 163, 311-318. [CrossRef]

344. Liu, H.; Kang, P.; Liu, Y.; An, Y.; Hu, Y.; Jin, X.; Cao, X.; Qi, Y.; Ramesh, T.; Wang, X. Zinc oxide nanoparticles synthesised from the Vernonia amygdalina shows the anti-inflammatory and antinociceptive activities in the mice model. Artif. Cells Nanomed. Biotechnol. 2020, 48, 1068-1078. [CrossRef]

Publisher's Note: MDPI stays neutral with regard to jurisdictional claims in published maps and institutional affiliations.

(C) 2020 by the authors. Licensee MDPI, Basel, Switzerland. This article is an open access article distributed under the terms and conditions of the Creative Commons Attribution (CC BY) license (http://creativecommons.org/licenses/by/4.0/). 